\author{
UNIVERSIDADE DE BRASÍLIA \\ FACULDADE DE TECNOLOGIA \\ DEPARTAMENTO DE ENGENHARIA CIVIL E AMBIENTAL
}

\begin{abstract}
ANÁLISE HIDROMECÂNICA DO PROBLEMA DE FRATURAMENTO HIDRÁULICO
\end{abstract}

LETÍCIA PEREIRA DE MORAIS

ORIENTADOR: MANOEL PORFÍRIO CORDÃO NETO, DSc

DISSERTAÇÃO DE MESTRADO EM GEOTECNIA

PUBLICAÇÃO: G.DM-268/2016

BRASÍLIA/DF: MARÇO/2016 


\author{
UNIVERSIDADE DE BRASÍLIA \\ FACULDADE DE TECNOLOGIA \\ DEPARTAMENTO DE ENGENHARIA CIVIL E AMBIENTAL
}

\title{
ANÁLISE HIDROMECÂNICA DO PROBLEMA DE FRATURAMENTO HIDRÁULICO
}

\section{LETÍCIA PEREIRA DE MORAIS}

DISSERTAÇÃO DE MESTRADO SUBMETIDA AO DEPARTAMENTO DE ENGENHARIA CIVIL E AMBIENTAL DA UNIVERSIDADE DE BRASÍLIA COMO PARTE dOS REQUiSITOS NECESSÁRIOS PARA A OBTENÇÃo DO GRAU DE MESTRE.

APROVADA POR:

Manoel Porfírio Cordão Neto, DSc. (ORIENTADOR)

André Pacheco de Assis, PhD (EXAMINADOR INTERNO)

Igor Fernandes Gomes, DSc. (EXAMINADOR EXTERNO)

DATA: BRASÍLIA/DF, 31 DE MARÇO DE 2016 


\section{FICHA CATALOGRÁFICA}

\section{MORAIS, LETÍCIA PEREIRA DE}

Análise hidromecânica do problema de Fraturamento Hidráulico [Distrito Federal] 2016 xviii,110p.,297mm (ENC/FT/UnB, Mestre, Geotecnia, 2016)

Dissertação de Mestrado - Universidade de Brasília. Faculdade de Tecnologia. Departamento de Engenharia Civil e Ambiental

1. Fraturamento Hidráulico

2.XFEM

3. Modelo PKN

4.Hidromecânico

I. ENC/FT/UNB

II. Título (série)

\section{REFERÊNCIA BIBLIOGRÁFICA}

Morais, L. P. (2016). Análise hidromecânica do problema de Fraturamento Hidráulico.

Dissertação de Mestrado, Publicação G.DM- 268/2016, Departamento de Engenharia Civil e Ambiental, Universidade de Brasília, Brasília, DF, 110p.

\section{CESSÃO DE DIREITOS}

NOME DO AUTOR: Letícia Pereira de Morais

TÍTULO DA DISSERTAÇÃO DE MESTRADO: Análise hidromecânica do problema de Fraturamento Hidráulico

GRAU / ANO: Mestre / 2016

É concedida à Universidade de Brasília a permissão para reproduzir cópias desta dissertação de mestrado e para emprestar ou vender tais cópias somente para propósitos acadêmicos e científicos. $\mathrm{O}$ autor reserva outros direitos de publicação e nenhuma parte desta dissertação de mestrado pode ser reproduzida sem a autorização por escrito do autor.

Letícia Pereira de Morais

SMPW Qd. 17 conj 7 lote 6 casa B - Park way

71741-707- Brasília/DF- Brasil 


\section{AGRADECIMENTOS}

Gostaria de agradecer ao meu orientador pela paciência e dedicação em ensinar. Obrigada pelo suporte e incentivo na realização deste trabalho e pelas oportunidades oferecidas para o meu crescimento pessoal e profissional. Aos meus pais, pelo apoio, amor e confiança em mim depositados e as minhas irmãs pelo companheirismo e incentivo, vocês foram excenciais na minha caminhada. Obrigada a Universidade de Brasília, a todo o corpo docente e funcionários que auxiliaram e tornaram possível a conclusão do meu Mestrado. À todos os meus amigos que contribuiram direta ou indiretamente para a realização deste trabalho. À CAPES e ao CNPq pelo financiamento. E gostaria de agradecer à Deus por me guiar e me ajudar a superar todas as dificuldades e me fazer acreditar que tudo é possível com dedicação e esforço. 


\section{RESUMO}

Análise hidromecânica do problema de Fraturamento Hidráulico

O Fraturamento Hirdáulico é uma técnica de estimulação de poços que recentemente tem sido muito utilizada para extração de gás de folhelho. O gás de folhelho se mostrou uma fonte alternativa de combustível fóssil para alguns países, como os Estados Unidos, minimizarem sua dependência de países exportadores de petróleo. No Fraturamento Hidráulico um fluido é injetado nas formações sob pressão e vazão controladas. O diferencial de pressão gerado pela injeção do fluido inicia uma fratura que se propaga pela rocha, facilitando a extração dos hidrocarbonetos nela presentes. A técnica é utilizada em reservatórios convencionais e não convencionais de hidrocarbonetos. No primeiro a técnica é aplicada com o objetivo de aumentar a produção do poço. Nos reservatórios não convencionais (gás de folhelho) ela é utilizada para possibilitar a extração do gás dessas reservas devido a sua baixíssima permeabilidade. O processo de fraturar a rocha a grandes profundidades dificulta o controle do tipo de fratura criada ou reativada, pois isso irá depender de uma série de fatores. O estudo da técnica é importante para se ter um maior controle durante a execução e evitar possíveis imprevistos e acidentes. Neste trabalho foi estudado o Fraturamento Hidráulico primeiramente utilizando a formulação do modelo PKN e, em seguida, utilizando análise numérica. Com a formulação do modelo PKN foi possível observar o padrão da fratura criada considerando os efeitos da poroelasticidade e o leak off: o comportamento dos parâmetros abertura da fratura (w), comprimento da fratura (L) e pressão (P) variando com o tempo. Para o estudo do fraturamento hidráulico por análise numérica foi necessário implementar em um código de elementos finitos uma formulação capaz de representar descontinuidades em uma malha contínua. Foi escolhido o Método dos Elementos Finitos Estendido (XFEM) que, após implementado, foi validado e se mostrou eficiente quando comparado com soluções analíticas existentes na literatura. Utilizando o código implementado foram realizadas análises de como a permeabilidade do meio e a permeabilidade da fratura influenciam no Fraturamento Hidráulico, sendo observado que mantendo as propriedades mecânicas constantes, as propriedades hidráulicas tem grande influência no processo de Fraturamento Hidráulico. 


\section{ABSTRACT \\ Hydromechanical analysis of a hydraulic fracturing problem}

Hydraulic Fracturing is a technique of stimulation of wells which recently has been widely used for shale gas extraction. The shale gas has proven to be an alternative source of fossil fuel to some countries, such as the United States, minimizing their dependence on oil exporting countries. In the hydraulic fracturing, a fluid is injected into the formation under controlled pressure and flow. The differential pressure generated by the injection of fluid initiates a fracture that will propagate into the rock, promoting the extraction of hydrocarbons present in it. The technique is used in conventional and unconventional reservoirs of hydrocarbons. In the first case, in conventional reservoirs, the technique is applied in order to increase the production of the well, while in unconventional reservoirs (shale gas) the technique is used to enable the extraction of the gas due to its very low permeability. The process of fracturing the rock at great depths involves the control over the type of fracture created or reactivated, as this will depend on a number of factors. The study of the technique is important for the improvement of the control over the execution and also to avoid possible contingencies and accidents. In this work, the Hydraulic Fracturing was studied using both a PKN model and numerical analysis. With the formulation of the PKN model, it was possible to observe the pattern of fractures created considering the effects of poroelasticity and leak off: the behavior of the fracture opening (w), the length of the fracture L) and the pressure of the fluid (P) varying with time. In order to study the hydraulic fracturing using numerical analysis, it was necessary to implement a formulation capable of representing discontinuities in a continuous mesh on a finite element code. The Extended Finite Element Method (XFEM) was chosen, implemented and validated. Comparisons between existing analytical solutions found in the literature and the XFEM used showed adequate results. Analyses of the implemented code were performed to identify how the permeability of the medium and the permeability of the fracture influence the hydraulic fracturing. It was observed that maintaining all of the mechanical properties constant, the hydraulic properties have a great impact on the hydraulic fracturing process. 


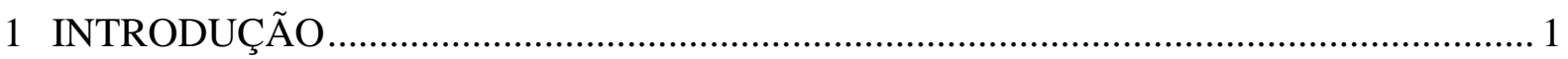

1.1APRESENTAÇÃ

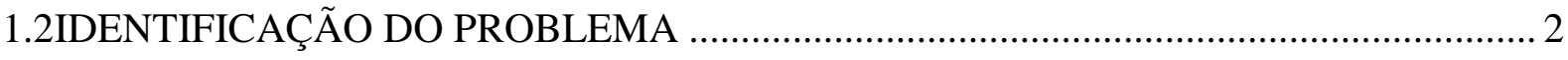

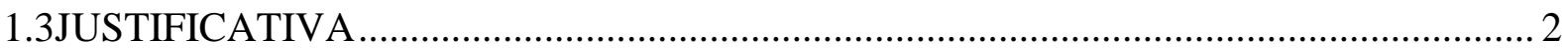

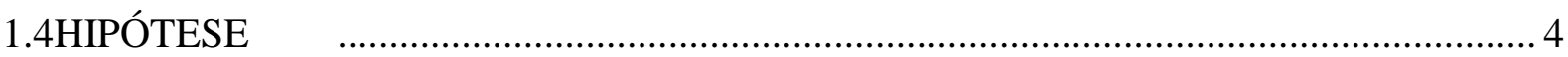

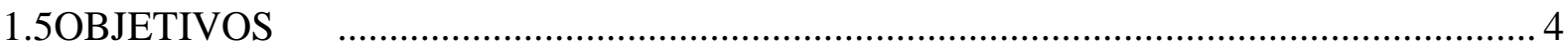

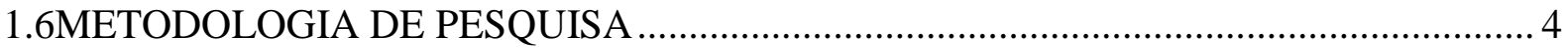

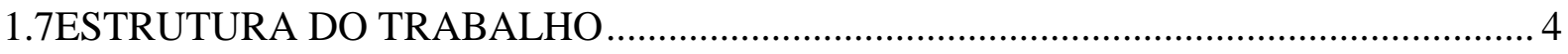

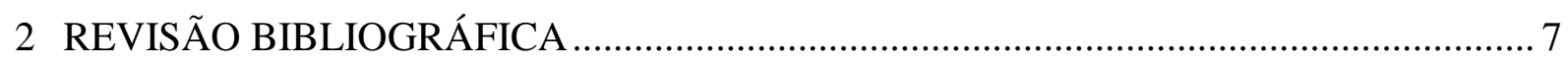

2.1FONTE CONVENCIONAL DE COMBUSTÍVEL FÓSSIL- GÁS E PETRÓLEO........... 7

2.1.1Formação do petróleo .................................................................................. 7

2.1.2Exploração e produção do petróleo ................................................................ 8

2.2FONTE NÃO CONVENCIONAL DE COMBUSTÍVEL FÓSSIL- GÁS DE FOLHELHO.

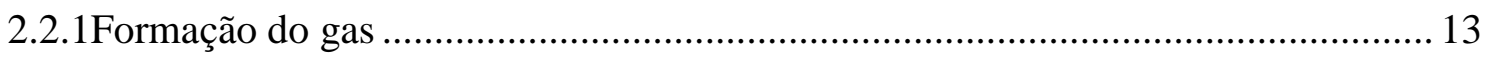

2.2.2Armazenamento do gás de folhelho na matriz rochosa e produção ....................... 14

2.2.3Tecnologias para produção de gás de folhelho ................................................. 15

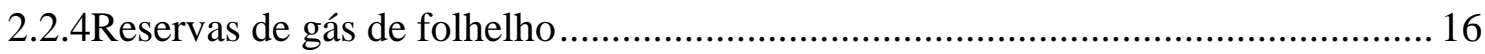

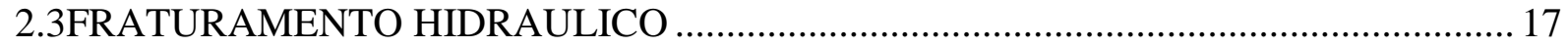

2.3.1Fraturamento Hidráulico em reservátorios não convencionais com fraturas préexistentes

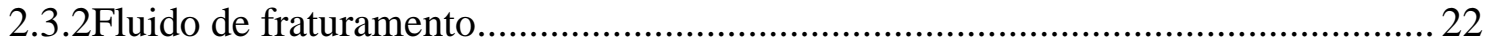

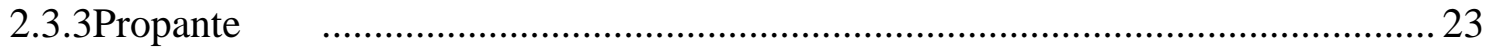

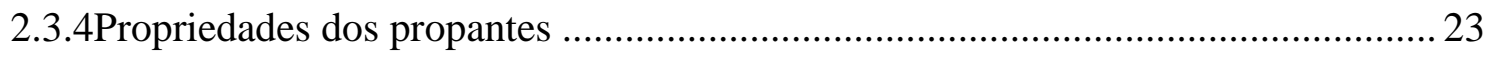

2.3.5Modelos de propagação das fraturas................................................................ 24

2.3.6Dificuldades no processo de fraturamento hidráulico ...................................... 27 


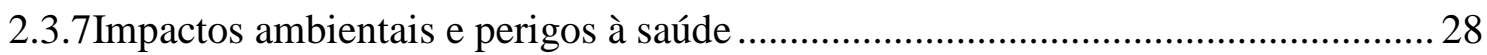

2.4PRINCIPAIS PROPRIEDADES DO RESERVATÓRIO ............................................... 30

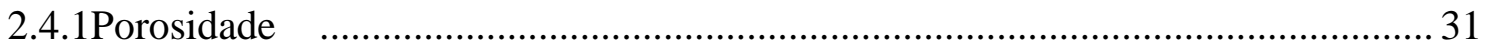

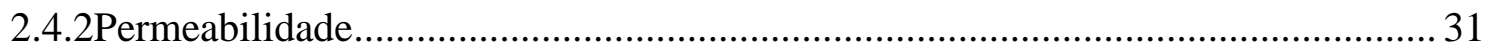

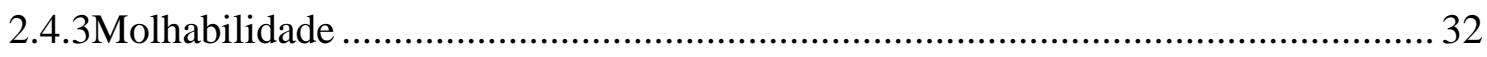

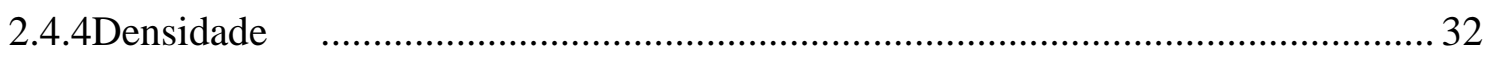

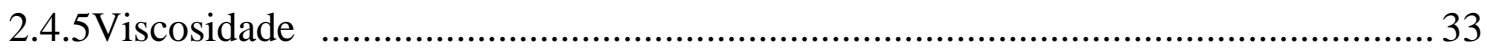

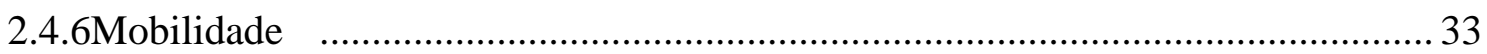

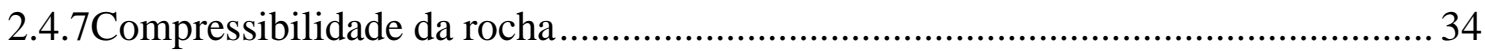

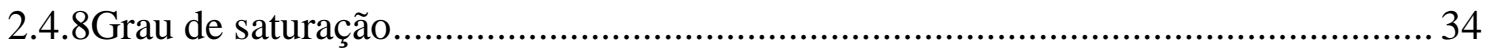

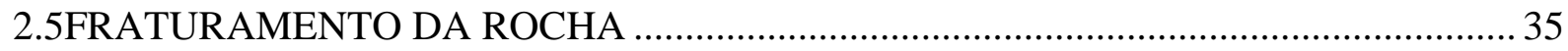

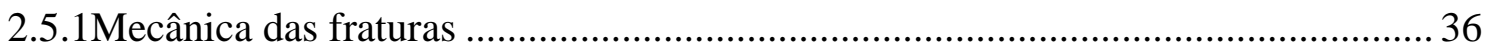

2.5.2Cálculo do fator de intensidade de tensões ........................................................ 40

2.6MODELAGEM DE FRATURAS E O MÉTODO DOS ELEMENTOS FINITOS

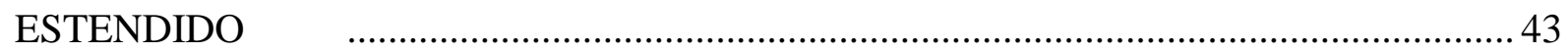

2.7XFEM- MÉTODO DOS ELEMENTOS ESTENDIDO ................................................ 43

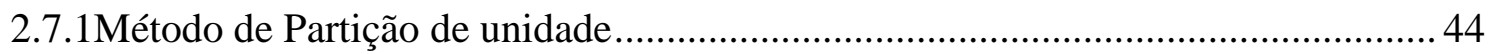

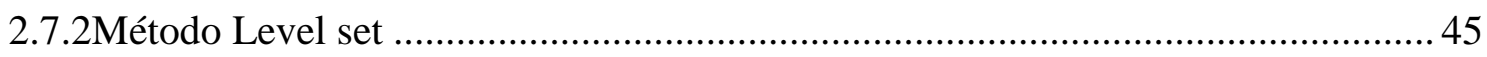

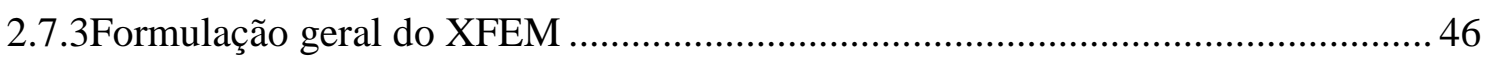

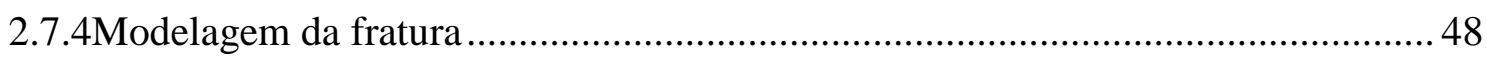

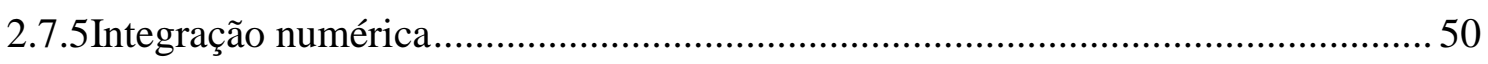

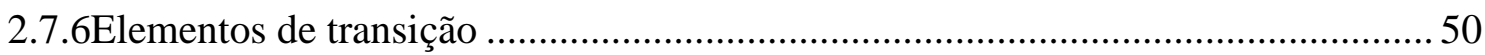

3 MODELO PKN DE FRATURAMENTO HIDRÁULICO .............................................. 52

3.1FORMULAÇÃO DE JING XIANG MODIFICADO POR MORAIS (2013) ...................52

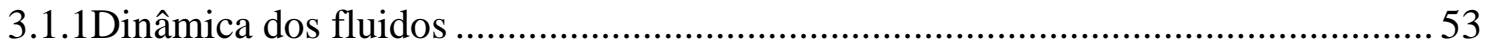

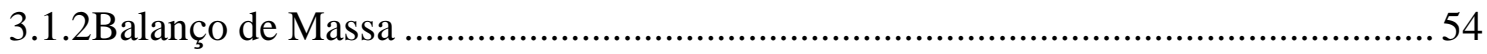

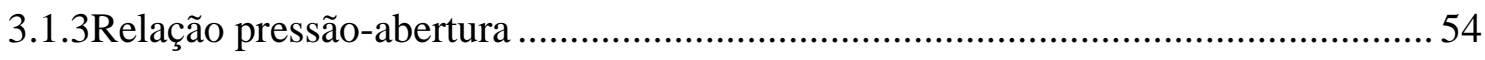




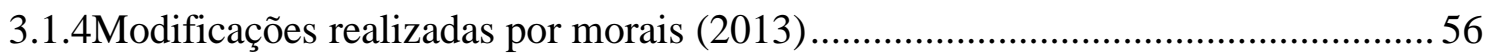

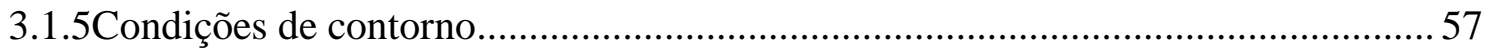

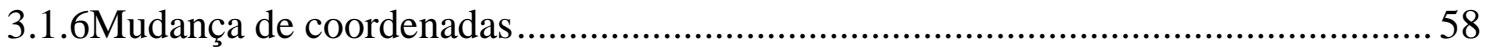

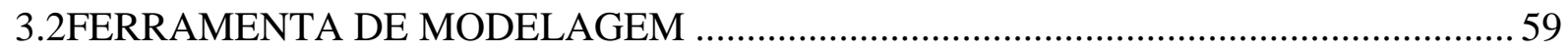

3.3SIMULAÇÃO DO MODELO PKN DE FRATURAMENTO HIDRÁULICO .................. 60

3.4SOLUÇÃO DO MODELO PKN DE FRATURAMENTO HIDRÁULICO ....................... 61

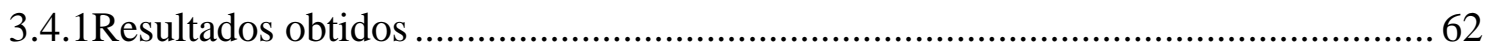

4 EQUAÇÕES BÁSICAS DO PROBLEMA DE EQUILIBRIO ACOPLADO ...................65

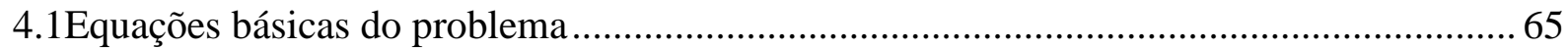

4.2RESOLUÇÃO ACOPLADA DO SISTEMA DE EQUAÇÕES UTILIZANDO

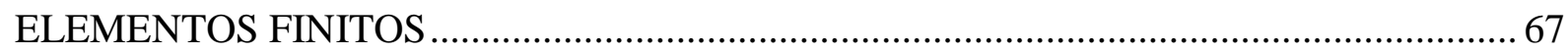

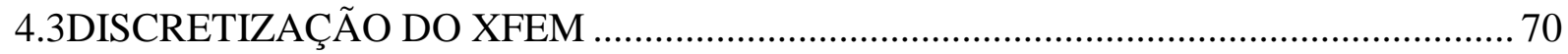

4.3.1Transformação das coordenadas polares em cartesianas - Função crack tip ......... 72

5 IMPLEMENTAÇÃO E VALIDAÇÃO DO CÓDIGO ....................................................... 74

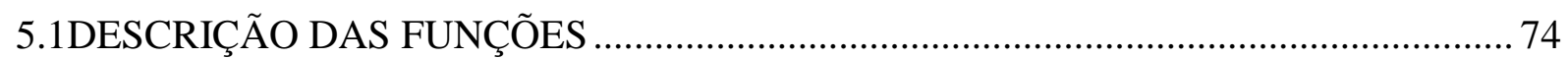

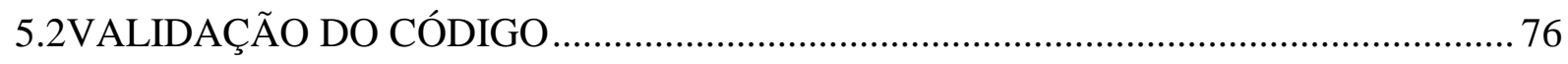

5.2.1Validação da formulação de fluxo e equilíbrio 2D ............................................. 77

5.2.2Validação da implementação do método dos elementos finitos estendido (XFEM).. 80

6 SIMULAÇÃO DE FRATURAMENTO HIDRÁULICO (INJEÇÃO DE FLUIDO PRESSURIZADO PARA FRATURAR O MEIO) ........................................................ 88

7 CONCLUSÕES E PROPOSTAS PARA TRABALHOS FUTUROS .............................. 99

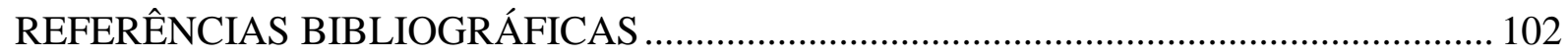




\section{LISTA DE TABELAS}

Tabela 1- Dados de entrada para verificação e simulação do problema (Xiang, 2011)

Tabela 2-Resultados obtidos Viga Bi-apoiada 


\section{LISTA DE FIGURAS}

Figura 1.1 Localização das potenciais reservas de gás de folhelho no Brasil (Advanced Resources International, 2016)

Figura 1.2 Metodologia da pesquisa

Figura 2.1 Armadilhas para acumulação de petróleo (SPE, 2007))

Figura 2.2 Etapas de exploração e produção de petróleo

Figura 2.3 Completação de poços quanto ao revestimento de produção (Garcia, 1997)

Figura 2.4 Zonas suplementadas simples, seletiva e dupla (Garcia, 1997)

Figura 2.5 Rocha folhelho (Norton Rose Fulbright, 2016)

Figura 2.6 Fonte convencional e não convencional de gás (modificado EIA, 2013)

Figura 2.7 Processo de movimentação do metano nas camadas do carvão semelhante ao que ocorre nos reservatórios de folhelho (Carestiato, 2014)

Figura 2.8 Tecnologias utilizadas extração de gás de folhelho a) poços horizontais b)ramificações de um único poço e c)poços multilaterais (TLR, 2011)

Figura 2.9 Bacias com formações de gás de folhelho avaliadas (modificada EIA, 2013)

Figura 2.10 Processo de fraturamento hidráulico

Figura 2.11 Estrutura do fluxo para um poço não fraturado e um fraturado (Castro, 2004)

Figura 2.12 Fraturamento Hidráulico (modificada Aljazeera, 2013)

Figura 2.13: Preenchimento da fratura pelo propante (Salas Cachay, 2004)

Figura 2.14 (a) Modelo Pseudo 3D e (b) Modelo 3D de fratura

Figura 2.15: Modelo de fraturamento PKN (Smith et al. , 2010)

Figura 2.16 Modelo de fraturamento KGD (Smith et al. , 2010)

Figura 2.17 Modelo Radial de fratura

Figura 2.18 Possíveis impactos gerados pela operação de Fraturamento Hidráulico (Ewen, 2012)

Figura 2.19 Região de exploração de gás de folhelho em Jonah Gasfield, Wyoming (Institution of Civil Engineers, 2016)

Figura 2.20: Ângulo de contato de uma gota de óleo( verde) envolta em água (azul) em uma superfície fortemente molhável a água (esquerda), em uma superfície fortemente molhável ao óleo (direita) e uma superfície com grau de molhabilidade intermediária(centro) (Faerstein, 2010)

Figura 2.21 a)Material dúctil e b) material frágil

Figura 2.22 Tipos de fratura induzida (Oller, 2001)

Figura 2.23 Decomposição das densidade de energia na fratura (Oller, 2001) 
Figura 2.24 Domínio da Integral-J para determinar fator de intensidade de tensões (Khoei, 2015)

Figura 2.25 Diferença entre MEF e XFEM

Figura 2.26 Função level set para problema bidimensional (Khoei,2015)

Figura 2.27 Função Heaviside e Função Heaviside transladada

Figura 2.28 Funções de enriquecimento crack tip

Figura 2.29 Sistema de coordenadas polares na ponta da fratura

Figura 2.30 Subtriangularização do elemento cortado pela fratura (Khoei, 2015)

Figura 2.31 Domínio enriquecido, Domínio misto e Domínio padrão

Figura 3.1- Mecânica da poroelasticidade (Xiang, 2011).

Figura 3.2 Comparação entre as Funções $f\left(t^{*}\right)$ proposta por Boone e Detournay (1990) e Morais (2013)

Figura 3.3 Modelo PKN modificado por Morais (2013)

Figura 3.4-Exemplo de script do programa FLEX PDE

Figura 3.5 Variação do comprimento da fratura $\mathrm{x}$ tempo

Figura 3.6 Variação da abertura da fratura $\mathrm{x}$ tempo

Figura 3.7 Variação da Pressão do fluido x tempo

Figura 4.1 Conservação de massa (Cordão Neto, 1995)

Figura 5.1 Fluxograma do código de XFEM

Figura 5.2 Exemplo software GID

Figura 5.3 Problema Terzaghi (Cordão Neto, 2005)

Figura 5.4 Resultado da validação realizada utilizando o problema de TerzaghiFigura 5.4

Figura 5.5 Malha e propriedades do problema de consolidação de deformação plana, vista no plano x-y. (Cordão Neto,2005)

Figura 5.6 Resultados da validação utilizando o problema de deformação plana de Biot

Figura 5.7 Viga Bi-apoiada

Figura 5.8 Malha do problema e campo de distribuição de tensões da validação realizada $\sigma$ (MPa)

Figura 5.9 Campo de distribuição de deslocamentos da validação realizada $\delta(\mathrm{m})$

Figura 5.10 Viga em estado de deformação plana fraturada (Khoei,2015)

Figura 5.11 Malhas utilizadas para simulação do problema (Khoei,2015)

Figura 5.12 Esquema da variação do raio de integração da integral J no cálculo do SIF

Figura 5.13 Comparação resultados dos campos de tensão obtidos (a)XFEM (Morais,2016)

com (b) XFEM (Khoei, 2015) $\sigma\left(\mathrm{Kg} / \mathrm{cm}^{2}\right)$ 
Figura 5.14 Avaliação da influência da razão R/L no calculo da SIF (Malha 15x45)

Figura 5.15 Avaliação da influência da razão R/L no calculo da SIF (Malha 25x45)

Figura 5.16 Avaliação da influência da razão R/L no calculo da SIF (Malha 45x135)

Figura 5.17 Placa retangular fraturada (Tuan et al., 2014)

Figura 5.18 Avaliação da relação entre o comprimento da fratura e o erro da SIF (Malha 40x80)

Figura 5.19 Avaliação da relação entre a tensão aplicada e o erro da SIF (Malha 30x60)

Figura 5.20 Avaliação da relação entre a tensão aplicada e o erro da SIF (Malha 40x80)

Figura 6.1 Malha utilizada para realização da simulação do Fraturamento Hidráulico

Figura 6.2 Abertura da fratura com o tempo, em meio com permeabilidade de $10^{-8} \mathrm{~m} / \mathrm{s}$, com a injeção de um fluido

Figura 6.3 Poropressão no interior da fratura em meios com diferentes permeabilidades $\mathrm{u}_{\mathrm{w}}$ $(\mathrm{KPa})$

Figura 6.4 Avaliação do tamanho de passo de tempo ideal para meio com permeabilidade de $10^{-5} \mathrm{~m} / \mathrm{s}$

Figura 6.5 Verificação da estabilização da fratura após Fraturamento Hidráulico para meio com permeabilidade de $10^{-5} \mathrm{~m} / \mathrm{s}$

Figura 6.6 Simulação de Fraturamento Hidráulico em meios com permeabilidades maiores que $10^{-5} \mathrm{~m} / \mathrm{s}$

Figura 6.7 Simulação de Fraturamento Hidráulico em meios com permeabilidades menores que $10^{-5} \mathrm{~m} / \mathrm{s}$

Figura 6.8 Crescimento da fratura por Fraturamento Hidráulico para meios permeabilidades menores que $10^{-5} \mathrm{~m} / \mathrm{s}$

Figura 6.9 Abertura da fratura por Fraturamento Hidráulico pra meios com permeabilidades menores que $10^{-5} \mathrm{~m} / \mathrm{s}$

Figura 6.10 Variação da poropressão no interior da fratura por Fraturamento Hidráulico ao longo da altura

Figura 6.11 Variação da abertura da fratura por Fraturamento Hidráulico ao longo da altura da fratura

Figura 6.12 Variação do comprimento da fratura por Fraturamento Hidráulico para diferentes permeabilidades do interior da fratura

Figura 6.13 Fraturamento hidráulico de fraturas com mesma permeabilidade interna e diferentes permeabilidades do meio

Figura 6.14 Variação da poropressão no interior da fratura por Fraturamento Hidráulico ao 
longo da altura

Figura 6.15 Variação da abertura da fratura por Fraturamento Hidráulico ao longo da altura da fratura

Figura 6.16 Variação do comprimento da fratura por Fraturamento Hidráulico para diferentes permeabilidades do meio

Figura 6.17 Fraturamento hidráulico de fraturas com mesma permeabilidade interna e diferentes permeabilidades do meio 


\section{LISTA DE SÍMBOLOS}

a comprimento da fratura

$a_{\mathrm{c}} \quad$ comprimento da fratura crítico

$\bar{a}_{i j} \quad$ graus de liberdade adicionais devido ao enriquecimento

[B] matriz deformação-deslocamento

$b_{i} \quad$ forças de corpo

$\left[\mathrm{B}^{\mathrm{a}}\right]$ matriz deformação-deslocamento enriquecida

$\left[B_{p}\right]$ matriz gradiente-poropressão

$c$ coeficiente de difusividade

[C] matriz de acoplamento entre a fase sólida e a água

$C_{e f} \quad$ compressibilidade efetiva do reservatório

$C_{l} \quad$ coeficiente de vazamento

$\mathrm{c}_{\mathrm{v}} \quad$ coeficiente de compressibilidade

$[D]$ matriz da relação constitutiva tensão-deformação

E módulo de elasticidade

$F(r, \theta)$ Função crack tip

$\{F\} \quad$ vetor de taxa de forças externas

$f\left(t^{*}\right)$ Função para avaliar os efeitos da poroelasticidade e do fator de intensidade de tensão na ponta da fratura

$\left\{f^{h}\right\} \quad$ vetor de forças externas enriquecidas

G módulo de rigidez

$\mathrm{G}_{\mathrm{f}} \quad$ densidade total de energia dissipada

$\mathrm{G}_{\mathrm{s}} \quad$ densidade específica

$h$ gradiente hidráulico

$\mathrm{H}$ altura da fratura

$\{H\}$ vetor da relação constitutiva tensão-sucção

[H] matriz de fluxo

$H(\xi)$ Função Heaviside

HAPs perigosos poluentes do ar

j matriz Jacobiana

$[K] \quad$ matriz de rigidez

$K \quad$ constantes para fluidos viscosos

$\mathrm{K}_{\mathrm{I}}, \mathrm{K}_{\mathrm{II}}, \mathrm{K}_{\mathrm{III}}$ Fatores de intensidade de tensões (SIF) 
$K_{e} \quad$ SIF equivalente

$\mathrm{K}_{\mathrm{Ic}} \quad$ Fatores de intensidade de tensões característico

[L] matriz de acoplamento da fase sólida e da água

L comprimento da fratura

$\mathrm{L}_{0} \quad$ comprimento inicial da fratura

$\mathrm{L}_{\mathrm{D}} \quad$ comprimento admensional

$M_{c} \quad$ rigidez da fratura

n constantes para fluidos viscosos

$[N]$ matriz de interpolação de deslocamento

$\left[\mathrm{N}^{\mathrm{a}}\right]$ matriz de interpolação de deslocamento enriquecida

$N_{i} \quad$ funções de forma

$n_{j} \quad$ vetor normal

$N^{\text {Gauss }}$ número de pontos de integração

$\left[N_{p}\right]$ matriz de interpolação de poropressões

$\{p\} \quad$ vetor de poropressões nodais

p pressão do reservatório

$\mathrm{p}_{0} \quad$ pressão do fluido existente nos poros

$\mathrm{p}_{\mathrm{D}} \quad$ pressão admensional

pf pressão do fluido

$p_{j} \quad$ função de enriquecimento

q peso da função definido no domínio de integração

$q \quad$ fluxo por unidade de altura da fratura

Q fluxo do fluido

$\{q\} \quad$ vetor de vazões nodais impostas

$S$ grau de saturação

T temperatura do reservatório

t tempo

$t_{D} \quad$ tempo admensional

$\{\dot{u}\} \quad$ vetor de taxa de deslocamentos nodais

$\left\{u^{h}\right\} \quad$ vetor de deslocamentos enriquecidos

$u_{l} \quad$ velocidade do vazamento do fluido

$u^{\text {enr }}$ deslocamentos enriquecidos

$u^{h} \quad$ deslocamentos totais (padrão+enriquecido) 
$\mathrm{U}_{\mathrm{a}} \quad$ energia de relaxação liberada

$\mathrm{U}_{\mathrm{e}}$ densidade de energia elástica de deformação por unidade de volume

$U^{\text {int }}$ densidade total de energia de deformação de um meio fissurado

$\mathrm{u}_{\mathrm{x}}, \mathrm{u}_{\mathrm{y}}, \mathrm{u}_{\mathrm{z}}$ deslocamento nas direções $\mathrm{x}, \mathrm{y}, \mathrm{z}$ respectivamente

$u_{w} \quad$ poropressão

$\mathrm{U}_{\gamma} \quad$ densidade de energia necessária para criar uma nova superfície de fratura

$\mathrm{V} \quad$ volume total

$v_{i} \quad$ velocidade da água

VCOs compostos orgânicos voláteis

Ve volume de poros interconectados

$\mathrm{Vp} \quad$ volume poroso

$W \quad$ densidade de energia de deformação

w abertura da fratura

$w_{m} \quad$ peso de Gauss

$\mathrm{w}_{\mathrm{D}}$ abertura admensional

$w^{e} \quad$ parcela da abertura controlada tensão líquida

$\mathrm{W}^{\mathrm{p}} \quad$ parcela da abertura controlada pela pressão líquida

$w_{y} \quad$ função da área da seção transversal da fratura

$\{\dot{x}\} \quad$ derivada temporal de uma variável $\mathrm{x}$

$x_{1}$ direção da propagação da fratura

$\gamma_{0}$ relação entre a densidade do óleo e da água

$\gamma^{0} \quad$ densidade de energia de superfície

$\gamma^{\mathrm{p}} \quad$ densidade de energia plástica

$\delta \quad$ delta de Kronecker

$\delta \varepsilon^{*} \quad$ deformações virtuais

$\delta u^{*}$ deslocamentos virtuais

$\varepsilon_{i j} \quad$ tensor de deformações

$\varepsilon_{v} \quad$ deformação volumétrica

$\eta \quad$ coeficiente poroelástico

$\theta_{w} \quad$ volume de água no solo

$\theta_{0}$ direção de propagação da fratura

[k] matriz de condutividade 
$k \quad$ permeabilidade

$k_{i j} \quad$ matriz de permeabilidade

$\lambda$ mobilidade

$\mu \quad$ viscosidade dinâmica do fluido

$v \quad$ Poisson

$\rho \quad$ densidade

$\rho_{0} \quad$ densidade do óleo

$\rho_{w} \quad$ densidade da água

$\sigma_{\mathrm{o}}$ tensão normal ao plano de fratura

$\sigma_{\mathrm{f}}$ resistência do material a tração

$\sigma_{i j} \quad$ tensor de tensões

$\sigma_{\mathrm{n}}$ tensão normal a direção de propagação da fratura

$\tau \quad$ tempo de chegada da ponta da fratura em $\mathrm{x}$

$\emptyset_{e} \quad$ porosidade efetiva

$\varphi(x)$ Função rampa

$\psi \quad$ fator de forma dependente da geometria da seção vertical da fratura

${ }^{\circ} A P I$ gravidade API 


\section{INTRODUÇÃO}

\subsection{APRESENTAÇÃ̃o}

A disponibilidade de energia de uma nação está diretamente relacionada com o seu crescimento e desenvolvimento econômico. Dentre as diversas formas de energia, os combustíveis fósseis tiveram grande importância no desenvolvimento mundial. Dentre os combustíveis fósseis o petróleo e o gás natural merecem destaque devido a sua grande produção no último século. Com o surgimento da indústria automobilística, o petróleo se tornou a principal fonte de combustível mundial, o que gerou uma intensa busca por reservas desse hidrocarboneto. Os países que possuem as maiores reservas de petróleo se localizam no Oriente Médio. Essa região, entretanto, é uma das regiões politicamente mais instáveis do mundo, e diversos conflitos ocorrem na região devido a uma série de motivos dentre os quais estão a contestação das fronteiras traçadas pelo colonialismo, posição geográfica, posição no contexto geopolítico mundial e a própria presença de recursos estratégicos no subsolo, o petróleo. Devido as diversas crises envolvendo os países do Oriente Médio, ocorreu uma elevação no preço do petróleo na década de 70, o que viabilizou e impulsionou a utilização de novas fontes de energia pelos países consumidores de petróleo, dentre elas a hidrelétrica, a nuclear e o gás natural.

Nos Estados Unidos, além da crise devido aos altos preços do petróleo, ocorria uma crise interna devido a uma queda na produção do gás natural doméstico. Pesquisas foram iniciadas para obter formas de extrair gás natural de formações de folhelho, pois já se sabia que essas rochas possuem reservas de hidrocarbonetos, porém as tentativas de extrair esse combustível por meio de poços convencionais haviam falhado. Após estudos e combinando diversas técnicas foi possível extrair a um custo economicamente viável o gás natural dessas formações. Desde então o gás de folhelho tem interpretado um importante papel na economia Norte-americana, sendo responsável atualmente por mais de $40 \%$ da produção de gás natural desse país (US EIA, 2014a).

As reservas de gás de folhelho estão espalhadas ao redor do mundo sendo que as maiores reservas estimadas economicamente recuperáveis se encontram na China e Argentina, sendo o Brasil o décimo país da lista (US EIA, 2015).

No Brasil, as reservas nacionais de gás natural não convencionais já mapeadas são significativas, e concentram-se nos Estados do Mato Grosso, Minas Gerais, Paraná e Bahia principalmente. Isso gera um impasse, pois a disponibilidade de gasodutos e a capacidade de 
processamento e distribuição são nulas ou muito baixas nestas regiões. Além disso, o gás representa apenas $10 \%$ da matriz energética nacional, sendo que a oferta atual de gás natural é essencialmente oriunda de bacias off-shore e de importação de outros países, principalmente a Bolívia. Há uma falta de definição na política energética com respeito ao gás natural, e os principais obstáculos à produção de gás natural não convencional são a baixa demanda de gás residencial, a falta de infraestrutura para interiorizar a produção (malha de gasoduto), a falta de investimentos em tecnologia para a produção de gás on-shore e também tecnologia para a exploração devido as características diferentes da convencional. Além disso, os órgãos de competência ambiental não estão preparados quanto as operações de exploração do gás não convencional e os impactos que ele pode causar devido a localização dessas reservas (Figura 1.1) e a necessidade da utilização da técnica do fraturamento hidráulico (Lage et al., 2013).

Devido à necessidade de utilização da técnica do fraturamento hidráulico, a produção do gás natural não convencional tem gerado diversas discussões ao redor do mundo. $\mathrm{O}$ fraturamento hidráulico é uma técnica perigosa que pode causar diversos impactos ambientais, como a contaminação do solo, dos aquíferos, do ar, entre outros. Assim, o seu estudo é muito relevante para se ter um maior controle sobre os impactos que essa técnica pode gerar. Um dos problemas existentes no processo de fraturamento hidráulico é a dificuldade de se controlar as fraturas criadas, podendo estas atingirem regiões além do previsto, gerando problemas ambientais.

\subsection{IDENTIFICAÇÃO DO PROBLEMA}

Como simular propagação de fraturas utilizando técnicas numéricas avançadas com vistas a prever o comportamento do maciço em torno do poço de petróleo estimulado via fraturamento hidráulico?

\subsection{JUSTIFICATIVA}

Pesquisas na área de Petróleo vêm sendo desenvolvidas pelo grupo de Geotecnia da Universidade de Brasília buscando expandir os conhecimentos nessa área. Este trabalho busca acrescentar temas que vêm sendo estudados na área do Petróleo e ampliar o entendimento, acrescentando novas informações obtidas com a pesquisa realizada.

Além disso, o tema de fraturamento hidráulico é um tema bastante polêmico devido aos impactos ambientais que a técnica pode ocasionar. O fraturamento hidráulico é uma técnica necessária para a produção de gás natural dos reservatórios de folhelho. O folhelho é uma rocha com permeabilidade baixa e são necessárias algumas operações para tornar a 
extração do gás dessa rocha economicamente viável.

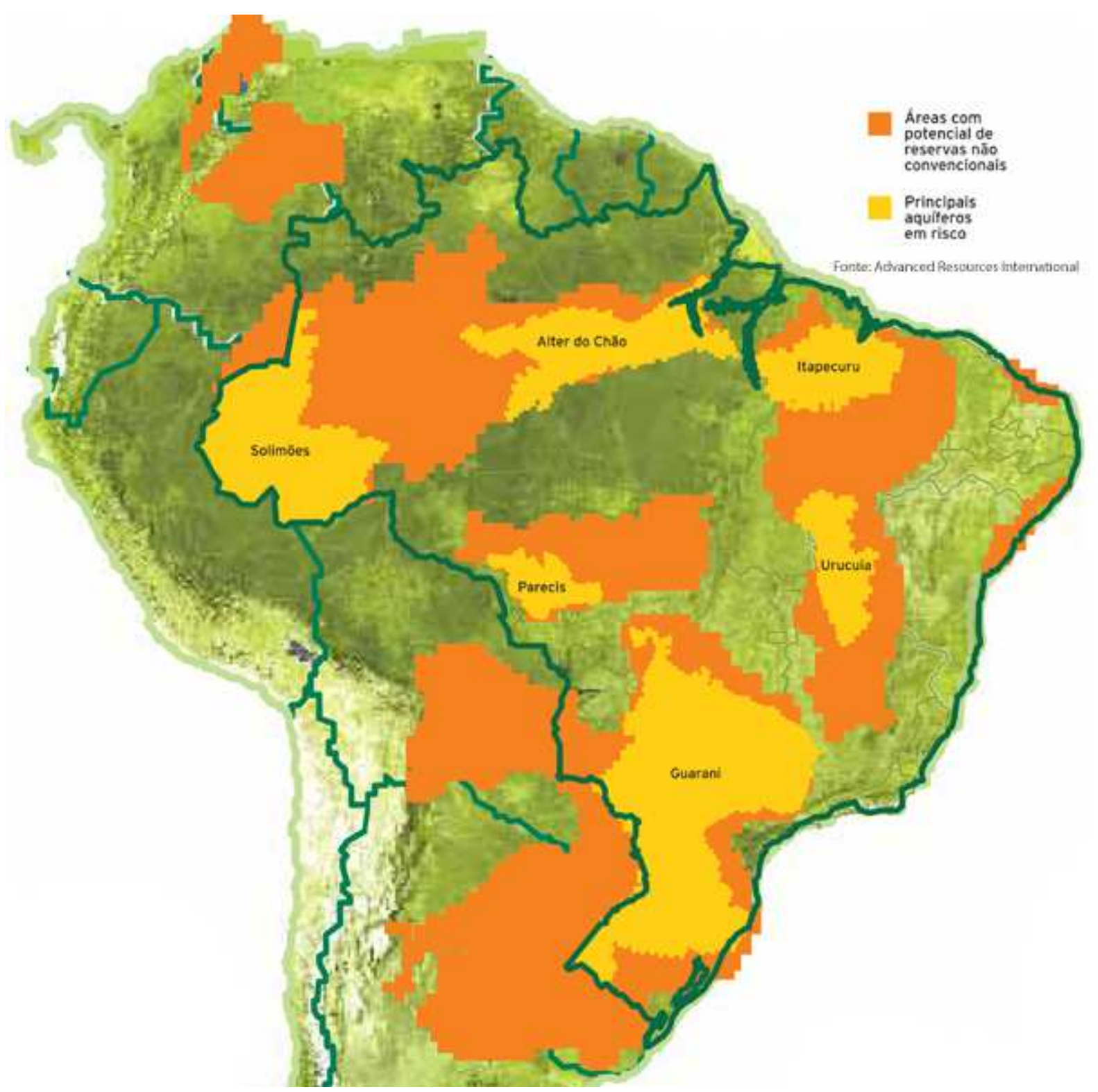

Figura 1.1 Localização das potenciais reservas de gás de folhelho no Brasil (Advanced Resources International, 2016)

O processo de fraturar a grandes profundidades pode gerar alguns imprevistos e com isso podem ocorrer impactos ambientais. A técnica é perigosa e acidentes já ocorreram em decorrência dela. Em 2011 um poço explodiu devido ao fraturamento hidráulico na Pensilvânia. Com a explosão, grande quantidade de fluido de fraturamento foi derramado em águas superficiais da região.

Além disso, estudos realizados próximo às reservas de Marcellus na Pennsylvania e de Utica em Nova York mostraram haver altas concentrações de metano na água de consumo da 
região, ou seja, o processo de extração do gás metano pode estar gerando a contaminação do lençol freático nessas regiões. (Osborn et al., 2011)

É necessário estudar todas as variáveis envolvidas no processo, os possíveis cenários e avaliar quais os procedimentos corretos e os cuidados que devem ser tomados para evitar imprevistos.

\subsection{HIPÓTESE}

O Método dos Elementos Finitos Estendido (XFEM) com uma formulação hidromecânica acoplada (equilíbrio e fluxo) é capaz de simular a propagação de descontinuidades geradas via Fraturamento Hidráulico.

\subsection{OBJETIVOS}

Este trabalho tem como objetivo principal a simulação da propagação de descontinuidades geradas via Fraturamento Hidráulico utilizando o método dos elementos estendido (XFEM) com uma formulação acoplada.

Além disso, esse trabalho tem como objetivos específicos:

- Implementação de uma ferramenta capaz de simular a propagação da fratura no maciço rochoso e suas consequências nos campos de tensões, deslocamentos e poropressões;

- Validação da formulação implementada utilizando formulações analíticas existentes na literatura;

- $\quad$ Avaliação da influencia da permeabilidade no processo de Fraturamento Hidráulico

\subsection{METODOLOGIA DE PESQUISA}

Para atingir os objetivos propostos na pesquisa serão seguidas as seguintes atividades apresentadas na Figura1.2.

\subsection{ESTRUTURA DO TRABALHO}

Este projeto está estruturado da seguinte maneira:

No Capítulo 1 é feita uma introdução ao presente trabalho sendo inicialmente apresentado um contexto geral do problema, seguido da motivação para a realização do trabalho e os objetivos do presente trabalho. Além disso, é apresentado a estrutura geral do trabalho, e o conteúdo de cada capítulo. 


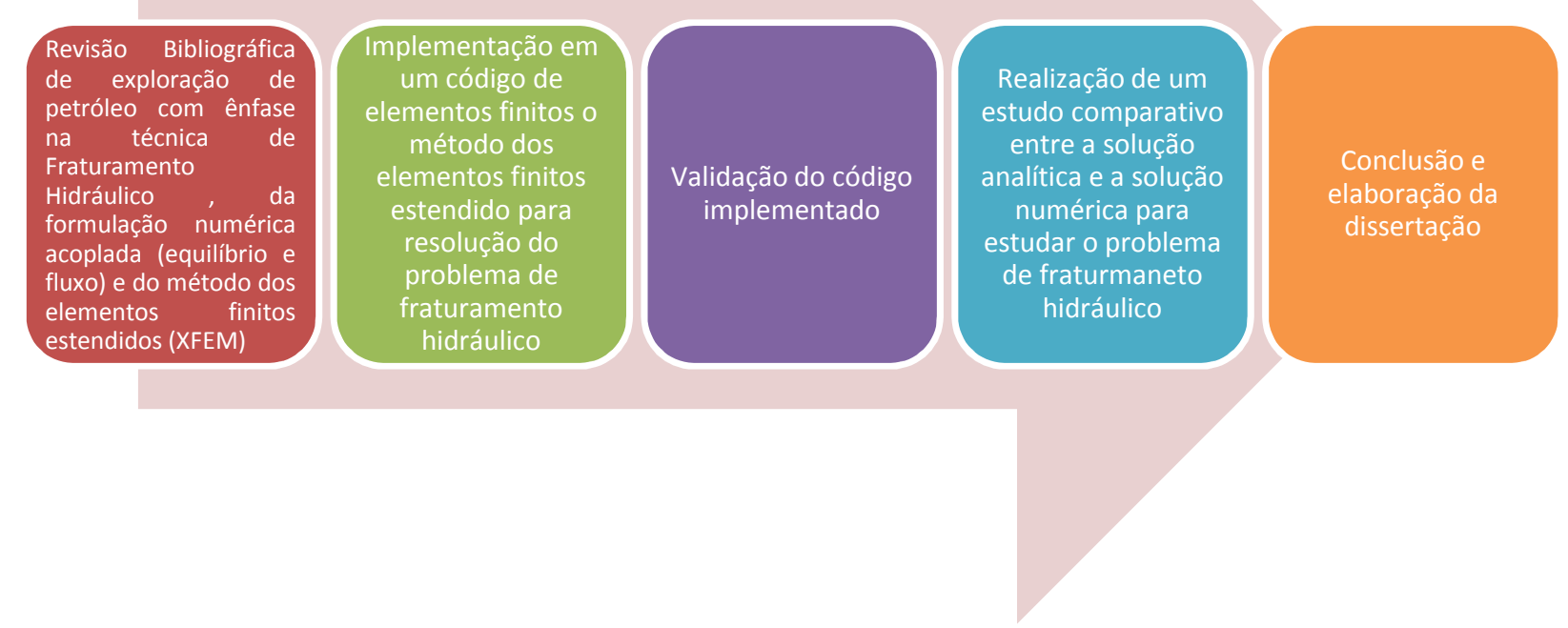

Figura 1.2 Metodologia da pesquisa

No Capítulo 2 é realizada uma revisão bibliográfica sobre os principais temas necessários para entender o presente estudo. Inicialmente é feito uma revisão sobre fraturamento hidráulico e gás de folhelho. Em seguida serão revisadas algumas das principais propriedades dos fluidos e dos reservatórios de petróleo, conceitos sobre geomecânica das rochas, sobre mecânica das fraturas, modelagem de fraturas e o Método dos Elementos Finito Estendido (XFEM).

No Capítulo 3 é apresentada a formulação desenvolvida por Jing Xiang (2011) modificado por Morais (2013) para estudar o Fraturamento Hidráulico. Nessa formulação são utilizadas equações de balanço de massa, uma lei de fluxo para fluidos não-newtonianos e uma relação pressão-abertura para estudar como se dará a abertura de uma fratura com a injeção de um fluido. Além disso, é apresentada a resolução dessas equações pelo método dos elementos finitos pelo do software FLEXPDE (PDE Solutions inc, 2015) os resultados para a pressão do fluido no interior da fratura e a abertura e o comprimento da fratura.

No Capítulo 4 são apresentadas as equações para resolução do fraturamento hidráulico de forma acoplada (equações de equilíbrio e continuidade), levando em consideração o meio rochoso onde está inserida a fratura.

No Capítulo 5 é feito a validação do código desenvolvido para a resolução das equações do problema. Primeiramente é apresentado um fluxograma do código e as principais 
funções desenvolvidas. Em seguida serão apresentadas validações para avaliar a correta resolução pelo código de problemas de equilíbrio, problemas acoplados e problemas envolvendo fraturas.

No Capítulo 6 é feita a simulação do problema de Fraturamento Hidráulico de forma simplificada, sendo apresentado alguns resultados obtidos.

No Capítulo 7 são apresentadas a principais conclusões do trabalho bem como propostas para futuras pesquisas. 


\section{REVISÃO BIBLIOGRÁFICA}

O Fraturamento Hidráulico é um método complexo para produção de petróleo e gás natural que exige um amplo conhecimento sobre vários assuntos, os quais serão abordados neste capítulo. Inicialmente serão apresentados conceitos sobre as fontes convencionais de combustíveis fósseis, mais especificamente sobre o gás natural e o petróleo, sobre as fontes não convencionais de combustível fóssil, mais especificamente sobre o gás de folhelho, o processo de fraturamento hidráulico, com suas principais etapas envolvidas, alguns modelos utilizados para prever como ocorrerá a fratura e os impactos que o fraturamento pode gerar. Posteriormente serão revisadas algumas das principais propriedades dos fluidos e dos reservatórios de petróleo, a mecânica das fraturas, modelagem de fraturas e o Método dos Elementos Finitos Estendido (XFEM).

\subsection{FONTE CONVENCIONAL DE COMBUSTÍVEL FÓSSIL- GÁS E PETRÓLEO}

O óleo e o gás natural são fontes de combustível não renovável, de origem fóssil, que são utilizadas há milhares de anos pelo homem. Comumente chamados de petróleo, ele foi utilizado de forma mais intensiva no último século, sendo o óleo e o gás uma das principais fontes de energia mundial, além de o petróleo ser matéria-prima para vários produtos, como os plásticos, asfaltos, entre outros. O petróleo é composto essencialmente por carbono (80 a 90\%), hidrogênio (10 a 15\%), enxofre (até 5\%), oxigênio (até 4\%), nitrogênio (até 2\%) e traços de outros elementos (ex: níquel, vanádio, etc) (Petroleum Geoscience Technology, 2016).

\subsubsection{FORMAÇÃO DO PETRÓLEO}

Com os dados disponíveis atualmente acredita-se que o petróleo é gerado a partir da transformação da matéria orgânica acumulada nas rochas sedimentares, submetidas às condições adequadas. Os fatores condicionantes para a geração do petróleo são: a presença de uma rocha rica em matéria orgânica (rocha geradora) submetida a condições adequadas (temperatura, tempo e pressão). A matéria orgânica acumulada nas rochas sedimentares passa por uma série de transformações (diagênese, catagênese e metagênese) que irão resultar na geração do petróleo.

O sistema petrolífero é composto pela existência de rochas com porosidade e permeabilidade necessárias a acumulação e produção do petróleo (rocha reservatório), condições favoráveis para migração do petróleo da rocha geradora até a rocha reservatório, 
existência de uma rocha impermeável para reter o petróleo (rocha capeadora), arranjo geométrico das rochas reservatório e capeadora que favoreça a acumulação do petróleo (PGT, 2016).

O petróleo gerado é expulso da rocha geradora (migração primária) e se desloca através do meio poroso até encontrar uma barreira (migração secundária) e acumula. A migração primária ocorre devido ao aumento de pressão nas rochas geradoras por causa da compactação e expansão volumétrica ocasionada pela formação do petróleo. Isso gera um gradiente de pressão entre a rocha geradora e as camadas adjacentes, favorecendo o deslocamento dos hidrocarbonetos. A migração geralmente ocorre através de descontinuidades, geralmente falhas geológicas. A migração secundária é impulsionada pelo gradiente de potencial de fluido, o qual é subdivido em: a) desequilíbrio de pressão causado pela compactação, b) flutuabilidade ou força vertical resultante da diferença de densidade entre o petróleo e a água da formação e c) pressão capilar, resultante da tensão interfacial entre as fases petróleo e água e as rochas (PGT, 2016).

As rochas reservatórios são rochas com porosidade e permeabilidade adequadas que permitem a acumulação do petróleo e a sua posterior produção. Elas são principalmente os arenitos e as rochas carbonáticas. Além da rocha reservatório, é necessária a rocha capeadora formando a trapa ou armadilha, que é a situação que favorece a acumulação do petróleo. As rochas capeadoras devem apresentar baixa permeabilidade e alta pressão capilar, de modo a impedir a migração vertical do petróleo (PGT, 2016). Na Figura 2.1 é possível observar as diversas configurações que favorecem a acumulação do petróleo.

\subsubsection{EXPLORAÇÃO E PRODUÇÃO DO PETRÓLEO}

As etapas para a exploração e produção dos reservatórios convencionais de petróleo podem ser divididas em: prospecção, perfuração e produção, sendo esta última a que será dado maior enfoque por ser onde se situa a técnica do Fraturamento Hidráulico. É possível observar na Figura 2.2 a subdivisão das etapas de exploração e produção dos reservatórios convencionais de Petróleo. Na exploração do petróleo a primeira etapa consiste em encontrar petróleo. A prospecção consiste na caracterização do terreno em busca de reservatórios de petróleo. Com ela é possível obter informações do terreno e prever possíveis locais de ocorrência de jazidas de petróleo. A prospecção se divide em métodos potenciais e sísmicos, sendo os métodos sísmicos os mais utilizados por fornecerem de maneira mais acurada a geologia local. 


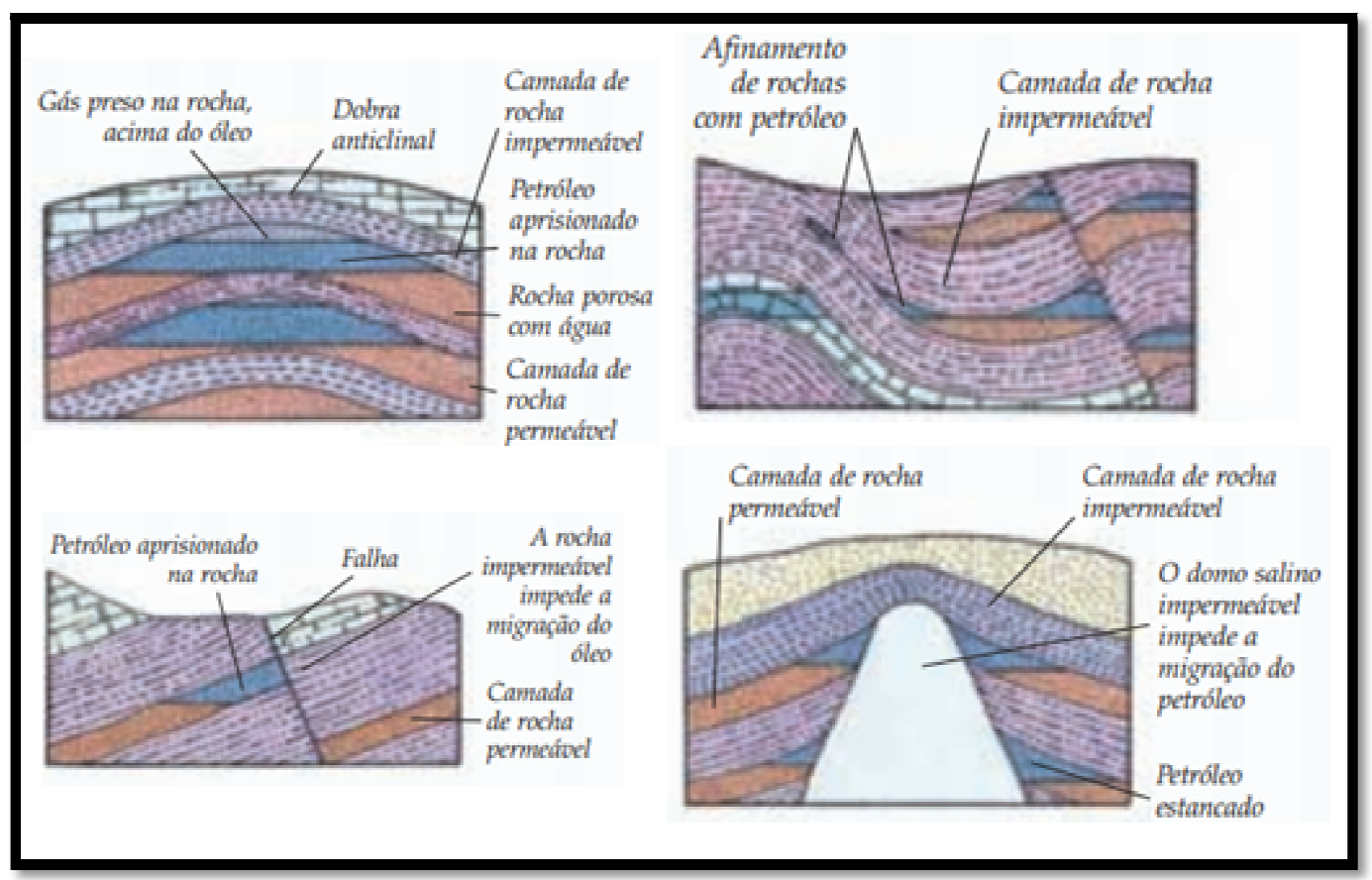

Figura 2.1 Armadilhas para acumulação de petróleo (SPE, 2007)

A perfuração consiste no conjunto de atividades realizadas para atravessar as formações rochosas e chegar aos reservatórios de petróleo. A perfuração pode ser realizada em terra (on-shore) ou no mar (off-shore). Os métodos de perfuração existentes são: o método percussivo e o método rotativo. O método percussivo consiste na fragmentação da rocha por esmagamento, sendo que esse método foi posteriormente substituído pelo método rotativo, onde a rocha é perfurada utilizando uma broca que se encontra na extremidade de uma coluna de perfuração.

A última etapa na exploração do petróleo é a produção. Para a ANP (Lei Nº 9478 /97) produção é o conjunto de ações coordenadas para extração de petróleo ou gás natural de uma jazida e o preparo para a sua movimentação. O processo de produção é considerado encerrado quando se termina o içamento dos produtos pela válvula, sobre o campo de produção. No caso de outras circunstâncias operacionais, pode-se considerar o fim do processo de produção quando se termina a entrega de um gasoduto, um transportador, uma refinaria ou um terminal marítimo (Domingues, 2009). O processo de produção divide-se, como observado na Figura 2.2, em completação de poços, recuperação e processamento primário. 


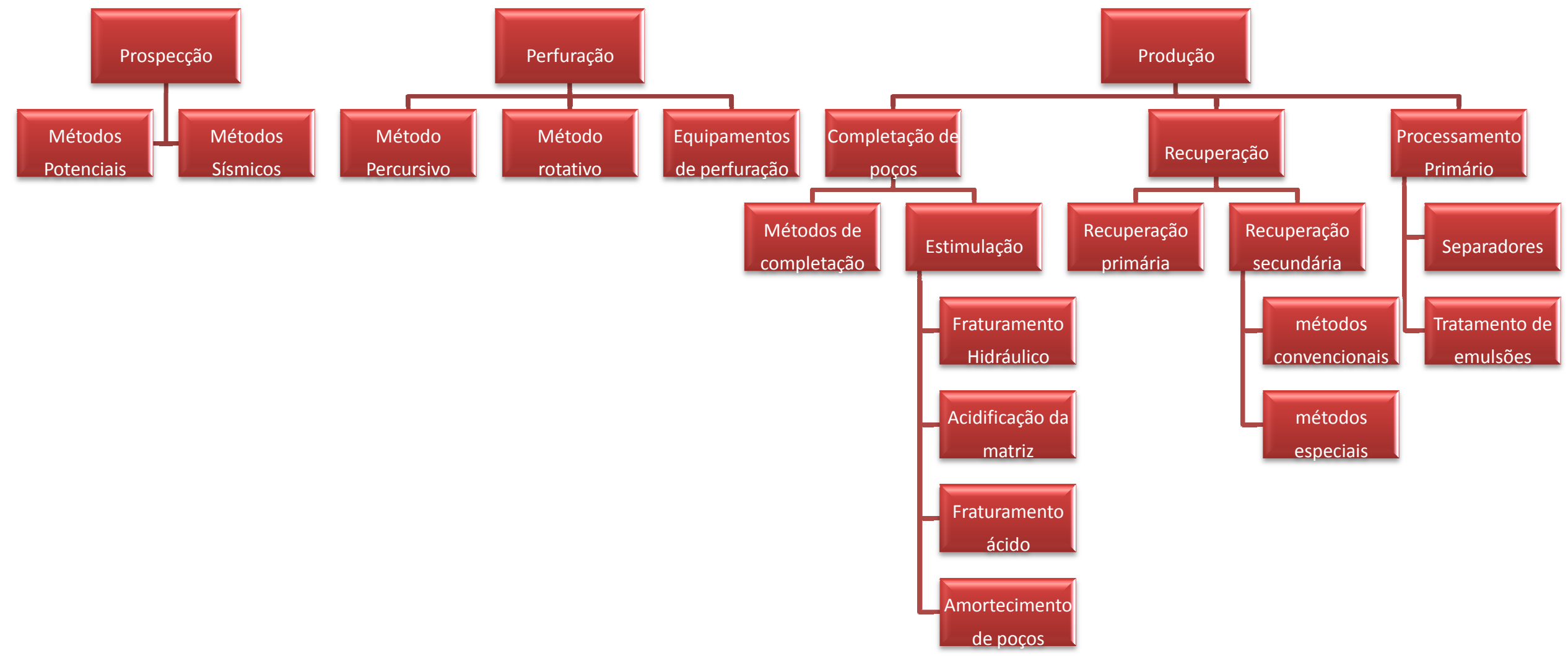

Figura 2.2 Etapas de exploração e produção de petróleo 
A completação é o processo de preparação do poço para a sua produção. Nele são realizadas diversas operações, visando a segurança do processo e os aspectos técnico, operacional e econômico da extração do petróleo. Dentro dessa etapa se encontram os métodos de completação propriamente ditos e os métodos de estimulação de poços, onde se situa o fraturamento hidráulico. Os métodos de completação são as diferentes formas de produção do poço, podendo ser classificados quanto a zona de produção (surgentes ou elevação artificial), revestimento de produção (poço aberto, linear rasgado, revestimento canhoeado), obsevado na Figura 2.3, e quanto ao número de zonas suplementadas (simples, seletiva ou dupla), observado na Figura 2.4. Cabe ao grupo que irá operar a produção decidir a melhor forma de produção do poço.

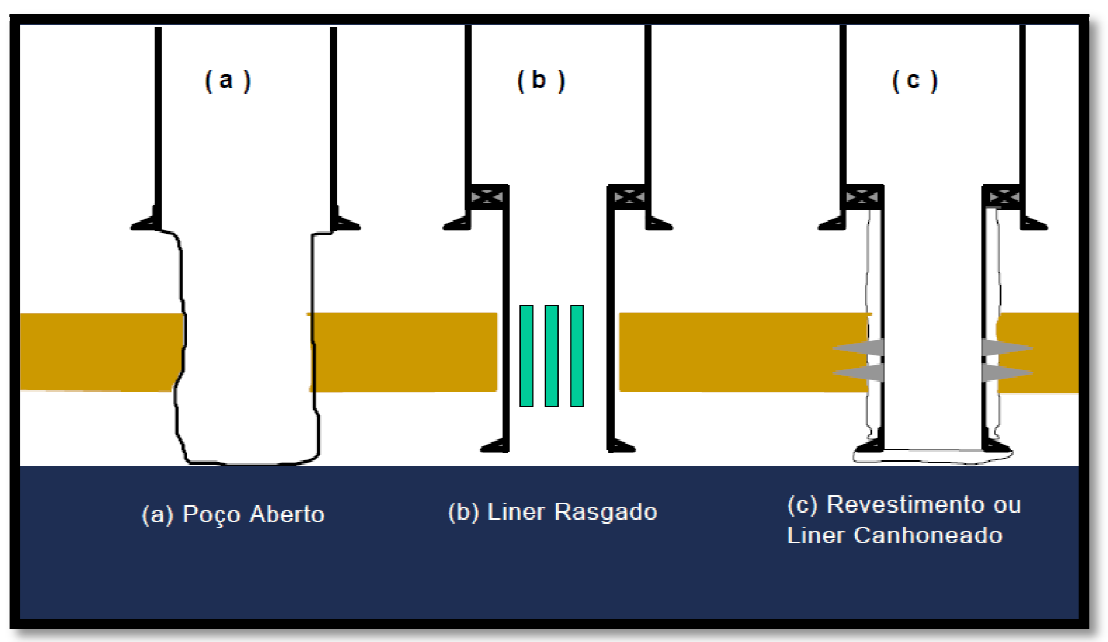

Figura 2.3 Completação de poços quanto ao revestimento de produção (Garcia, 1997)

As operações de estimulação de poços é o conjunto de técnicas utilizadas para aumentar a produtividade dos reservatórios. As principais técnicas existentes de estimulação de poços são: fraturamento hidráulico, fraturamento ácido, acidificação da matriz, que consistem basicamente na criação de caminhos preferenciais de fluxo para o petróleo aumentando a produção, sendo que cada uma irá utilizar diferentes operações para atingir o objetivo. A técnica do fraturamento hidráulico, tema deste trabalho, será explicada posteriormente com mais detalhes.

A recuperação é a etapa onde ocorre o fluxo do óleo para o poço de perfuração. Ela é dividida em recuperação primária e secundária. Na recuperação primária, o fluxo do petróleo para o poço ocorre utilizando a energia natural existente no reservatório. Os principais tipos 
de recuperação primária são: mecanismo de gás em solução, mecanismo de capa de gás e mecanismo de influxo de água.

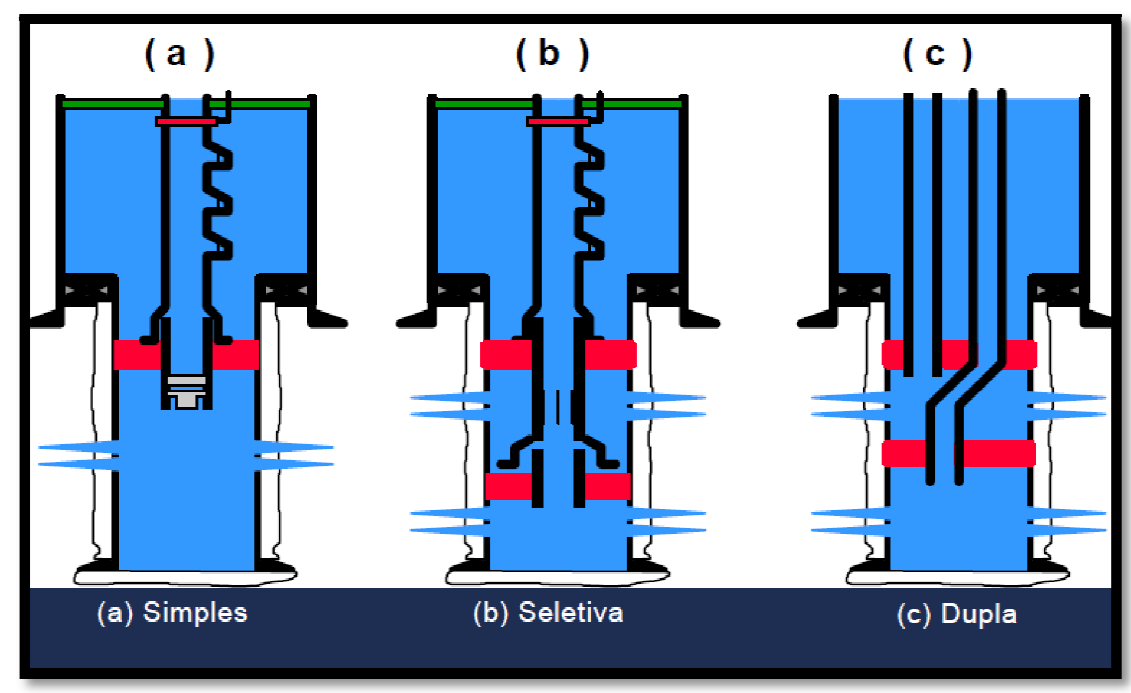

Figura 2.4 Zonas suplementadas simples, seletiva e dupla (Garcia, 1997)

Com a produção, o reservatório perde pressão e a energia existente neste não é mais suficiente para produzir o poço, sendo necessário realizar a recuperação secundária para continuar a produção do poço. Essa etapa pode ser realizada de forma convencional onde é injetado água e gás imiscível no reservatório para manter ou aumentar a pressão dos reservatórios, continuando assim com a produção, ou de forma especial, onde são utilizados métodos térmicos, químicos e miscíveis de acordo com as características da jazida.

Após a recuperação é realizado o processamento primário onde o petróleo extraído do reservatório irá passar por uma série de processos para que ele seja comercializado. A finalidade do processamento primário é: realizar a separação óleo/gás/água, tratar os hidrocarbonetos para que possam ser transferidos para refinaria e tratar a água para que seja destinada à condição ambiental.

\subsection{FONTE NÃO CONVENCIONAL DE COMBUSTÍVEL FÓSSIL- GÁS DE FOLHELHO}

A necessidade por novas fontes de combustível, em substituição ao petróleo, e o desenvolvimento de novas tecnologias possibilitou a exploração de reservas de gás e petróleo cujo acesso era difícil ou que precisavam passar por processos químicos específicos para se tornarem apropriados ao uso. Dentre essas novas fontes de combustíveis fósseis se encontra o 
gás de folhelho que necessita aplicar, dentre outras tecnologias, a técnica do fraturamento hidráulico para viabilizar sua produção.

A exploração do gás de folhelho se iniciou da necessidade que os Estados Unidos tinham de aumentar a produção de gás doméstico, a partir da crise energética mundial que se instalou na década de 70. Era conhecida a existência de hidrocarbonetos dentro de formações de folhelho, entretanto, não se possuía uma forma eficiente de extraí-los, pois o uso de tecnologia convencional de extração de petróleo havia falhado. Com a descoberta de tecnologias para exploração dessas formações de forma economicamente viável, iniciou-se a exploração desse gás que é hoje uma fonte representativa de energia para a matriz energética dos Estados Unidos, sendo este país o pioneiro na extração desse gás.

\subsubsection{FORMAÇÃO DO GÁS}

Rochas sedimentares são formadas a partir da deposição de sedimentos na superfície da terra ou sob a superfície da água. Os principais tipos de rochas sedimentares são os arenitos, os calcários e os folhelhos. Os folhelhos são rochas sedimentares formadas pela deposição de lama, siltes, argilas e matéria orgânica. Os folhelhos possuem uma estrutura laminada de baixa permeabilidade e são caracterizados por possuírem fissuras ao longo das camadas paralelas laminares. Outra característica é a grande quantidade de material carbonífero presente nos folhelhos, o que dá a rocha a sua coloração característica escura (Norton Rose Fulbright, 2016). É possível observar na Figura 2.5 a coloração escura dos folhelhos.

O gás natural foi formado pelo processo termogênico do carbono a milhões de anos a grandes profundidades na crosta terrestre, onde as altas pressões e temperaturas transformaram o material acumulado em gás. O gás consiste basicamente de metano $(80 \%$ ou mais), mas outros gases também estão presentes em menores proporções como o dióxido de carbono, nitrogênio, além de outros hidrocarbonetos como o etano e o propano. A quantidade de hidrocarbonetos vai depender da matéria orgânica acumulada na formação e o nível de maturidade térmica (Norton Rose Fulbright, 2016).

Os gases termogênicos sob altas pressões naturalmente migrariam para locais de menor pressão, mas o gás de folhelho está aprisionado nas formações devido a sua baixa porosidade e permeabilidade. Essas formações situam-se entre 2 e $3 \mathrm{Km}$ abaixo da superfície da terra, variando de acordo com a geologia local (Norton Rose Fulbright, 2016).

A principal diferença com relação as fontes convencionais de combustíveis fósseis é que as rochas geradoras de hidrocarbonetos atuam também como rochas reservatórios, ao 
contrário dos reservatórios convencionais de petróleo, em que, devido a migração do petróleo no tempo geológico, a rocha reservatório não será a mesma rocha onde foram gerados os hidrocarbonetos. Na Figura 2.6 é possível observar as duas formas de encontrar os hidrocarbonetos citadas acima.

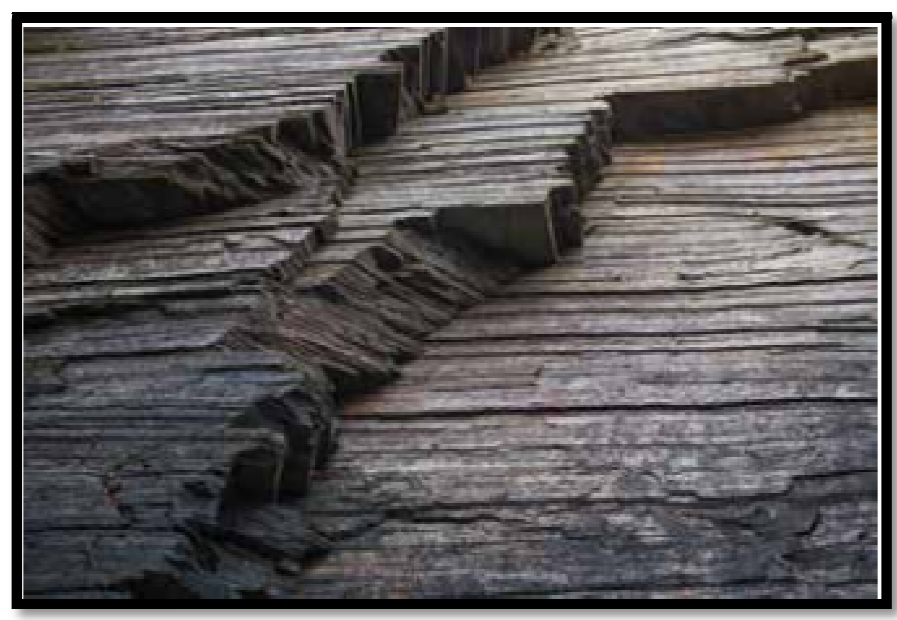

Figura 2.5 Rocha folhelho (Norton Rose Fulbright, 2016)

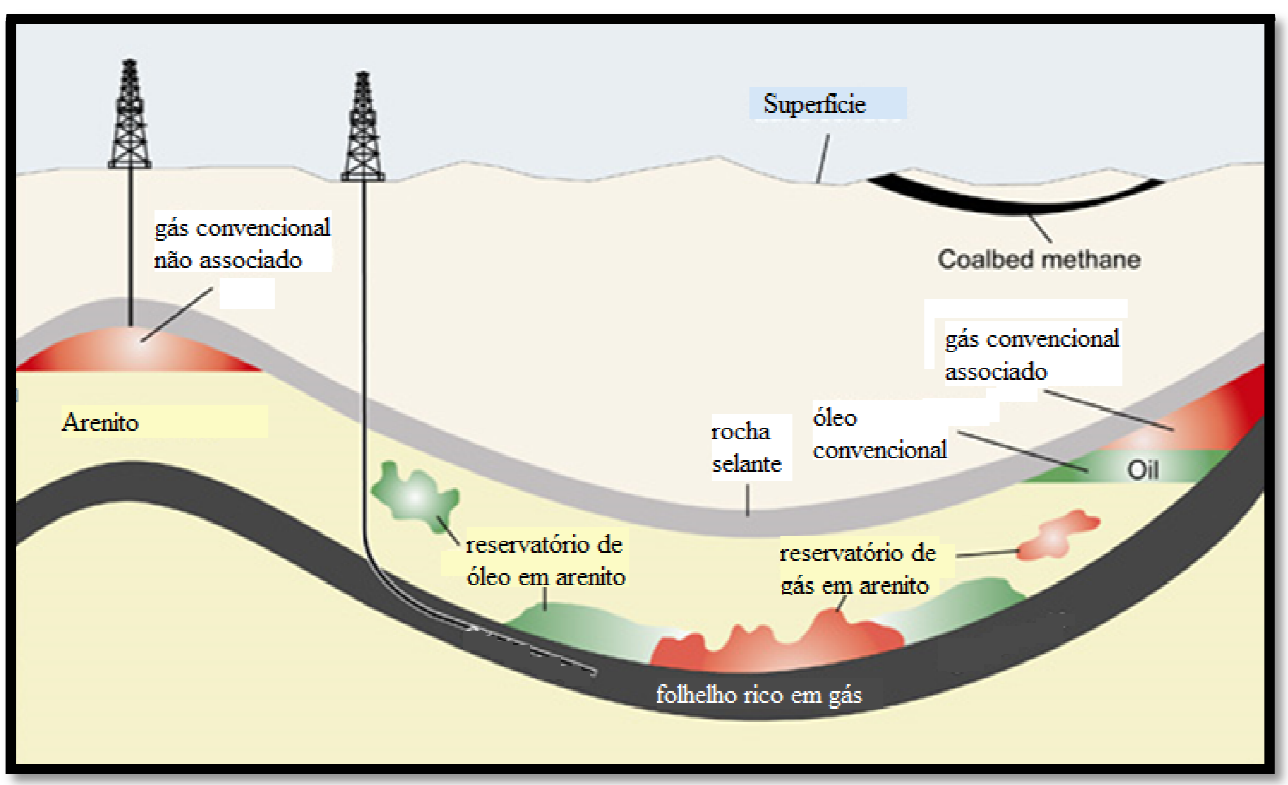

Figura 2.6 Fonte convencional e não convencional de gás (modificado EIA, 2013)

\subsubsection{ARMAZENAMENTO DO GÁS DE FOLHELHO NA MATRIZ ROCHOSA E PRODUÇÃO}

O armazenamento do gás de folhelho na matriz rochosa é complexo. Esse gás fica armazenado nas fraturas do maciço, nos micro-poros do folhelho ou adsorvido na rocha. A 
quantidade e a distribuição do gás na rocha são determinadas principalmente pela pressão inicial do reservatório, as propriedades petrofísicas da rocha reservatório e características de adsorção da rocha. Entretanto, aproximadamente $15 \%$ do gás produzido se encontra armazenado nas fraturas naturais e nos poros do folhelho. Os $85 \%$ do gás restante se encontra adsorvido na matriz do folhelho. Para produzir esse gás adsorvido é preciso permitir a ocorrência do processo de dessorção, o que ocorre com a redução da pressão do reservatório (TLR, 2011).

Durante a produção do gás de folhelho ocorrem três processos. Inicialmente ocorre a depleção do gás de dentro das fraturas. Este tipo de produção é baixa devido a capacidade de armazenamento limitada da fratura. Após isso ocorre a depleção do gás contido na matriz rochosa. A quantidade de gás na matriz rochosa vai depender das propriedades do reservatório e é de difícil estimativa. Por fim ocorre a dessorção, onde o gás adsorvido é liberado devido a queda de pressão no reservatório. Essa etapa vai depender de uma queda significativa da pressão do reservatório (TLR, 2011). Esse processo pode ser observado na Figura 2.7.

Existem dois tipos de processo de dessorção: dessorção física ou de Van der Waals e dessorção química. Na dessorção física o gás se encontra adsorvido na matéria orgânica presente nos folhelhos e em alguns casos nos minerais argilosos. Essa adsorção é resultado das forças intermoleculares de atração entre as partículas e o gás natural, sendo esse fenômeno facilmente reversível. A atração intermolecular entre o gás natural e as partículas de argila é maior que a atração entre as moléculas do gás, e o gás condensa na superfície da matriz rochosa. O gás natural fixado na matriz rochosa pode ser removido ou dessorvido diminuindo a pressão da fase de gás ou aumentando a temperatura do gás adsorvido (Das, 2012).

A adsorção química é a interação química entre o gás e outra substância. As forças adesivas são muito maiores que as encontradas na adsorção física e grande quantidade de calor é liberada quando a interação é desfeita. As chances de ocorrerem interações químicas do gás nas formações de folhelhos são pequenas, e o processo é geralmente irreversível, sendo que, quando ocorre há também uma alteração química das substâncias. Estudar os efeitos da dessorção do gás nas formações de folhelho pode ajudar a entender e aumentar a produtividade da produção desse gás (Das, 2012).

\subsubsection{TECNOLOGIAS PARA PRODUÇÃO DE GÁS DE FOLHELHO}

Para produzir gás natural de folhelhos, é preciso realizar uma série de processos, incluindo o fraturamento hidráulico, para possibilitar a extração do gás e tornar a produção economicamente viável. Inicialmente é necessário preparar uma área na superfície, as plataformas de perfuração, onde serão armazenados todos os componentes necessários à 
produção do poço como os equipamentos de perfuração, tanques de água e caminhões de transporte. Além disso, é necessária a construção de estradas e instalações de apoio que servirão a plataforma.

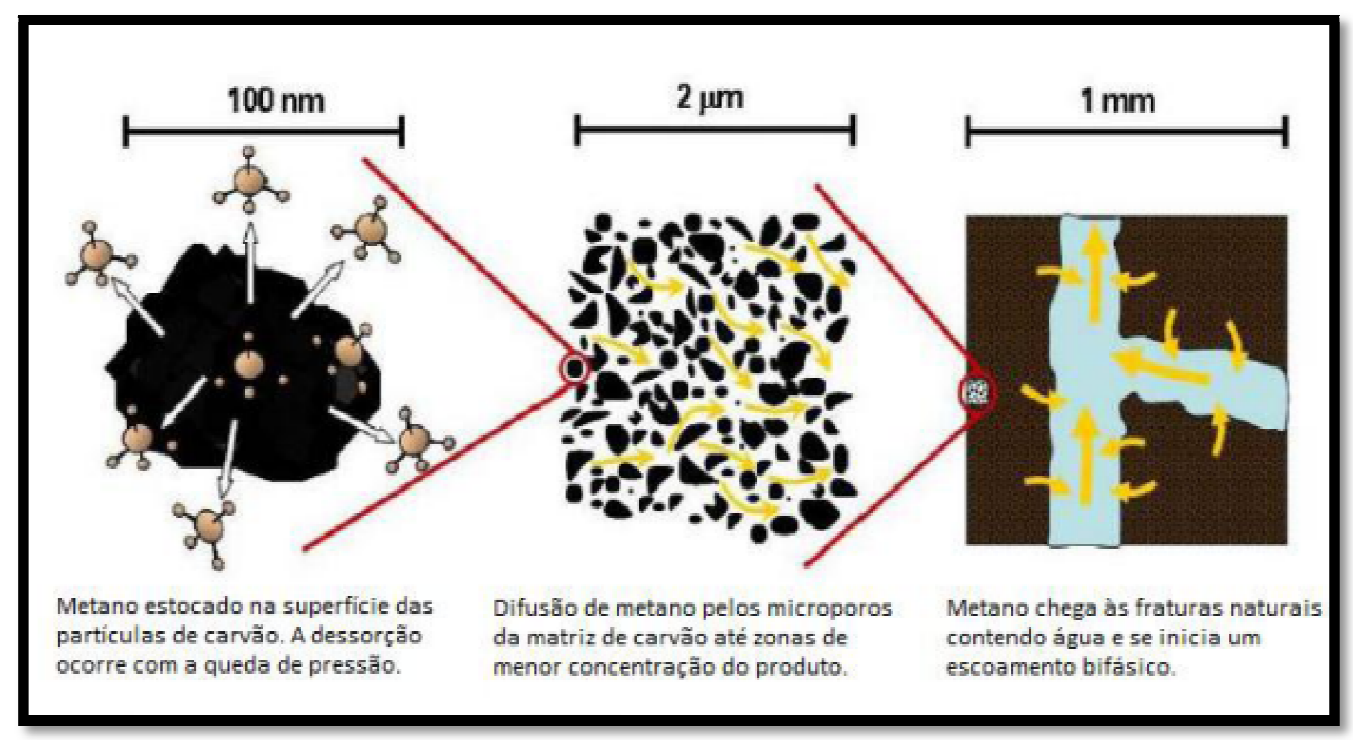

Figura 2.7 Processo de movimentação do metano nas camadas do carvão semelhante ao que ocorre nos reservatórios de folhelho (Carestiato, 2014)

As reservas de gás de folhelho normalmente estão situadas a grandes profundidades e possuem pequena espessura, sendo, portanto mais eficiente a produção utilizando poços horizontais. Vários poços horizontais acessando diferentes partes da formação podem ser perfurados, desenvolvendo assim uma grande área na subsuperfície, aumentando a eficiência e diminuindo os custos com infraestrutura e com o uso da terra. Outra tecnologia utilizada na produção de gás de folhelho foi a de poços empilhados. A eficiência dos poços empilhados vai depender da espessura do reservatório ser suficiente. Com isso, apenas um poço vertical é utilizado para perfurar várias ramificações na horizontal. Também o uso de poços multilaterais aumentou a eficiência e diminuiu os custos do processo (TLR, 2011). Na Figura 2.8 é possível observar algumas das tecnologias utilizadas para a produção do gás de folhelho.

\subsubsection{RESERVAS DE GÁS DE FOLHELHO}

Os reservatórios de gás de folhelho estão espalhados pelo mundo e segundo a EIA (2010) estima-se que 138 fontes de gás e de óleo de folhelho, espalhados por 42 países, contêm $10 \%$ do óleo bruto e $32 \%$ do gás natural mundial tecnicamente explorável. As reservas se encontram principalmente em cinco países do mundo: China, Argentina, Argélia, 
Estados Unidos e Canadá. Na Figura 2.9 é possível observar a distribuição das reservas de gás de folhelho, sendo apresentadas as reservas com recursos estimados, as bacias avaliadas com recursos não estimados, além dos países avaliados e dos países que não foram avaliados.
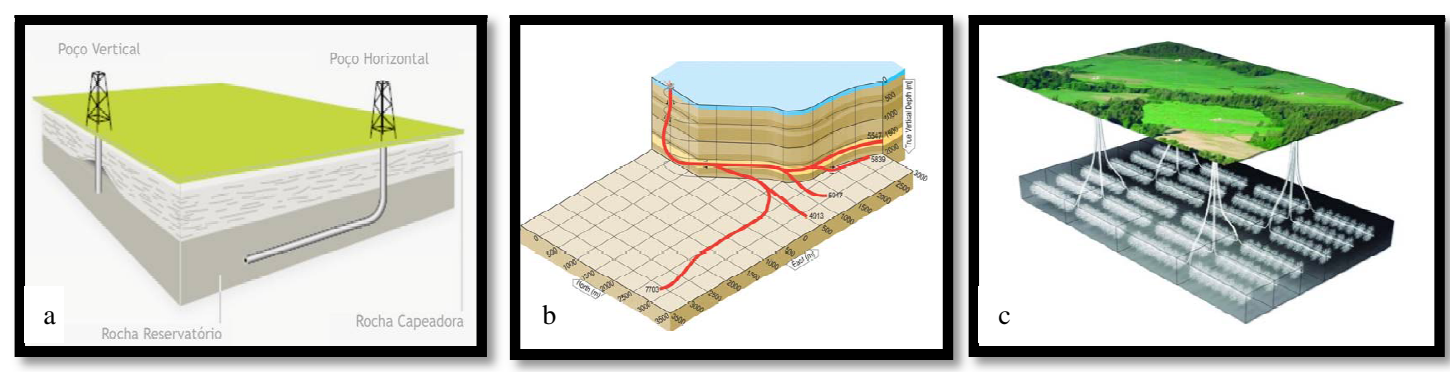

Figura 2.8 Tecnologias utilizadas extração de gás de folhelho a) poços horizontais b)ramificações de um único poço e c)poços multilaterais (TLR, 2011)

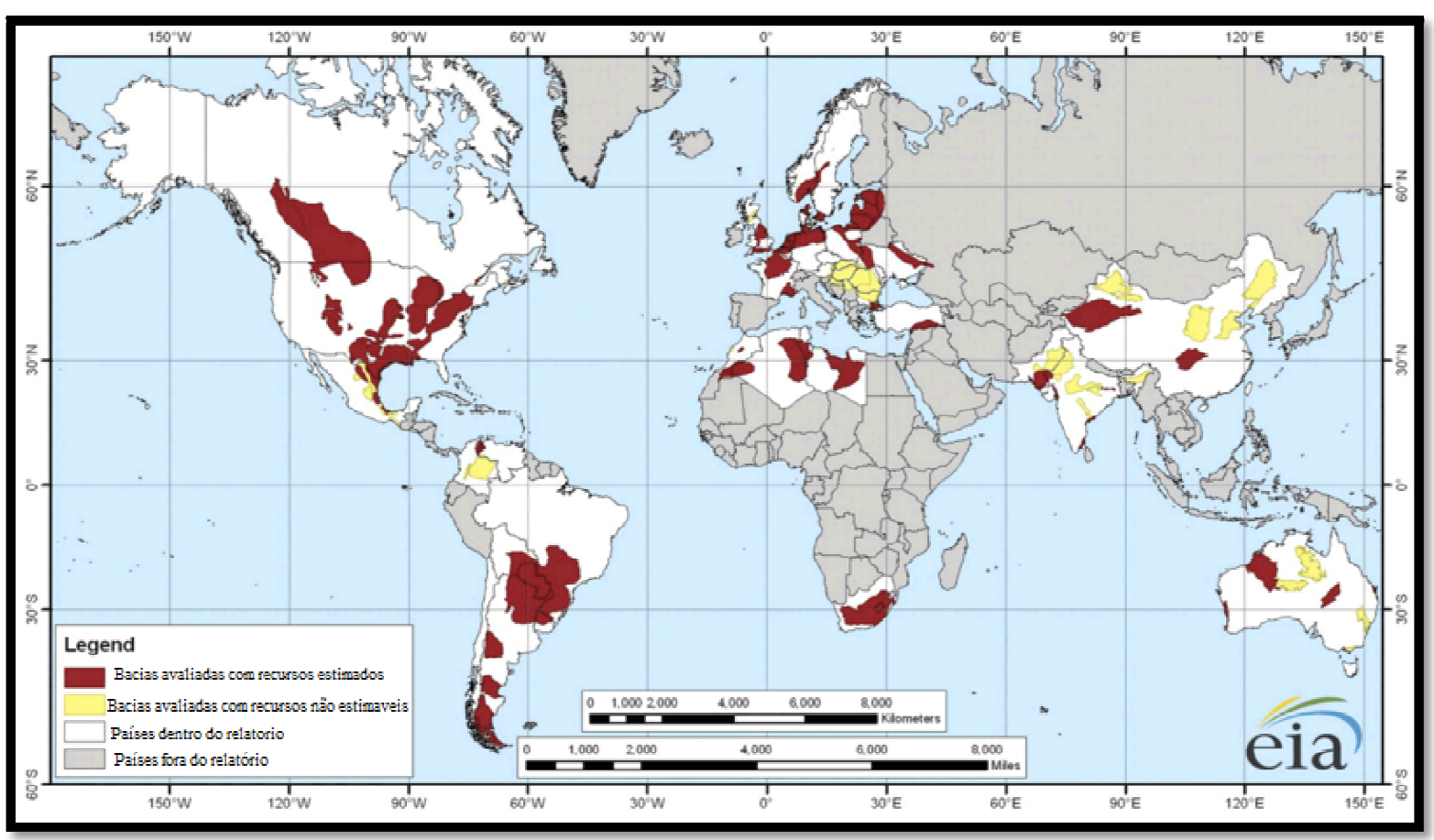

Figura 2.9 Bacias com formações de gás de folhelho avaliadas (modificada EIA, 2013)

\subsection{FRATURAMENTO HIDRAULICO}

O fraturamento hidráulico é uma técnica que tem sido utilizada em larga escala a partir de 2003, quando as companhias energéticas expandiram a exploração do gás natural, com ênfase no gás de folhelho. Entretanto, ela é utilizada desde a década de 40 pela indústria do petróleo para aumentar a produtividade dos poços convencionais de hidrocarbonetos. 
Segundo Taleghani (2009), o fraturamento hidráulico tem sido utilizado não só para aumentar a produtividade de poços de hidrocarbonetos, mas também para extração de energia geotérmica (Sasaki, 1998; Berumen et al., 2000), disposição de lixo sólido tóxico(Hunt et al., 1994;Hainey et al. 1999), medição de tensões in situ (Hayashi et al., 1997; Raaen et al.,2001), reativação de falhas em minas (Board et al. 1992).

O fraturamento hidráulico tem tido um desenvolvimento bastante significativo nos últimos anos e vários estudos têm sido realizados (Gidley J. L., et al., 1989, Jeffrey R.G., Zhang X., Thiercelin M., 2009) e equipamentos desenvolvidos para viabilizar a aplicação da técnica nos mais diversos ambientes. No Brasil, o fraturamento tem sido aplicado principalmente na Bacia de Campos, para aumentar a produtividade dos poços de petróleo.

É possível observar na Figura 2.10 as etapas do processo de fraturamento Hidráulico. Inicialmente o poço é perfurado horizontalmente a aproximadamente 2000 metros abaixo da superfície, em uma segunda etapa o poço é revestido, sendo em seguida criados pequenos orifícios ou pontos de fraqueza na parede do poço por meio da detonação de explosivos. Uma mistura pressurizada é injetada e quando a pressão supera a tensão de resistência à tração da rocha a fratura se inicia e cresce na rocha reservatório. Em seguida uma mistura contendo água, areia e químicos (propante) é injetada e se desloca no interior da fratura criada, mantendo-a aberta, criando um caminho de elevada condutividade e fazendo o hidrocarboneto fluir do reservatório para o poço. A fratura irá crescer na direção normal a menor tensão do reservatório, abrindo na direção onde é oferecida a menor resistência.

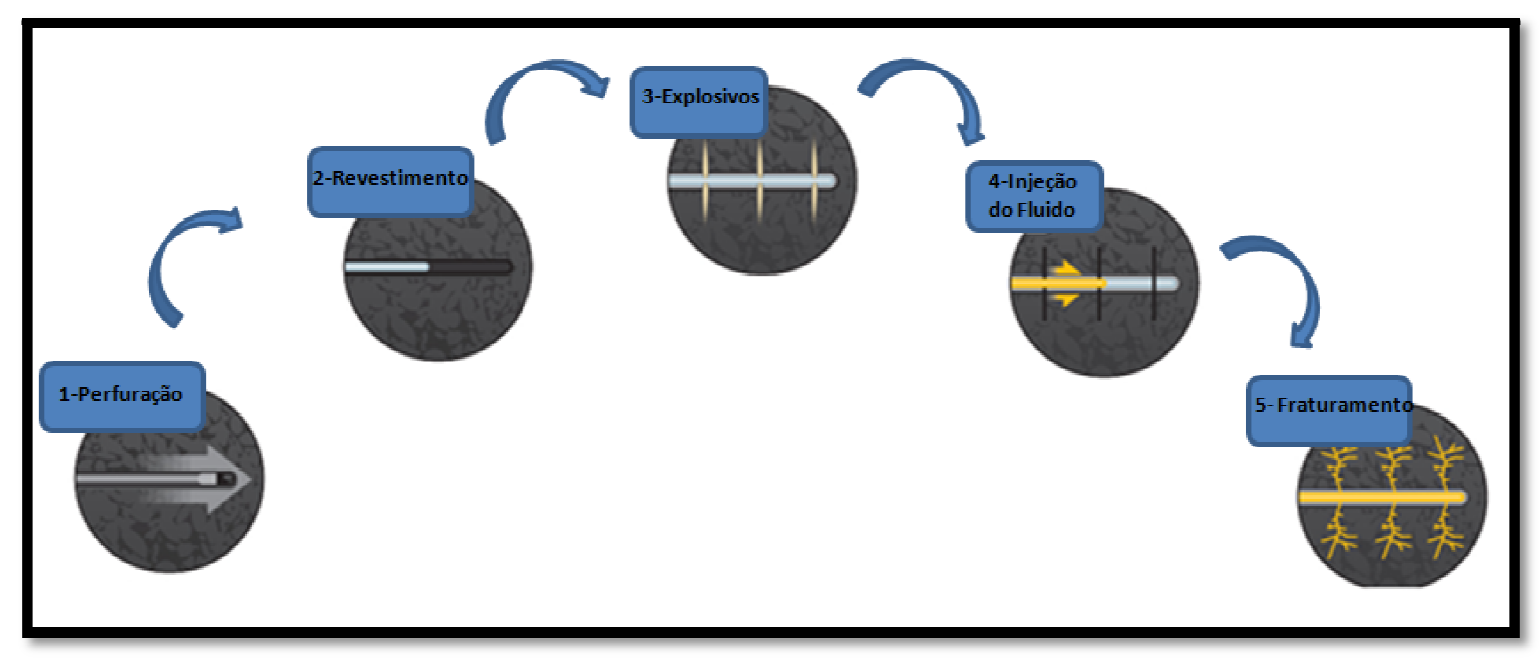

Figura 2.10 Processo de fraturamento hidráulico

A técnica é muito útil não só por aumentar a produtividade de poços convencionais, 
mas por proporcionar o aumento de reservas, pois tornou viável a exploração de novos reservatórios de hidrocarbonetos, os reservatórios não convencionais. Segundo Thomas (2001), o fraturamento não altera a permeabilidade da rocha, mas aumenta o índice de produtividade dos poços das seguintes formas:

- Modifica o modelo de fluxo do reservatório (Figura 2.11), tornando-o linear dentro da fratura e proximidades e pseudo-radial mais distante da fratura. Com isso uma área maior do reservatório é exposta ao fluxo para o poço e criam-se caminhos preferenciais de fluxo;

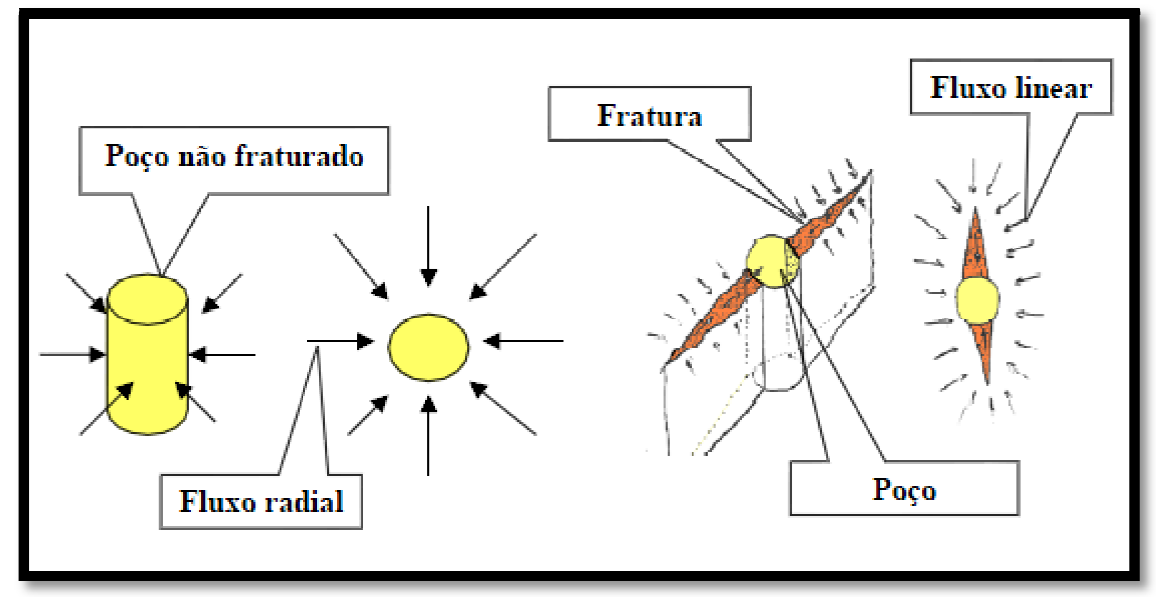

Figura 2.11 Estrutura do fluxo para um poço não fraturado e um fraturado (Castro, 2004)

- Existe a possibilidade de a fratura atingir uma área do reservatório mais distante ao poço, com melhores condições de escoamento do óleo;

- $\quad$ Em reservatórios lenticulares (seções produtoras de pequenas espessuras, intercalada por folhelhos) a fratura poderá atingir zonas previamente não conectadas ao poço, colocando-as em produção;

- Em reservatórios naturalmente fraturados, uma fratura induzida hidraulicamente também pode conectar fissuras naturais, em quantidade suficiente para aumentar a produção.

Com o uso da mecânica das rochas é possível explicar o que ocorre no fraturamento hidráulico. O estado de tensões irá controlar a direção e o plano da fratura. A resistência da formação depende da sua estrutura, compactação e a forma como foi cimentada. Assim as forças que tendem a manter a rocha unida são a tensão aplicada na rocha pelo peso das camadas e a sua resistência natural (Castro, 2004).

Quando um poço de petróleo está cheio de fluido e uma pressão é aplicada na superfície, a pressão do fluido que preenche o reservatório irá aumentar formando uma tensão 
interna na formação igual em todas as direções. Quando a tensão aplicada se tornar maior que a tensão que mantém a rocha coesa, tem-se o surgimento de uma fratura perpendicular ao plano de menor tensão principal. A fratura se estenderá enquanto pressão suficiente for aplicada pela injeção adicional de fluido do poço (Castro, 2004).

Durante e após a perfuração do poço de petróleo, várias operações devem ser realizadas para iniciar a produção. Após a preparação do poço o fluido de fraturamento é bombeado a altas vazões na formação, ocasionando o aumento de pressão, resultando na falha da rocha por tração. A fratura se propaga pelo bombeio do fluido de fraturamento a uma vazão superior a vazão de filtração do fluido pela formação. Esse fluido irá criar uma abertura suficiente para o posterior bombeio do agente de sustentação (propante), o qual irá manter a fratura aberta e irá criar um caminho preferencial de alta condutividade, facilitando o deslocamento do fluido do reservatório e aumentando a produção (Azevedo, 2011). A Figura 2.12 mostra um esquema do processo.

Vários fatores podem afetar a produção de um poço após o fraturamento, acarretando declínios de produção mais acentuados do que aqueles previstos no projeto. Falhas operacionais, baixa qualidade do fluido de fraturamento, fechamento de fraturas devido a despressurização (fechamento por tração e cisalhamento), comunicação com outras formações acarretando perdas de fluido (perda de eficiência), desconhecimento de propriedades mecânicas e hidráulicas da formação, refluxo de propante e utilização de materiais inadequados para a sustentação de fraturas podem reduzir drasticamente a produção do poço, diminuindo, consideravelmente, a economicidade do fraturamento (Salas Cachay, 2004).

\subsubsection{FRATURAMENTO HIDRÁULICO EM RESERVÁTORIOS NÃO CONVENCIONAIS COM FRATURAS PRÉ-EXISTENTES}

Os reservatórios de folhelho possuem baixíssima permeabilidade na matriz rochosa e baixa permeabilidade na rede de fraturas naturais existentes. Amostras de reservatórios de folhelho mostraram que eles podem conter fraturas naturais cimentadas, o que não deve ser ignorado no projeto de estimulação do poço desses reservatórios, pois elas podem agir como caminhos preferenciais para o crescimento da fratura. A existência dessas fraturas pode ou não ser vantajosa. 


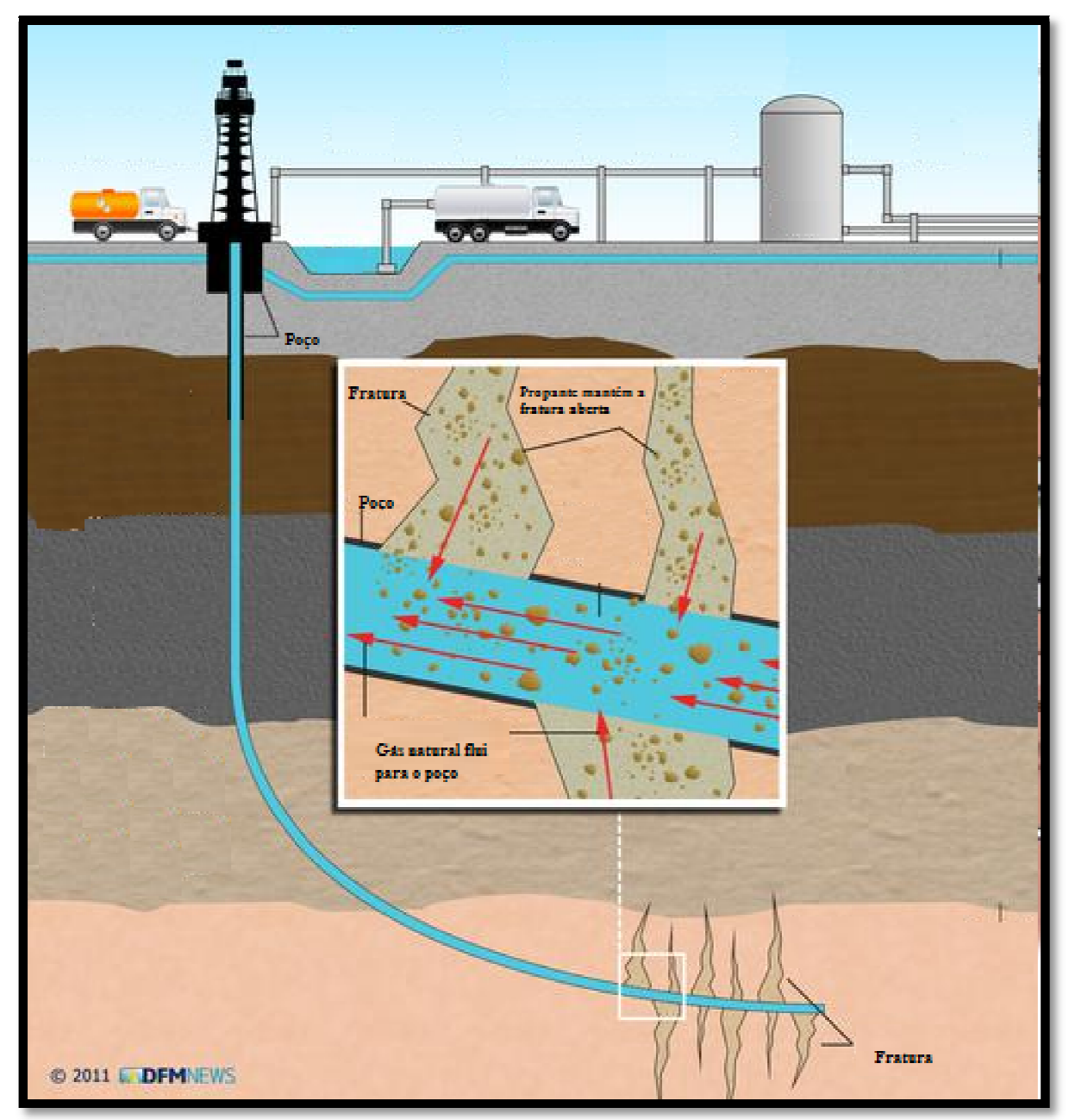

Figura 2.12 Fraturamento Hidráulico (modificada Aljazeera, 2013)

Segundo Taleghani (2009), foi observado que em reservatórios naturalmente fraturados ocorrem altas taxas de vazamento de fluidos para a formação durante o fraturamento hidráulico, podendo o vazamento ser até cinquenta vezes maior do que em reservatórios não fraturados. As taxas de vazamento para a formação de fluido de fraturamento em reservatórios não fraturados são extremamente dependentes da permeabilidade da formação, pressão líquida do processo e parâmetros do fluido de fraturamento, enquanto as observações em campo de reservatórios naturalmente fraturados mostraram que o vazamento de fluido depende da pressão líquida do processo e dos parâmetros do fluido de fraturamento, mas não depende da permeabilidade da formação. Algumas tentativas de fraturar reservatórios naturalmente fraturados não obtiveram sucesso devido as grandes perdas de fluido para a formação, sendo que existe um limiar para a pressão líquida acima do qual as fraturas se abrem, e caso se respeite esse limiar as fraturas ficam 
fechadas, não contribuindo para o vazamento do fluido.

É muito importante se obter um prévio conhecimento do local onde será aplicado a técnica do fraturamento hidráulico, para obter eficiência no processo. $O$ fraturamento hidráulico, entretanto, pode se tornar um problema bastante complexo se considerada todas as variáveis envolvidas, como a existência de um meio complexo fraturado com propagação de múltiplas fraturas hidráulicas, que exigirá melhores modelos e teorias para explicar a interação entre fraturas naturais e fraturas hidráulicas. Neste trabalho não foi considerado na simulação a existência de fraturas naturais no reservatório devido a maior complexidade das análises e a necessidade de um tempo maior para desenvolvimento.

\subsubsection{FLUIDO DE FRATURAMENTO}

Os fluidos do fraturamento hidráulico são utilizados para iniciar e/ou expandir as fraturas, e também para transportar o propante para o interior da fratura. A viscosidade do fluido de injeção é importante para o eficiente transporte e locação do propante. A maior parte do fluido de injeção é expelida do poço durante a produção.

Foram desenvolvidos ao longo dos anos diversos tipos de fluidos de fraturamento baseados tanto em água, quanto em óleo, com o objetivo de obter e manter fraturas permeáveis e produtivas. Cada fluido possui suas características, e possuem aspectos positivos e negativos durante a performance. Segundo EPA (2004), o fluido ideal deveria possuir as seguintes características:

- $\quad$ Ser viscoso o suficiente para criar fraturas de largura adequada;

- Maximizar o trajeto do fluido aumentando o comprimento da fratura;

- $\quad$ Poder transportar grande quantidade de propante para a fratura;

- $\quad$ Requerer pequena quantidade de agente geleificante para permitir a fácil degradação ou quebra, e reduzir os custos.

Muitos tipos de aditivos podem ser incorporados ao fluido de fraturamento por diversas razões como para limpeza da formação, estabilização da espuma, inibir vazamentos e redução da tensão superficial.

Deve-se decidir qual o fluido mais adequado a ser utilizado na formação. Para realizar o estudo numérico do fraturamento, uma dificuldade encontrada é a de representar corretamente as propriedades do fluido de fraturamento, sendo que nesse trabalho será considerado como fluido de fraturamento apenas a água. 


\subsubsection{PROPANTE}

O propante é um material granular utilizado no fraturamento (Figura 2.13) para manter as fraturas abertas. A escolha do propante é de extrema importância, pois suas propriedades irão influenciar na condutividade e sustentação das paredes da fratura. A areia foi um dos propantes mais utilizados por sua viabilidade econômica, disponibilidade e propriedades de condutividade adequada. Além dela, são utilizados como propante areia tratada com resina e propantes cerâmicos.

$\mathrm{Na}$ simulação numérica do processo existe uma grande dificuldade de levar em consideração todos os aspectos e o propante está incluído nessa dificuldade. Seria necessário utilizar um fluido com mais de uma fase para levar em conta a parte sólida (areia) do propante, além de algumas propriedades relacionadas às características dele. Entretanto para a realização da técnica é de extrema importância estudar esse fluido e suas propriedades.

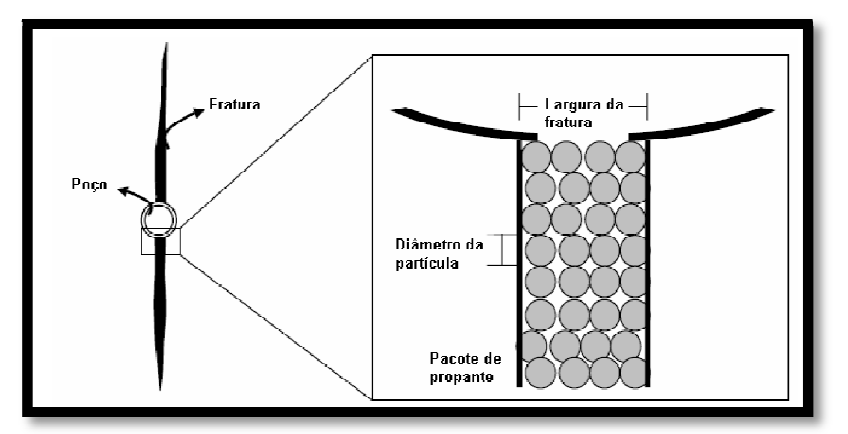

Figura 2.13: Preenchimento da fratura pelo propante (Salas Cachay, 2004)

\subsubsection{PROPRIEDADES DOS PROPANTES}

As principais propriedades físicas que irão influenciar na condutividade do propante são a resistência ao esmagamento, o tamanho das partículas, a quantidade de finos, o arredondamento e a esfericidade dos grãos.

A primeira propriedade é a resistência ao esmagamento. A tensão de fechamento é determinada pela diferença entre a pressão de fraturamento e a pressão de produção do poço. A resistência do material de sustentação deve ser maior que a tensão de fechamento de modo a impedir o esmagamento dos grãos, consequente produção de finos e redução da condutividade da fratura (Salas Cachay, 2004).

É importante conhecer sobre o tamanho e a distribuição dos grãos, pois eles irão influenciar na condutividade da fratura. Para aumentar a condutividade da fratura, o mais 
indicado é o uso de propantes de grandes diâmetros. Entretanto, deve-se observar que o uso de propantes com grande diâmetro deve ocorrer apenas a baixas pressões de fechamento, pois quanto maior o diâmetro mais facilmente o grão é esmagado em grandes profundidades. Em formações com grande teor de finos e impurezas, não é aconselhável a utilização de propantes de grande dimensão, pois os finos tendem a invadir os canais entre o propante, diminuindo a condutividade da fratura. Além disso, é sabido que os propantes de pequeno diâmetro, apesar de possuírem uma pequena condutividade inicial, tendem a manter a condutividade constante ao longo da vida útil do poço, enquanto os propantes com grandes diâmetros apresentam um rápido declínio na sua produção (Salas Cachay, 2004).

O tamanho das partículas de propante deve ser compatível com o tamanho das fraturas para não ocorrer uma filtragem prematura, e que ele seja eficientemente transportado.

O arredondamento é a medida de quanto a borda do grão é pontiaguda e a esfericidade dos grãos define o quanto o grão se aproxima da forma esférica. Quanto mais arredondados e uniformes forem os grãos sob elevadas tensões de fechamento, menor será o esmagamento e consequente produção de finos.

\subsubsection{MODELOS DE PROPAGAÇÃO DAS FRATURAS}

No estudo do fraturamento hidráulico busca-se prever como se dará a evolução da fratura. Para isso deve-se estudar o aumento da abertura da fratura, da pressão do fluido no poço e o comprimento da fratura, sendo estas importantes para a estimativa da produção. Existem diversos modelos para estudar as fraturas, desde os mais simples como os 2D, pseudo 3D (Figura 2.14a), 3D (Figura 2.14b) e os mais complexos que seriam as simulações numéricas que levam em consideração o campo de tensões e deformações do meio fraturado (Martínez, E.R., 2015). Os modelos 2D consideram a altura da fratura fixa e relacionam seu comprimento e a abertura. Alguns dos principais modelos 2D conhecidos são: PKN, KGD e radial.

Umas das formas escolhidas para estudar o fraturamento hidráulico nesse trabalho foi o modelo PKN de fraturamento hidráulico, cuja formulação será apresentada posteriormente. Além disso, será realizado o estudo do problema utilizando uma solução numérica, visando considerar o campo de tensões e deformações do meio fraturado. 


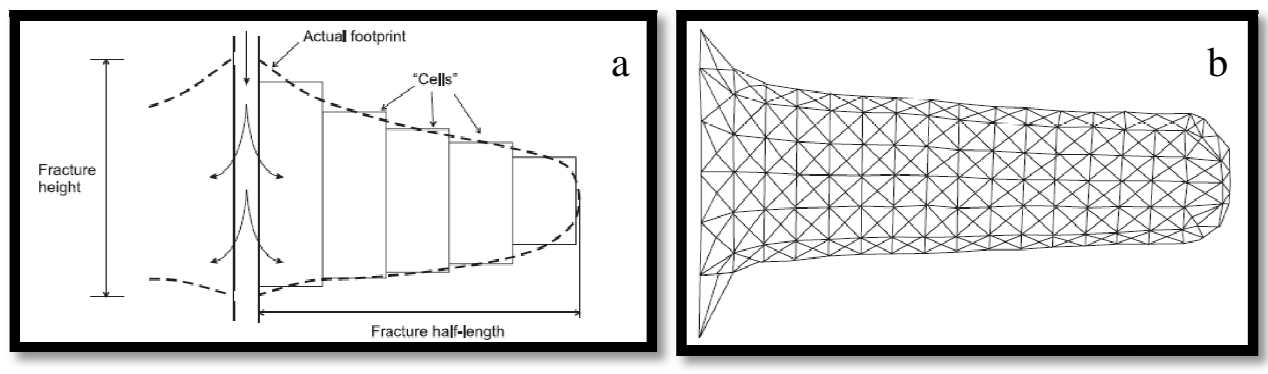

Figura 2.14 (a) Modelo Pseudo 3D e (b) Modelo 3D de fratura

\subsubsection{MODELO PKN}

O modelo PKN (Figura 2.15) foi desenvolvido por Perkin e Kern (1961) e estabelece que a condição de estado plano de deformação ocorre no plano vertical, normal à direção de propagação da fratura, a qual é considerada a dimensão infinita. Dessa forma, a hipótese assumida implica que o comprimento da fratura é muito maior que a altura da fratura, e que a abertura é ainda menor que estas duas dimensões (Azevedo, 2011).

O modelo assume algumas hipóteses como a que considera que a pressão líquida é constante ao longo do plano vertical, sendo função apenas do comprimento da fratura. $\mathrm{O}$ formato da fratura definido pela hipótese é o elíptico no plano vertical, onde a máxima abertura em uma seção é proporcional a pressão naquele ponto. Nordgren (1972) adicionou ao modelo de Perkin e Kern a equação de continuidade, introduzindo o conceito filtração ao modelo, utilizando o coeficiente de Carter (1957). No trabalho apresentado por Perkin e Kern e Nordgren não são levados em conta a mecânica da fratura e o efeito de extremidade, concentrando-se no fluxo dos fluidos (Azevedo, 2011).

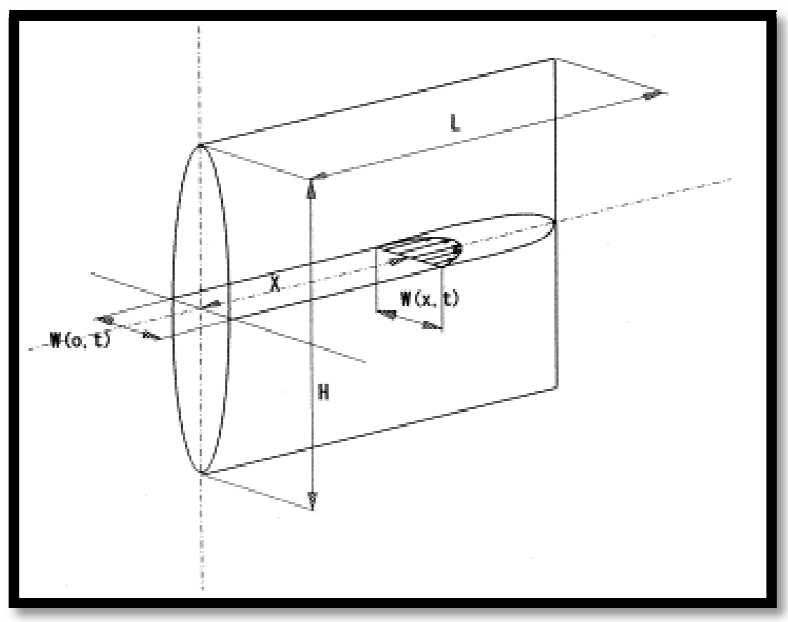

Figura 2.15: Modelo de fraturamento PKN (Smith et al. , 2010) 


\subsubsection{MODELO KGD}

O modelo KGD (Figura 2.16) desenvolvido por Khristianovich e Zheltov (1955) estabelece que a fratura é criada com a mesma abertura ao longo de todo o plano vertical, de forma que a seção vertical resultante é um retângulo. Essa hipótese é razoável quando se considera que a fratura é muito maior que o seu comprimento e a abertura é função apenas do comprimento da fratura. O estado de deformação plana ocorre no plano horizontal da fratura, que é considerada a dimensão infinita, implicando uma altura de fratura muito maior que o seu comprimento e uma abertura ainda menor que essas duas dimensões (Azevedo, 2011).

Algumas hipóteses assumidas pelo modelo são que a vazão na fratura é constante e que a pressão na fratura pode ser aproximada por uma pressão constante, exceto em uma região próxima à extremidade da fratura, onde não há penetração do fluido e consequentemente não há pressão. Utilizando o conceito de Khristianovich e Zheltov de que a ponta da fratura é muito pequena, Geertsma e de Klerk (1969) apresentaram uma solução simplificada do problema e a estendeu acrescentando o modelo de vazamento do fluido apresentado por Carter (1957).

\subsubsection{MODELO RADIAL}

As fraturas radiais são as que se desenvolvem sem encontrar barreiras (Figura 2.17). Elas podem se desenvolver no fraturamento de reservatórios homogêneos ou no fraturamento ocorridos a partir de um pequeno intervalo canhoneado. Para o desenvolvimento de um modelo radial pode-se realizar uma analogia dos modelos PKN e KGD, a partir da relação de suas aberturas médias, considerando o raio da fratura igual ao comprimento da fratura, o qual é metade da altura. O modelo considera as hipóteses de vazão de injeção constante, sem filtração e que a pressão líquida diminui com o tempo (Azevedo, 2011).

Os modelos PKN, KGD e radial apresentam resultados satisfatórios na simulação prática, porém eles são limitados, pois neles é necessário determinar a altura da fratura ou assumir que uma fratura radial irá ocorrer. A limitação é relevante, pois é difícil de prever esses dados, além da altura da fratura variar desde o poço até a ponta. Para resolver esse problema foram desenvolvidos modelos pseudo-3D que não possuem essas limitações, além de modelos 3D mais complexos, os quais podem ser aplicados a fraturas de diferentes formatos e orientação. 


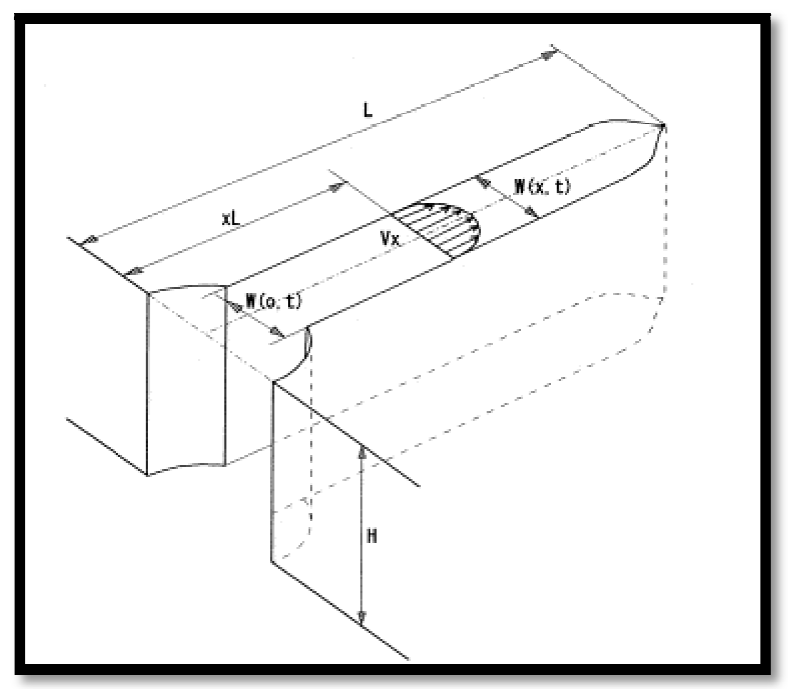

Figura 2.16 Modelo de fraturamento KGD (Smith et al. , 2010)

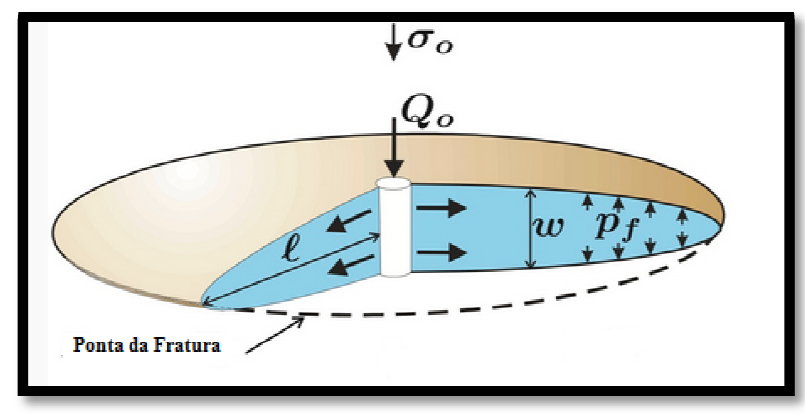

Figura 2.17 Modelo Radial de fratura

\subsubsection{DIFICULDADES NO PROCESSO DE FRATURAMENTO HIDRÁULICO}

Apesar dos estudos desenvolvidos para a aplicação do fraturamento hidráulico, nem sempre ele ocorre de acordo com o que foi previsto. Algumas das dificuldades envolvidas na aplicação do método são: o fluxo não segue a lei de Darcy, o regime de fluido é transiente, pode ocorrer migração da fratura para camadas superior e inferior da formação, diminuição da permeabilidade devido à aplicação do fluido de fraturamento, perda de fluido de fraturamento em fraturas pré-existentes, erros na estimativa do gás armazenado no reservatório, além de uma má estimativa da permeabilidade local.

Na maioria dos poços, quando o fluxo não segue a Lei de Darcy, ocorre uma diminuição da pressão na fratura, criando uma diminuição da condutividade e a produtividade do poço cai. Além disso, as formações em camadas podem diminuir significamente a produtividade do poço, pois a fratura irá ocorrer em múltiplas camadas, com valores de porosidade, e permeabilidade ou, ambas, diferentes (Holditch et al., 1975). 


\subsubsection{IMPACTOS AMBIENTAIS E PERIGOS À SAÚDE}

A prática do fraturamento hidráulico pode ser muito perigosa e agressiva ao meio e por isso tem gerado muita discussão na mídia mundial. Já ocorreram acidentes em decorrência do uso da técnica como se observou no acidente da Bacia de Campos, no Rio de janeiro, em 8 de novembro de 2011 (R7, 2015) onde o vazamento de petróleo contaminou o mar local. Devido a isso é necessário realizar um estudo prévio de como será realizada a operação para não ocorrer nenhum imprevisto. Os especialistas da área, entretanto, temem que a prática resulte em diversos perigos na operação e impactos ambientais como a liberação de material tóxico e radioativo, contaminação dos aquíferos e contaminação do ar.

Segundo Ewen (2012), os perigos mais graves envolvendo as instalações técnicas são:

- $\quad$ Explosões;

- Vazamento químico de tanques nos sítios de perfuração ou de acidentes com caminhões de transporte;

- Vazamento nas tubulações de águas residuais;

- Vazamento do poço.

Além disso, os possíveis cenários relacionados diretamente a técnica de fraturamento e produção do poço são:

- $\quad$ Fluidos de fraturamento ascendem à superfície;

- $\quad$ Fluidos de fraturamento são transportados dentro de águas subterrâneas profundas;

- $\quad$ Gás metano ascende à superfície;

- $\quad$ Águas residuais ascendem à superfície;

- $\quad$ Águas residuais são transportadas dentro de águas subterrâneas profundas.

É possível observar na Figura 2.18 os diversos impactos citados acima.

O fluido bombeado para fora do poço, separado do óleo e do gás, contém além dos aditivos químicos utilizados na perfuração, metais pesados, radioativos, compostos orgânicos voláteis (VCOs), perigosos poluentes do ar (HAPs) como benzeno, tolueno, etilbenzeno e xileno. Além disso, o fraturamento cria caminhos na rocha por onde pode ocorrer vazamento de óleo e de materiais tóxicos e radioativos para as formações (The Network for Public Health Law, 2013). 


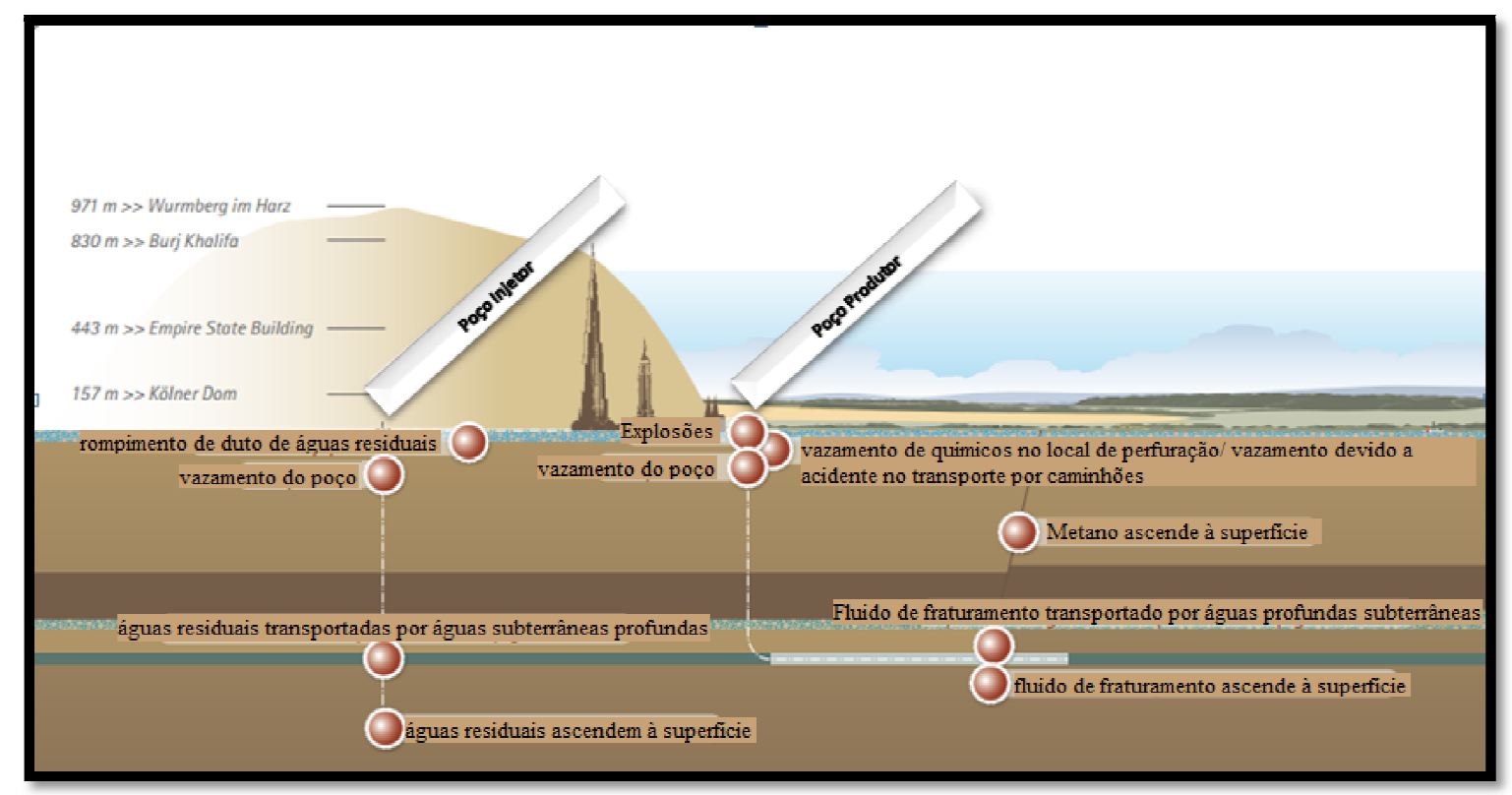

Figura 2.18 Possíveis impactos gerados pela operação de Fraturamento Hidráulico (Ewen, 2012)

A operação de fraturamento também gera preocupação quanto aos aquíferos. Primeiramente, em média 2 a 4 milhões de galões de água são necessários para fraturar um poço. Isso pode afetar a disponibilidade de água local, além de poder comprometer a qualidade da água existente. A injeção de água no poço requer também a injeção de galões de aditivos químicos que, por ser em grande quantidade, pode vazar e atingir águas superficiais ou subterrâneas, além do risco do transporte de produtos químicos. Outra preocupação é que devido a uma possível má cimentação ou revestimento do poço, pode ocorrer um vazamento de materiais presentes nas formações como gás natural, dióxido de carbono, sulfureto de hidrogênio, ácidos orgânicos, oligoelementos, e materiais radioativos, nos aquíferos, durante o processo de injeção. Pode ocorrer, por fim, o retorno das substâncias utilizadas no fraturamento para a superfície, contaminando a área se a substância não for corretamente recolhida (The Network for Public Health Law, 2013).

A água tratada pode ser reutilizada ou descarregada em águas superficiais, porém, muitas vezes o tratamento da água não é eficiente para eliminar todos os elementos tóxicos e radioativos presentes em sua composição (The Network for Public Health Law, 2013).

Além da contaminação da água, há várias fontes de poluição do ar no processo de fraturamento. Após o processo, uma mistura de gás e líquido retorna à superfície, sendo muitas vezes liberado na atmosfera ou queimado, sendo uma das principais fontes de contaminação do ar. Além disso, para remover a água do que foi produzido, utiliza-se trietileno glicol desidratado, que libera VCOs e HAPs para a atmosfera. Quando se utiliza 
tanques de condensação, os vapores com produtos químicos também são liberados diretamente na atmosfera. A ocorrência de vazamentos da tubulação, tanques de armazenamento e outros equipamentos podem causar a liberação de VCOs e HAPs para a atmosfera. O transporte de água e químicos requeridos no fraturamento e as máquinas utilizadas no processo causam a liberação de grande soma de óxido de nitrogênio, monóxido de carbono e hidrocarbonetos (The Network for Public Health Law, 2013).

Além dos impactos ambientais o fraturamento hidráulico também causa impactos sociais, pois ele modifica não só a paisagem, mas afeta a região com tráfego devido a grande quantidade de água necessária para o processo. Na Figura 2.19 é possível observar uma região de exploração de gás de folhelho em Wyoming, EUA.

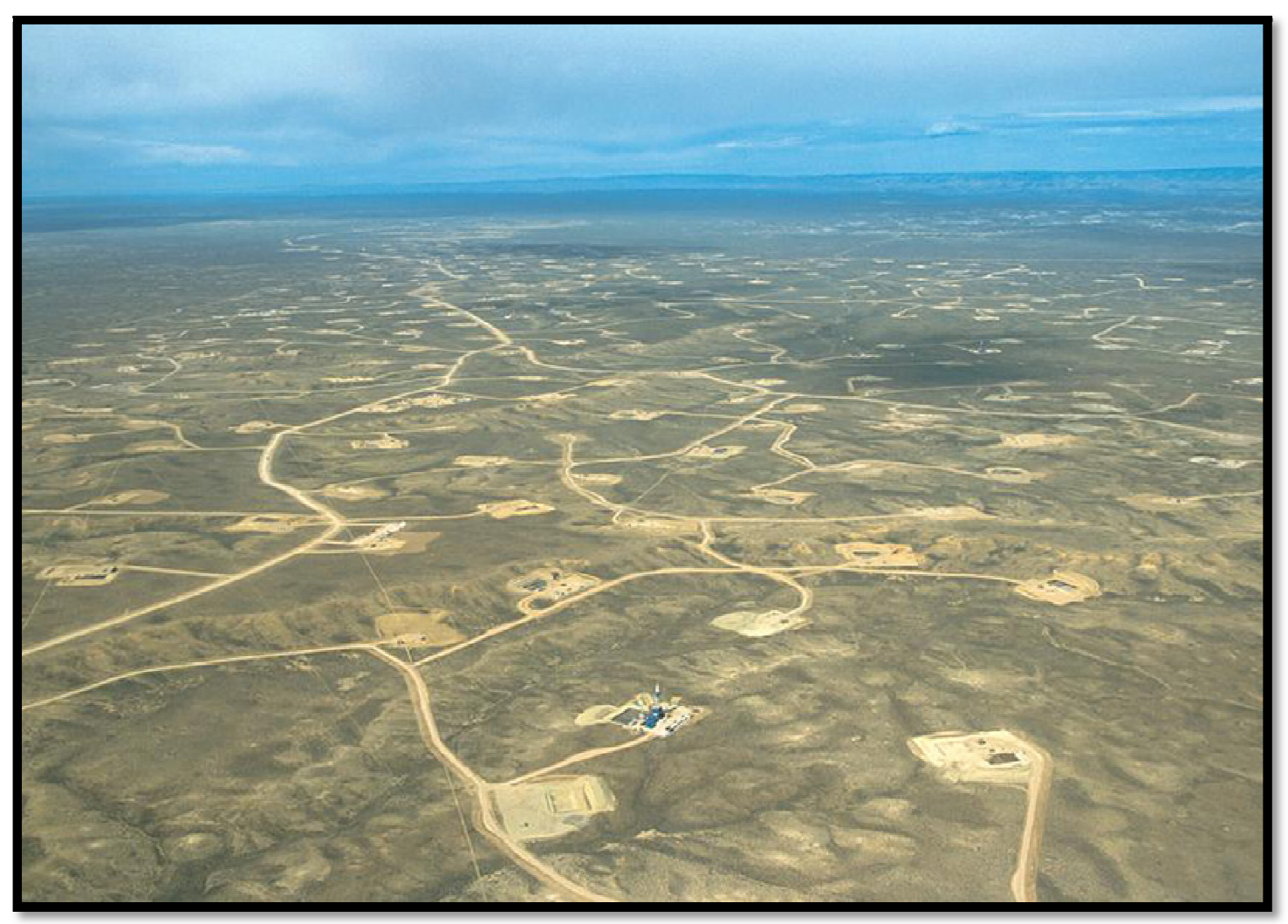

Figura 2.19 Região de exploração de gás de folhelho em Jonah Gasfield, Wyoming (Institution of Civil Engineers, 2016)

\subsection{PRINCIPAIS PROPRIEDADES DO RESERVATÓRIO}

Para o estudo do fraturamento hidráulico algumas propriedades do reservatório devem ser levadas em consideração, pois elas influenciam diretamente na produtividade do poço de petróleo. As propriedades apresentadas a seguir são geralmente estudadas em trabalhos de 
petróleo e reservatórios de hidrocarbonetos, mas devido a abordagem do problema de fraturamento hidráulico aqui adotada, algumas das propriedades apresentadas não serão utilizadas. Além disso, a nomenclatura utilizada para apresentar as propriedades no estudo de reservatórios de petróleo difere da nomenclatura utilizada comumente na Engenharia Geotécnica como poderá ser observado ao longo do capítulo.

\subsubsection{POROSIDADE}

A porosidade de uma rocha é uma propriedade adimensional que relaciona a quantidade de espaços vazios ou poros existentes na formação. Essa propriedade definirá a quantidade de fluido que poderá ser armazenado na rocha.

A porosidade absoluta é definida como a relação entre o volume de vazios e o volume total. Entretanto, a porosidade efetiva é a que se tem maior interesse por considerar a intercomunicação entre os poros, permitindo a percolação do fluido no interior da rocha. Ela é dada pela relação entre o volume de poros interconectados $(\mathrm{Ve})$ (pode ser obtido por imagem ou injeção de mercúrio e gás) e o volume total (V) (Barreto, 2010):

$\emptyset_{e}=\frac{V_{e}}{V}$

\subsubsection{PERMEABILIDADE}

A permeabilidade é definida como a medida da transmissibilidade de um fluido no meio poroso. A maior ou menor facilidade com que a percolação ocorre através do meio é influenciada pela densidade e viscosidade do fluido, que são função da pressão e temperatura as quais este está submetido. Na ocorrência de mais de um fluido, o deslocamento de cada um será diferente, sendo esse aspecto importante para os reservatórios de petróleo onde pode haver mais de um fluido.

A permeabilidade pode ser expressa de três formas: a permeabilidade absoluta, a efetiva e a relativa.

A permeabilidade absoluta é a condutividade do meio poroso quando este se encontra saturado por um único fluido. A permeabilidade efetiva é a condutividade de um fluido quando mais de uma fase estão presentes, sendo utilizada para o petróleo e seus componentes. A permeabilidade relativa será a razão entre a permeabilidade efetiva de cada fluido e a permeabilidade absoluta. 


\subsubsection{MOLHABILIDADE}

A molhabilidade é definida como a tendência de um fluido se espalhar ou aderir em uma superfície sólida, na presença de outro fluido imiscível (Craig, 1971). No contexto do petróleo, é a tendência da rocha reservatório estar preferencialmente em contato com um determinado fluido em um sistema bifásico ou multifásico (Agbalaka et al., 2008).

A molhabilidade é medida pelo ângulo de contato entre a rocha ou mineral e o fluido. Quanto mais molhável o fluido ao meio, maior será o ângulo de contato entre este e o meio, chegando a um máximo de $180^{\circ}$. Segundo Jesus (2012), apud Ahmed (2001), no reservatório, o ângulo de contato do fluido armazenado no reservatório (óleo) com a rocha do reservatório é nulo, caracterizando como a fase não-molhante. A fase de água no reservatório adere completamente à rocha matriz, caracterizando-se como a fase molhante. Na Figura 2.20 é possível observar essa propriedade.

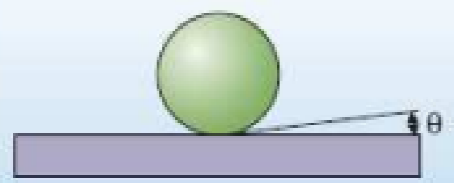

$\theta \sim 0^{\circ}$

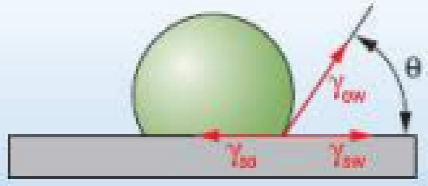

$\gamma_{s o}=\gamma_{w}+\gamma_{6 w} \cos \theta$

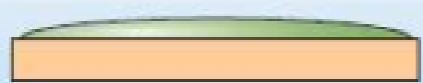

$\theta \sim 180^{\circ}$

Figura 2.20: Ângulo de contato de uma gota de óleo( verde) envolta em água (azul) em uma superfície fortemente molhável a água (esquerda), em uma superfície fortemente molhável ao óleo (direita) e uma superfície com grau de molhabilidade intermediária(centro) (Faerstein,

$$
\text { 2010) }
$$

\subsubsection{DENSIDADE}

A densidade ( $\rho$ ) é uma propriedade básica para caracterizar o fluido e a rocha do reservatório, sendo que ela relaciona a massa e o volume deste. A densidade específica $\left(\mathrm{G}_{\mathrm{s}}\right)$ é uma variável adimensional também utilizada para expressar a densidade das partículas sólidas, sendo ela dada pela razão entre a densidade da partícula sólida e a densidade da água. A densidade é uma propriedade que varia progressivamente com a mudança da pressão. Muitas vezes despreza-se essa variação, entretanto, na engenharia de reservatórios, ela deve ser levada em consideração. 


\subsubsection{VISCOSIDADE}

A viscosidade de um fluido é a propriedade que avalia a resistência interna do fluido, ou seja, qual a força necessária para romper o atrito interno entre as moléculas de um fluido permitindo o seu escoamento. Essa propriedade depende da pressão e temperatura a que o fluido está submetido, e irá influenciar na permeabilidade do meio.

Segundo Jesus (2012), na engenharia de reservatórios, há vários métodos empíricos para estimar a viscosidade do óleo. Esses métodos fazem correlação entre a viscosidade do óleo e a gravidade API do óleo cru. A gravidade API é um parâmetro para comparar a densidade do óleo com a da água dada pela expressão:

$$
{ }^{\circ} A P I=\frac{141,5}{\gamma_{0}}-131,5
$$

onde, $\gamma_{0}=\rho_{0} / \rho_{w}, \rho_{0}$ é a densidade do óleo a $16^{\circ} \mathrm{C}$ e $\rho_{w}$ é a densidade da água a $16^{\circ} \mathrm{C}$.

Um método empírico para estimar a viscosidade do óleo é o método de Beal, função da gravidade API e da temperatura:

$\mu=\left(0,32+\frac{1,8 \times 10^{7}}{{ }^{0} A P I^{4,53}}\right)\left(\frac{360}{T-200}\right)^{10^{\left(0,43+8,33 / o_{A P I}\right)}}$

onde, $\mu$ é a viscosidade dinâmica do fluido e $\mathrm{T}$ é a temperatura do reservatório, em ${ }^{\circ} \mathrm{F}$.

\subsubsection{MOBILIDADE}

A mobilidade de um fluido é a relação entre a permeabilidade efetiva e a viscosidade do fluido. A mobilidade do óleo, por exemplo, é dada por $\lambda_{o}=k_{o} / \mu_{o}$ e a da água é $\lambda_{w}=$ $k_{w} / \mu_{w}$. Assim como as permeabilidades efetivas, as mobilidades também dependem das saturações.

Segundo Thomas et al. (2001), quando um fluido é injetado ele tenderá a "furar" o banco de óleo, quanto maior for a razão de mobilidades dado por $\lambda_{w} / \lambda_{0}$. Tal fenômeno ocorre por causa da maior mobilidade do líquido em relação ao óleo, devido a grande viscosidade do óleo. Isso irá propiciar a criação de caminhos preferenciais entre os poços injetores e os 
produtores.

\subsubsection{COMPRESSIBILIDADE DA ROCHA}

Nos reservatórios de petróleo as rochas estão submetidas a um estado de tensão que irá afetar a distribuição dos poros. Dependendo da variação de pressão no solo, poderá ocorrer uma mudança da porosidade da rocha. A compressibilidade da rocha é a razão entre a variação de volume e a variação de pressão/tensão. A variação de volume pode ser ocasionada pela variação de volume dos grãos, dos poros ou em toda a rocha matriz.

Segundo Jesus (2012), na geomecânica dos reservatórios, a maior variação de volume é observada quando há variação dos poros da rocha, caracterizando o fenômeno de compressibilidade efetiva do reservatório descrito pela equação:

$$
C_{e f}=\frac{1}{\emptyset_{0}} \frac{\Delta \emptyset}{\Delta p}
$$

onde, $\mathrm{C}_{\mathrm{ef}}$ é a compressibilidade efetiva da rocha, $\emptyset_{0}$ é a porosidade inicial da rocha, $\Delta \mathrm{p}$ é a variação da pressão e $\Delta \emptyset$ é a variação da porosidade. Posteriormente será usado esse conceito para modelar o problema de fraturamento hidráulico.

\subsubsection{GRAU DE SATURAÇÃO}

Segundo Thomas (2001), nos reservatórios de petróleo estão presentes além do óleo, outros fluidos como a água e gases. Para determinar o volume de óleo precisa-se conhecer, além da porosidade da rocha, o grau de saturação do meio. Além disso, o grau de saturação é necessário para estimar a compressibilidade do fluido da formação.

A saturação de óleo, água e gás é o percentual do volume poroso (Vp) ocupado por cada uma dessas fases no reservatório. Ou seja:

$$
\begin{aligned}
& S_{o}=\frac{V o}{V p} \\
& S_{w}=\frac{V w}{V p} \\
& S_{g}=\frac{V g}{V p}
\end{aligned}
$$


sendo que $S_{o}$ o grau de saturação do óleo, $S_{w}$ o grau de saturação da água, $S_{g}$ é a saturação do gás , $V o$ o volume de óleo, $V w$ o volume de água e $V g$ o volume de gás, e:

$s_{o}+s_{w}+s_{g}=1$

\subsection{FRATURAMENTO DA ROCHA}

Para o estudo do fraturamento hidráulico outro tópico importante é a mecânica das fraturas. Este item foi baseado no trabalho de Oller (2001) e Khoei (2015). Na engenharia a fratura é uma descontinuidade física em um sólido. Para o estudo de fraturas foi desenvolvida a mecânica da fratura. Por meio dela é possível descrever o campo de tensões nas proximidades de uma fratura e prever a ruptura de um material comparando as tensões desenvolvidas com a tenacidade do material à fratura. $\mathrm{O}$ material pode ser considerado frágil quando a ruptura ocorre após pequenas deformações ou dúctil quando o material rompe após ocorrerem grandes deformações plásticas, ou seja, o material apresenta sinais de que irá romper (Figura 2.21).

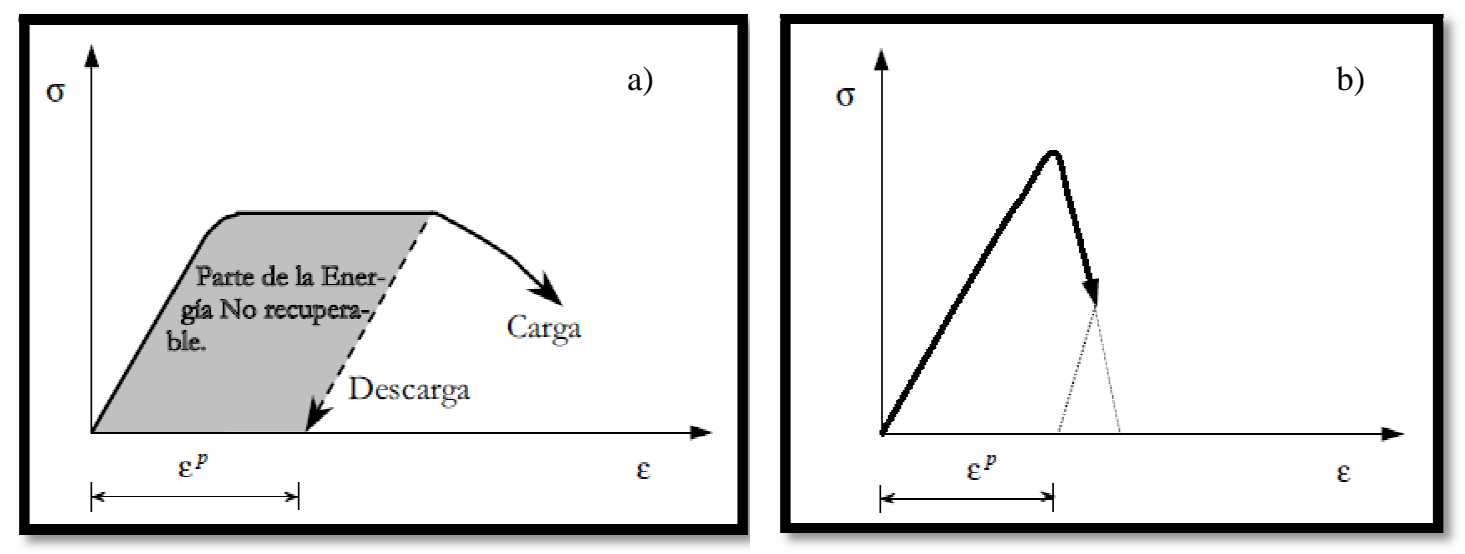

Figura 2.21 a)Material dúctil e b) material frágil

Irwin (1957) introduziu o estudo das formas de ruptura, que permite estudar a concentração de tensões no topo de uma fratura e o seu modo de propagação. A fratura pode ocorrer de maneira natural como as geradas pelo movimento das placas tectônicas ou elas podem ocorrer de maneira induzida, basicamente, por três movimentos cinematicamente independentes (Figura 2.22): 
- Modo de abertura ou Modo I. Nesse modo as faces da fratura se separam quase paralelamente entre si. Supõe-se que nesse modo só se desenvolvem tensões de tração;

- Modo de deslizamento ou Modo II. As faces da fratura deslizam uma sobre a outra. A partir de uma tensão tangencial, ocorrerá um deslizamento entre os átomos do plano superior em relação ao inferior, gerando uma falha na rocha;

- $\quad$ Modo de torsão ou Modo III- as faces da fratura deslizam lateralmente uma em relação a outra. Nesse caso também se supõe que ocorrem tensões tangenciais.

O modelo que tem sido mais estudado é o Modo I, entretanto dificilmente há a ocorrência das três de forma separada, sendo que nos casos de propagação mais complexos ocorre uma combinação dos três modos.

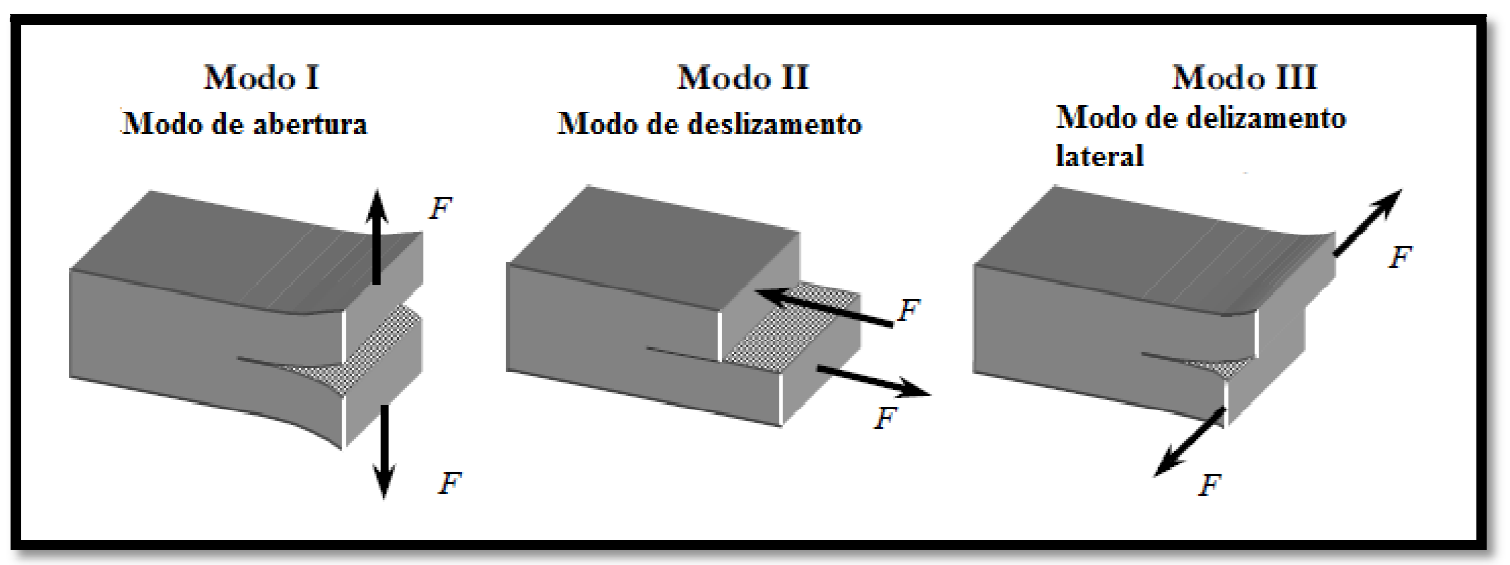

Figura 2.22 Tipos de fratura induzida (Oller, 2001)

\subsubsection{MECÂNICA DAS FRATURAS}

O comportamento não linear de um material é resultado de vários fenômenos de diferentes níveis de complexidade. Dentre esses fenômenos esta a fratura que produz descontinuidades em um meio. Os primeiros estudos sobre o fenômeno da fratura se iniciaram no século XX com Inglis (1913). As irregularidades na matriz da rocha nas bordas de uma descontinuidade são chamadas de concentrações de tensões. Inglis (1913) realizou os primeiros estudos sobre o fenômeno da fratura e introduziu o conceito de concentração de tensões. Ele estudou um material elástico que sofre alterações no seu estado de tensões, utilizando uma placa de dimensões finitas com um orifício circular.

Inglis (1913) desenvolveu o conceito de fator de concentração de tensões (SCF), este limitado pelas dimensões do orifício. Posteriormente, o SCF deu lugar ao fator de intensidade 
de tensões (SIF) K, a qual faz uma análise mecânica da ponta da fratura, onde as tensões tendem ao infinito. O SIF é determinado de acordo com o mecanismo de geração da fratura $\left(\mathrm{K}_{\mathrm{I}}, \mathrm{K}_{\mathrm{II}}\right.$ ou $\left.\mathrm{K}_{\mathrm{III}}\right)$ representando a intensidade de tensões desenvolvidos nos três modos de fraturamento.

Irwin (1957 e 1958) e Muskhelishvili (1953) determinaram uma expressão para o SIF em função do estado de tensões do material e do campo de deslocamentos gerados pela fratura. Para isso eles utilizaram o método semi-inverso de Westergaard citado por Owen e Fawkes (1983).

O modo I de fratura é o mais estudado e o que ocorre de maneira predominante nos problemas de fratura mecânica. Para obter o $\mathrm{K}_{\mathrm{I}}$ de forma analítica a partir das tensões externas aplicadas no contorno do material se utiliza a seguinte equação que dependerá da fratura e do formato da peça:

$\mathrm{K}_{\mathrm{I}}=\sigma_{\mathrm{n}} \sqrt{\mathrm{b} \pi \mathrm{a}} \mathrm{f}(\alpha, \theta)$

onde b e $\alpha$ são parâmetros que dependem da geometria e $\sigma_{\mathrm{n}}$ é a tensão normal à direção de propagação da fratura.

O SIF tem um valor limite que será igual ao valor da tenacidade do material. Esse valor irá corresponder ao $\mathrm{K}_{\mathrm{Ic}}$ que é quando o valor de tensões na ponta da fratura alcança $\mathrm{o}$ valor da resistência do material a tração $\left(\sigma_{\mathrm{f}}\right)$. Esse valor irá depender não só da resistência do material, mas também de características como a geometria e a forma de carregamento aplicado. $\mathrm{O} \mathrm{K}_{\mathrm{Ic}}$ é dado por:

$\mathrm{K}_{\mathrm{Ic}}=\sigma_{\mathrm{f}} \sqrt{\mathrm{b} \pi \mathrm{a}} \mathrm{f}(\alpha, \theta)$

Para obter os valores de SIF para os modos II e III de fraturamento se utiliza uma extensão conceitual do modo I, onde as tensões normais são substituídas pelas tangenciais e a função $f(\alpha, \theta)$ dependerá da geometria, forma da carga e o modo de fratura que está ocorrendo. O SIF para os modos II e III de fraturamento são dados por:

$$
\begin{aligned}
& \mathrm{K}_{\mathrm{II}}=\sigma_{\mathrm{xy}} \sqrt{\mathrm{b} \pi \mathrm{a}} \mathrm{f}_{\mathrm{II}}(\alpha, \theta) \\
& \mathrm{K}_{\mathrm{III}}=\sigma_{\mathrm{yz}} \sqrt{\mathrm{b} \pi \mathrm{a}} \mathrm{f}_{\mathrm{III}}(\alpha, \theta)
\end{aligned}
$$

A energia da fratura foi incorporada dentro da formulação da mecânica das fraturas, 
pois a energia é um parâmetro essencial para analisar o comportamento de um sólido durante um processo de fraturamento.

Grifitth (1920) desenvolveu uma teoria para estudar a propagação de fraturas em meios contínuos baseado nos teoremas fundamentais de energia mecânica. Para ele a densidade total de energia de deformação de um meio fissurado pode ser descrito por:

$\mathrm{U}^{\mathrm{int}}=\mathrm{U}_{\mathrm{e}}+\left(\mathrm{U}_{\gamma}-\mathrm{U}_{\mathrm{a}}\right)$

onde $\mathrm{U}_{\mathrm{e}}$ é a densidade de energia elástica de deformação por unidade de volume para um meio fissurado. É dado por:

$\mathrm{U}_{\mathrm{e}}=\frac{\sigma_{\mathrm{ij}}^{2}}{2 \mathrm{E}}$

sendo $\mathrm{E}$ o módulo de elasticidade longitudinal. Além disso, $\mathrm{U}_{\gamma}=2 \mathrm{~A}_{\mathrm{f}} \gamma^{0}$ é a densidade de energia necessária para criar uma nova superfície de fratura de largura unitária e área $\mathrm{A}_{\mathrm{f}}=2 \mathrm{a}$, onde 2a é o maior eixo da elipse que representa a fissura e $\gamma^{0}$ é densidade de energia de superfície. $U_{\mathrm{a}} \mathrm{e}$ a energia de relaxação liberada ao se formar uma trinca.

Pela Figura 2.23 é possível observar a decomposição das densidades de energia.

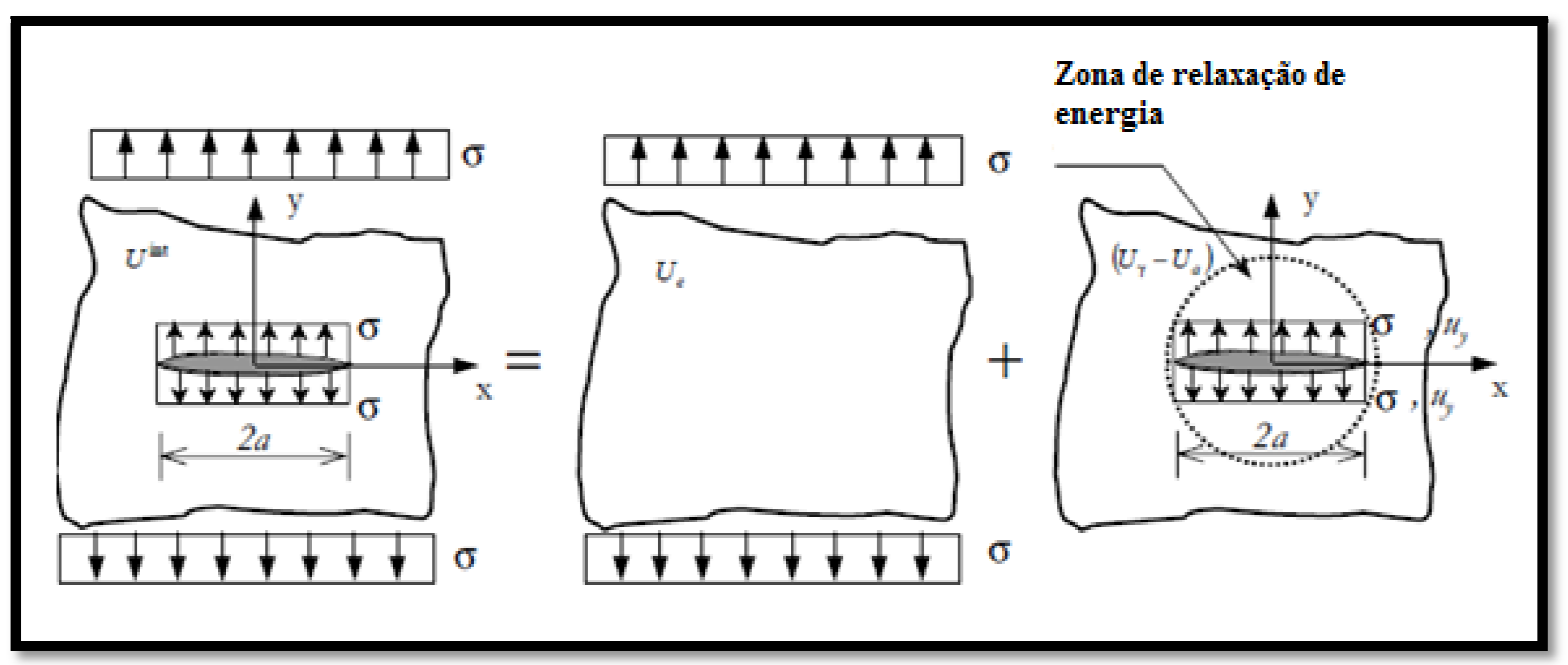

Figura 2.23 Decomposição das densidade de energia na fratura (Oller, 2001)

Para determinar a energia necessária para abrir uma nova fratura com formato simétrico a partir dos seus extremos, parte-se da decomposição da energia como na Equação 2.19 onde a energia de relaxação $U_{\mathrm{a}}$ é obtida a partir do trabalho que as tensões $\sigma_{\mathrm{y}}$ realizam para um deslocamento $\mathrm{u}_{\mathrm{y}}$ das faces da fratura dado por: 
$\mathrm{U}_{\mathrm{a}=} \frac{1}{2}\left(4 \int_{0}^{\mathrm{a}} \sigma_{\mathrm{y}} \mathrm{u}_{\mathrm{y}} \mathrm{d}_{\mathrm{x}}\right)$

onde o fator 4 representa as semi-superfícies que compõem a face de uma fratura e o deslocamento $\mathrm{u}_{\mathrm{y}}$ é dado segundo Irwin (1957) por:

$\mathrm{u}_{\mathrm{y}}=\frac{\sigma^{2}}{2 \mathrm{E}}(1+v)(\mathrm{k}+1) \sqrt{\mathrm{a}^{2}-\mathrm{x}^{2}} \quad \forall \mathrm{x} \leq \mathrm{a}$

sendo $k=3-4 v$ para problemas de deformação plana e $k=(3-v) /(1+v)$ para problemas de tensão plana.

Substituindo a Equação 2.16 na Equação 2.15 tem-se que a energia de relaxação é dada por:

$\mathrm{U}_{\mathrm{a}}=\frac{\sigma^{2} \pi \mathrm{a}^{2}}{4 \mathrm{E}}(1+v)(\mathrm{k}+1)$

Além disso, substituindo todos os termos na Equação 2.13, tem-se que a energia total interna é dada por:

$\mathrm{U}^{\mathrm{int}}=\frac{\sigma^{2}}{2 \mathrm{E}}+\left(2 \mathrm{a} \gamma^{0}-\frac{\sigma^{2} \pi \mathrm{a}^{2}}{4 \mathrm{E}}(1+v)(\mathrm{k}+1)\right)$

A partir dessa equação é possível determinar a estabilidade da fratura, calculando a condição de mínima energia em relação ao comprimento da fratura dada por:

$\frac{\partial \mathrm{U}^{\mathrm{int}}}{\partial \mathrm{da}}=2 \gamma^{0}-\frac{\sigma^{2} \pi \mathrm{a}}{2 \mathrm{E}}(1+v)(\mathrm{k}+1)=0$

A partir da Eq. 2.19, se obtém a tensão crítica que é função da energia da fratura $\gamma^{0}, o$ comprimento da fratura $a$ e o módulo de elasticidade E dado por:

$\sigma=\sqrt{\frac{4 \mathrm{E} \gamma^{0}}{\pi \mathrm{a}(1+v)(\mathrm{k}+1)}}$

A partir da Eq. 2.19 pode-se obter comprimento crítico da fratura $a_{c}$ que garante a 
estabilidade do sólido por:

$\mathrm{a}_{\mathrm{c}}=\frac{4 \mathrm{E} \gamma^{0}}{\pi \sigma^{2}(1+v)(\mathrm{k}+1)}$

Irwin (1948) propôs que a teoria desenvolvida por Grifitth para materiais frágeis, poderia ser aplicada para materiais dúcteis se fosse considerada a densidade de energia plástica $\gamma^{\mathrm{p}}$. Desta forma, seria possível introduzir na Equação 2.20 a densidade total de energia dissipada $\mathrm{G}_{\mathrm{f}}=\gamma^{\mathrm{p}}+\gamma^{0}$ no lugar da densidade de energia de superfície $\gamma^{0} \cdot$ :

$\sigma=\sqrt{\frac{4 \mathrm{EG}_{\mathrm{f}}}{\pi \mathrm{a}(1+v)(\mathrm{k}+1)}}$

A Equação 2.13 pode ser descrita em termos de intensidade de tensão da seguinte forma:

$\mathrm{K}_{\mathrm{I}}^{2}=\sigma^{2} \pi \mathrm{a}\left(\mathrm{bf}^{2}(\alpha, \theta)\right)=\frac{\mathrm{EG}_{\mathrm{f}}}{\left(1-v^{2}\right)}\left(\mathrm{bf}^{2}(\alpha, \theta)\right)$

onde $\mathrm{K}_{\mathrm{I}}$ é o fator de intensidade de tensões para o modo I de fratura.

A Eq. 2.23 pode ser reescrita para o Modo I de fraturamento, que será descrito adiante, considerando que $\mathrm{bf}^{2}=1$

$\mathrm{K}_{\mathrm{I}}=\sigma \quad \sqrt{\pi \mathrm{a}}=\sqrt{\frac{\mathrm{EG}_{\mathrm{f}}}{\left(1-v^{2}\right)}}$

A partir desses conceitos foi desenvolvido um método baseado nos conceitos de energia para calcular o SIF utilizando o campo de deslocamentos, tensões e deformações.

\subsubsection{CÁLCULO DO FATOR DE INTENSIDADE DE TENSÕES}

O conceito de fator de intensidade de tensões é muito utilizado para avaliar os campos de tensões, deformações e deslocamentos na mecânica das fraturas. Para obter o SIF existem alguns métodos na literatura, dentre os quais temos: método de correlação do deslocamento, o método da extensão virtual da fratura e o método da integral J. Eles são divididos em dois grupos, os métodos de avaliação direta, a partir dos valores obtidos pelo FEM e os métodos de energia baseados na taxa de liberação de energia. 
Os métodos baseados na taxa de liberação de energia utilizam integrais de contorno e de domínio para obter o valor de $\mathrm{K}_{\mathrm{I}}$. A técnica da integral $\mathrm{J}$ foi definida por Cherepanow (1967) e Rice (1968) para calcular a taxa de liberação de energia em problemas de fraturas e pode ser escrita por:

$$
J=\int_{\Gamma}\left(w \delta_{1 j}-\sigma_{i j} \frac{\partial u_{i}}{\partial x_{1}}\right) n_{j} d \Gamma
$$

onde $w$ é a densidade de energia de deformação dado por $w=\frac{1}{2} \sigma_{i j} \varepsilon_{i j}$, onde $\sigma_{i j}$ é o tensor de tensões, $u_{i}$ é o campo de deslocamentos, $n_{j}$ é o vetor normal do contorno da integral $\Gamma, \delta$ é o delta de Kronecker, $\varepsilon_{i j}$ é o tensor de deformações e $x_{1}$ é a direção da propagação da fratura.

A integral $\mathbf{J}$ independe do caminho da integração e não deve ser computado no seu cálculo forças de corpo ou de tração nas faces da fratura.

Li, Shih, and Needleman (1985) transformaram a integral J de contorno em uma integral de área, sendo a integral de área definida por:

$J=\int_{\mathrm{A}}\left(\sigma_{i j} \frac{\partial u_{i}}{\partial x_{1}}-w \delta_{1 j}\right) \frac{\partial q}{\partial x_{1}} d \mathrm{~A}$

onde q é o peso da função definido no domínio de integração (Figura 2.24).

Segundo Khoei (2015) o domínio da integração deve ser escolhido de maneira que é, primeiramente, suficiente perto da ponta da fratura, segundo que seja fácil de implementar em uma simulação e por último deve ser consistente com a geometria e limitações de contorno do problema quando esses são complexos ou de múltiplas fraturas.

A integral J é uma integral de área assumindo um círculo virtual de raio específico ao redor da ponta da fratura, e a integração é feita nos elementos que são atravessados por esse círculo. A integral de contorno pode ser avaliada numericamente usando a regra de integração Gaussiana sobre um elemento com:

$J=\sum_{m=1}^{N^{\text {Gauss }}}\left\{\left(-w \delta_{1 j}+\sigma_{i j} \frac{\partial u_{i}}{\partial x_{1}}\right) \frac{\partial q}{\partial x_{j}}\right\}_{m} w_{m} \operatorname{det} j$

onde $N^{\text {Gauss }}$ é o número de pontos de integração de um elemento, $w_{m}$ é o peso de Gauss e j é a matriz Jacobiana.

A taxa de liberação de energia para problemas 2D com modos I e II de fraturamento pode ser definido, baseado nos fatores de intensidade de tensões $K_{I}$ e $K_{I I}$ segundo Rice 
(1968), por:

$J \equiv G=\frac{1}{E^{\prime}}\left(K_{I}^{2}+K_{I I}^{2}\right)$

onde $E^{\prime}=\frac{E}{1-v^{2}}$ para problemas de deformação plana.

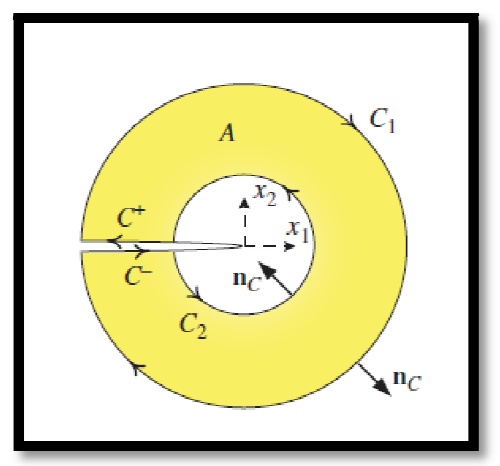

Figura 2.24 Domínio da Integral-J para determinar fator de intensidade de tensões (Khoei, 2015)

A direção de propagação da fratura $\theta_{0}$ é obtida quando a expressão:

$K_{I} \sin \theta_{0}+K_{I I}\left(3 \cos \theta_{0}-1\right)$

é igualada a zero para se obter o ângulo de propagação da fratura:

$\theta_{0}=2 \arctan \left[\frac{1}{4}\left(\frac{K_{I}}{K_{I I}}\right) \pm \sqrt{\left(\frac{K_{I}}{K_{I I}}\right)^{2}}+8\right]$

Por esse critério, o SIF equivalente é dado por:

$K_{e}=K_{I} \cos ^{3}\left(\frac{\theta_{c}}{2}\right)-3 K_{I I} \cos ^{2}\left(\frac{\theta_{c}}{2}\right) \sin \left(\frac{\theta_{c}}{2}\right)$

Quando o SIF equivalente é maior que a tenacidade do material, a fratura se propaga. 


\subsection{MODELAGEM DE FRATURAS E O MÉTODO DOS ELEMENTOS FINITOS ESTENDIDO}

A mecânica das fraturas é a área da engenharia que estuda o processo que pode levar ao aparecimento de falhas. Muitas soluções foram desenvolvidas ao longo dos anos para o estudo da mecânica das fraturas, tanto analíticas como numéricas. Dentro das soluções numéricas estão o MEF, métodos dos elementos de contorno, e mais recentemente alguns métodos que não utilizam malha. Cada método possui suas vantagens e desvantagens com relação à descrição do problema, tempo de processamento, acurácia, entre outros.

Ao longo dos anos foram criados diversos métodos para estudar fraturas utilizando como base o método dos elementos finitos, sendo que o XFEM surgiu a partir da evolução desses modelos. Segundo (Mohammadi, 2008) nesses modelos os principais problemas encontrados eram a falta de acurácia dos resultados, grande dependência da malha utilizada, dificuldade de representar um campo de singularidade ao redor da ponta da fratura, necessidade de refazer a malha devido ao crescimento da fratura. O método dos elementos enriquecidos, que utiliza funções de enriquecimento para representar o campo de deslocamento, foi adicionado ao MEF possibilitando a representação de fraturas nesse modelo. A grande vantagem do modelo é não ser preciso refazer a malha em caso de propagação da fratura, sendo que ele possibilita ainda a simulação de múltiplas fraturas e intersecção de fraturas.

\subsection{XFEM- MÉTODO DOS ELEMENTOS ESTENDIDO}

O XFEM é um método numérico utilizado para modelar principalmente descontinuidades fortes e fracas dentro de uma malha de elementos finitos. O modelo utiliza para isso o princípio da partição da unidade, que, juntamente com funções descontínuas, são capazes de representar uma fratura sem adicioná-la a malha explicitamente, ou seja, a localização dela é arbitrária com respeito à malha de elementos finitos. Na Figura 2.25 é possível observar a diferença entre o FEM e o XFEM.

O Método dos Elementos Finitos Estendido (XFEM) foi desenvolvido por Belytschko e Black (1999) e Möes, Dolbow e Belytschko (1999) para estudar a propagação de fraturas elásticas e eles utilizaram uma função de enriquecimento descontínua para descrever a presença de uma fratura no campo de deslocamentos.

O XFEM é um método poderoso e pode ser aplicado em várias áreas como a mecânica 
das fraturas, grandes deformações, plasticidade, fluxo multifásico, fraturamento hidráulico e problemas de contato (Khoei, 2015). Dentre as vantagens do XFEM pode-se citar que nele não há a necessidade de refazer a malha de elementos finitos devido à presença de uma descontinuidade, o que gera uma grande economia computacional. Além disso, refazer a malha pode ter um grande impacto na qualidade dos resultados.

Além do XFEM, existe também o GFEM (Método dos Elementos Finitos Generalizados). Segundo Khoei (2015) o XFEM e o GFEM são praticamente idênticos sendo que o XFEM foi desenvolvido para resolver descontinuidades, como fraturas, utilizando o enriquecimento local enquanto o GFEM utilizou inicialmente o enriquecimento global do domínio.

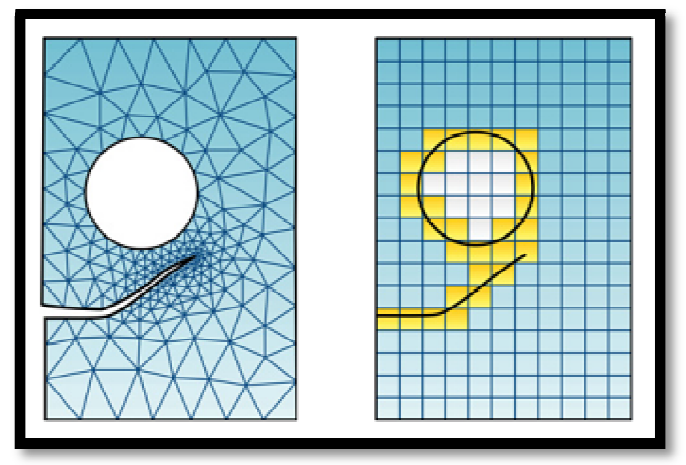

Figura 2.25 Diferença entre MEF e XFEM

No XFEM, ao invés de refazer a malha, enriquece-se os elementos perto da ponta da fratura e os elementos cortados pela fratura. Primeiramente deve-se traçar uma malha de elementos finitos sem levar em conta a geometria das descontinuidades. Em seguida deve-se adicionar a presença das fraturas, vazios e descontinuidades enriquecendo os campos de deslocamentos com funções adicionais, utilizando para isso o método da partição de unidades.

\subsubsection{MÉTODO DE PARTIÇÃO DE UNIDADE}

O método de partição de unidade utiliza funções $f_{i}(x)$ que tem como propriedade, dentro de um subdomínio $\Omega$, que:

$\sum_{\forall i} f_{i}(x)=1, \forall x \in \Omega$

Ou seja, a soma das funções em cada ponto do subdomínio é uma unidade. Por meio deste método, qualquer função pode ser representada pelo somatório do seu produto por uma 
função de partição de unidade.

O MEF (Método dos elementos finitos) é um método de partição de unidade onde as funções de partição de unidade são chamadas de funções de forma, ou de interpolação $N(x)$ :

$\sum_{\forall i} N(x)_{i} f(\mathrm{x})=f(\mathrm{x}), \forall x \in \Omega$

Essa propriedade é também utilizada pelo XFEM para enriquecer a malha de elementos finitos e representar características descontínuas dentro do domínio. Com isso o método de partição da unidade permite modelar a propagação de descontinuidades sem alterar a malha de elementos finitos, enquanto as funções de enriquecimento evoluem juntamente com a interface da geometria da descontinuidade. As funções de forma utilizadas no XFEM podem ou não ser as mesmas utilizadas pelo modelo clássico de elementos finitos (Khoei, 2015).

\subsubsection{MÉTODO LEVEL SET}

O Método Level Set (LSM) é um esquema numérico que foi desenvolvido por Sethian(1996) para modelar interfaces/descontinuidades. Nesse método a descontinuidade possui valor igual a zero em seu contorno e valores opostos no interior e exterior da interface. É possível acoplar o LSM com o XFEM para a resolução de problemas de descontinuidades, pois ele fornece informações de onde e como realizar o enriquecimento. O XFEM posiciona a fratura no nível zero, enriquecendo os nós nas proximidades utilizando para isso a função Heaviside, por exemplo. Com o LSM é possível modelar a descontinuidade e atualizar as suas mudanças a cada etapa e o XFEM é utilizado para resolver o problema e determinar a direção da descontinuidade (Khoei, 2015).

Considerando um domínio $\Omega$ com uma interface $\Gamma$, a ideia geral do Método Level Set é aplicar uma função $\varphi(x, t)$ no espaço com uma interface, onde x é um ponto no espaço e t é incremento de tempo (Figura 2.26). A função é definida separando o domínio em duas zonas separadas $\Omega_{a} \mathrm{e} \Omega_{b}$ por:

$\varphi(x, t)<0$ se $x \in \Omega_{a}$

$\varphi(x, t)=0$ se $x \in \Gamma$ 
$\varphi(x, t)>0$ se $x \in \Omega_{b}$

Onde a interface pode ser capturada a cada incremento de tempo, localizando $\Gamma(t)$ para o qual a função é zero (Figura 2.26).

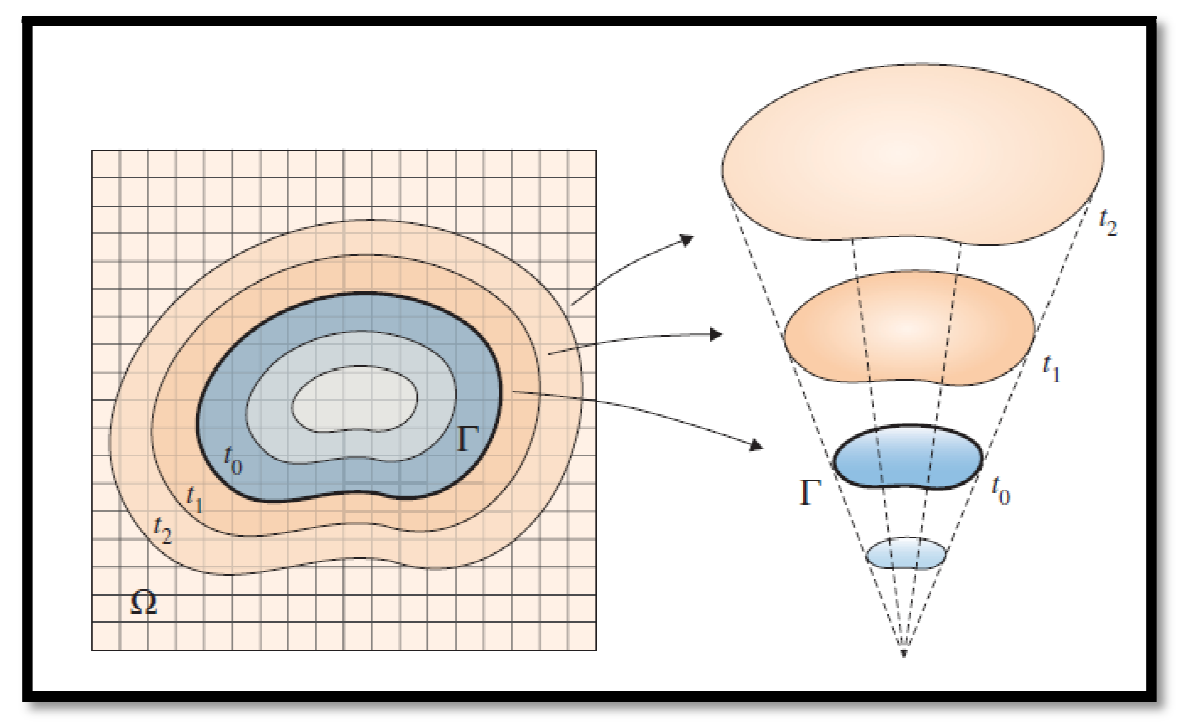

Figura 2.26 Função level set para problema bidimensional (Khoei,2015)

\subsubsection{FORMULAÇÃO GERAL DO XFEM}

A aproximação do deslocamento pelo método dos elementos finitos estendido será descrito generalizadamente por:

$u(x)=\sum_{i=1}^{n} N_{i}(x) \overline{u_{\imath}}+$ termos enriquecidos

onde n é o conjunto de todos os nós e $N_{i}$ são as funções de forma.

A incorporação de um enriquecimento local no espaço aproximado foi introduzido por Melenk e Babuska pelo método de partição de unidade dos elementos finitos. Nele, as funções de forma nodais são multiplicadas pelas funções de enriquecimento definidas nos nós em que há influência da descontinuidade que se quer representar. A aproximação do domínio enriquecido pode ser escrito por:

$u^{h}(x)=u^{E F}+u^{e n r}=\sum_{i=1}^{n} N_{i}(x) \bar{u}_{l}+\sum_{j=1}^{m} N_{j}(x) \psi(x) \bar{a}_{j}$

sendo o primeiro termo a interpolação padrão (MEF) e o segundo a interpolação enriquecida. 
$n$ é o conjuto total de nós do domínio, $m$ é o conjunto de nós dos elementos cortados pela descontinuidade, $\bar{a}_{i j}$ são os graus de liberdade adicionais devido ao enriquecimento relacionados a $\psi(x)$, que é a função de enriquecimento.

As funções de enriquecimento são escolhidas de acordo com o tipo de descontinuidade, sendo que os principais tipos de descontinuidades em que se utiliza o método são:

- $\quad$ Reproduzir um campo ao redor da ponta da fratura

- Continuidade de deslocamento entre elementos finitos adjacentes

- Campos de deformação independentes dos dois lados da superfície de uma fratura

- $\quad$ Outras características de problemas descontínuos

Para a modelagem de campos de descontinuidade forte são utilizadas funções como a função Heaviside e a função sinal. A função Heaviside (Figura 2.27) pode ser definida como uma função degrau dada por:

$$
H(\xi)= \begin{cases}1 & \forall \xi>0 \\ 0 & \forall \xi<0\end{cases}
$$

A aproximação do campo de deslocamentos para a modelagem de uma descontinuidade forte utilizando a função Heaviside é dada por:

$$
u^{h}(x)=\sum_{j=1}^{N} N_{j}(x) u_{j}+\sum_{k=1}^{m} N_{k}(x) H(\xi) a_{k}
$$

Para que a aproximação acima seja uma interpolação, deve-se deslocar a função Heaviside ao redor do nó de interesse, garantindo assim a interpolação:

$$
u^{h}(x)=\sum_{j=1}^{N} N_{j}(x) u_{j}+\sum_{k=1}^{m} N_{k}(x)\left(H(\xi)-H\left(\xi_{k}\right)\right) a_{k}
$$

Para a modelagem de campos de descontinuidades fracas, o método XFEM deve ser utilizado substituindo a função $H(\xi)$ por uma função de enriquecimento apropriada $p_{j}(x)$ (Bordas and Legay 2005) definida em termos da função rampa $\varphi(x)$ :

$$
|\varphi(x)|=\left\{\begin{array}{c}
-\varphi(x) \text { se } \varphi(x)<0 \\
\varphi(x) \text { se } \varphi(x)>0
\end{array}\right.
$$




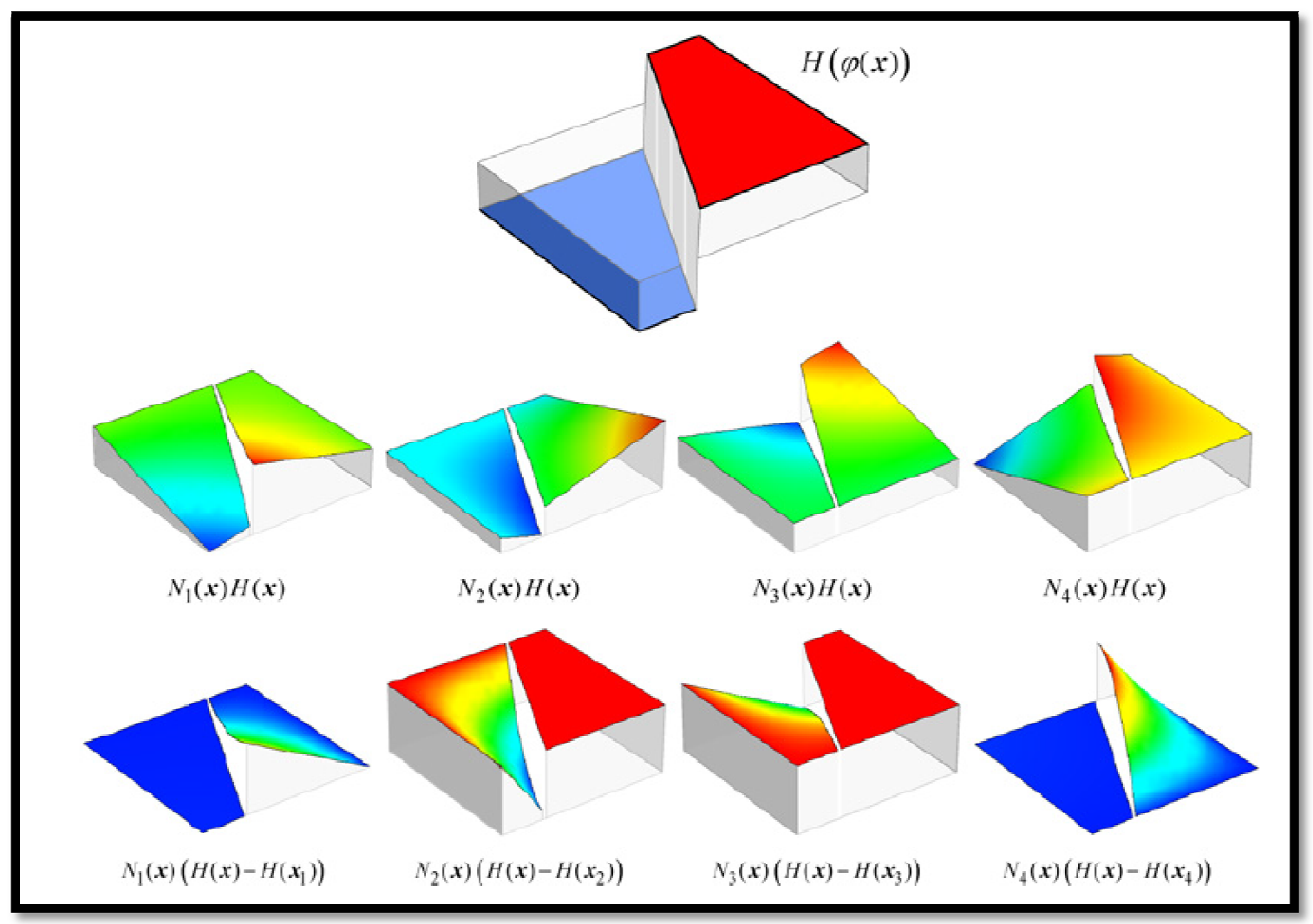

Figura 2.27 Função Heaviside e Função Heaviside transladada

\subsubsection{MODELAGEM DA FRATURA}

Möes et al. (1999) definiu que a aproximação do deslocamento para modelar as faces da fratura e suas pontas pelo método dos elementos estendido, incluindo as modificações para se corrigir o problema da interpolação, é:

$$
\begin{aligned}
& u^{h}(x)= \\
& \sum_{j=1}^{n} N_{j}(x) u_{j}+\sum_{h=1}^{m} N_{h}(x)\left(\left(H(\xi(x))-H\left(\xi\left(x_{h}\right)\right) a_{h}+\sum_{k=1}^{m t_{1}} N_{k}(x)\left(\sum _ { l = 1 } ^ { m f } \left(F_{l}^{1}(x)-\right.\right.\right.\right. \\
& \left.\left.F_{l}^{1}\left(x_{k}\right)\right) b_{k}^{l 1}\right)+\sum_{k=1}^{m t_{2}} N_{k}(x)\left(\sum_{l=1}^{m f}\left(F_{l}^{2}(x)-F_{l}^{2}\left(x_{k}\right)\right) b_{k}^{l 2}\right)
\end{aligned}
$$

A função Heaviside irá acrescentar 1 grau de liberdade (dois graus adicionais por nó para problemas $2 \mathrm{D}$-xy) a mais a cada nó do elemento além dos graus provenientes do Método dos Elementos Finitos. A função $F$, ou funções crack tip irá aproximar o comportamento da ponta da fratura dentro do elemento. Para descrever o movimento em uma direção qualquer são necessários quatro graus de liberdade adicionais em cada nó do elemento (oito graus adicionais por nó em problemas 2D-xy), associados a cada termo da função $\mathrm{F}$ dada por: 


$$
F(r, \theta)=\sqrt{r}\left\{\cos \frac{\theta}{2}, \sin \frac{\theta}{2}, \sin \frac{\theta}{2} \cdot \sin \theta, \cos \frac{\theta}{2} \cdot \sin \theta\right\}
$$

As funções crack tip (Figura 2.28) são calculadas por um sistema de coordenadas polares $r$ e $\theta$ (Figura 2.29), sendo necessário realizar a transformação para o sistema de coordenadas cartesianas. Essas transformações serão apresentadas no Capítulo 4.

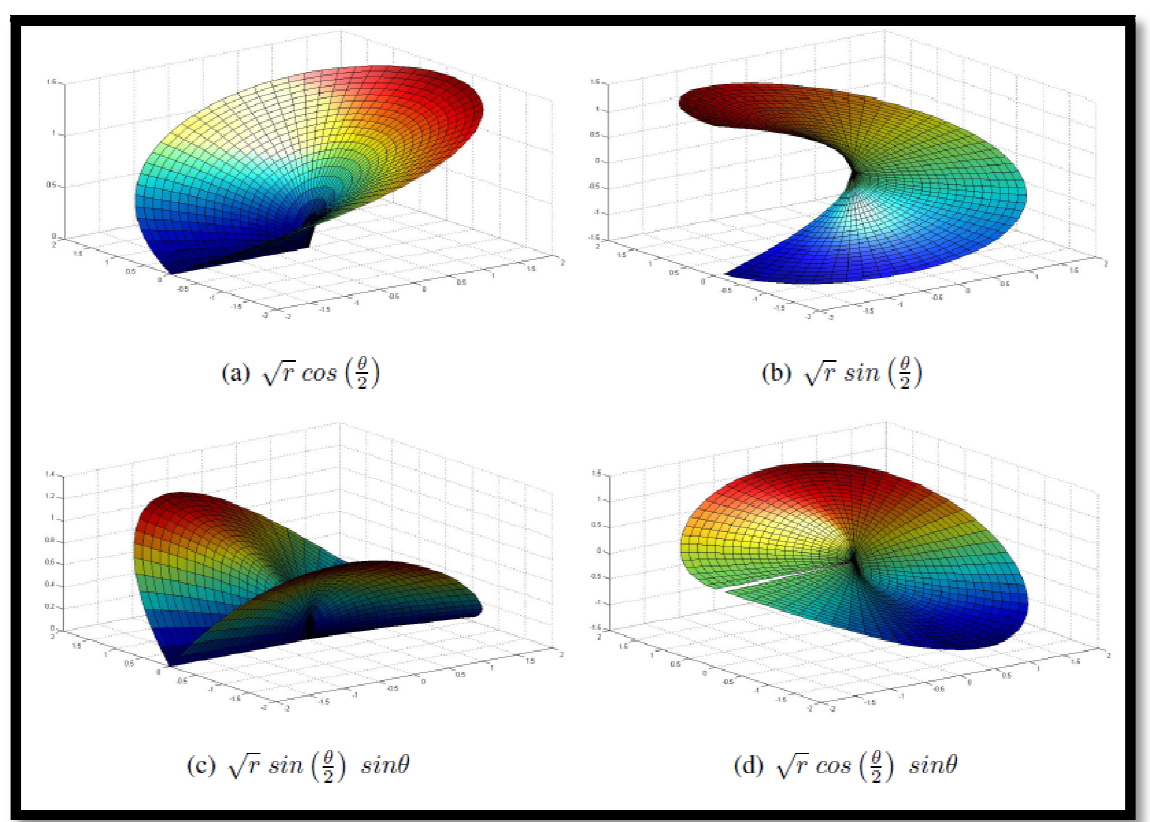

Figura 2.28 Funções de enriquecimento crack tip

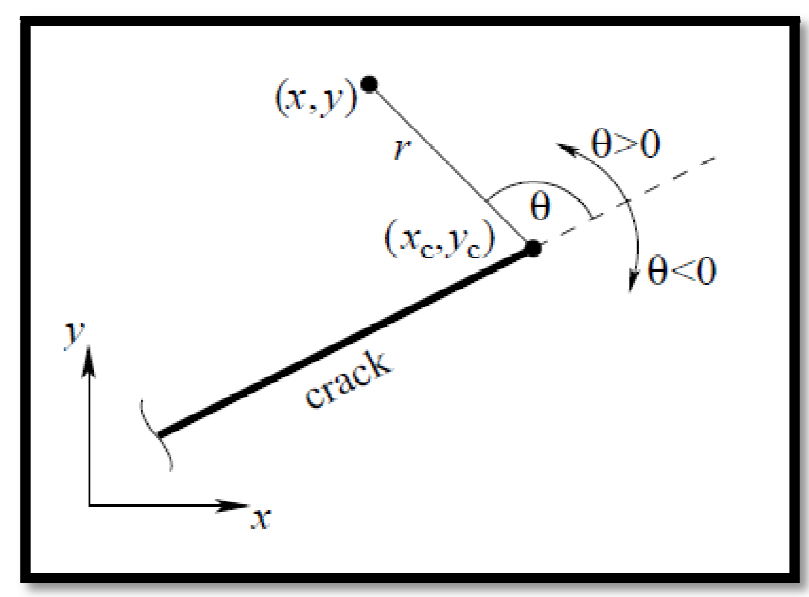

Figura 2.29 Sistema de coordenadas polares na ponta da fratura

No XFEM aplicado a elementos quadrados de quatro nós $2 \mathrm{D}$ são necessários então dezesseis graus de liberdade quando é aplicada a função $\mathrm{H}$, sendo 8 deles relativos ao 
enriquecimento. Para o elemento que contem a função $F$ são necessários 40 graus de liberdade, sendo 32 deles relativos ao enriquecimento.

\subsubsection{INTEGRAÇÃO NUMÉRICA}

Devido à presença de uma fratura no XFEM é gerado um campo de deslocamento descontínuo no elemento fraturado e os resultados obtidos pela integração numérica pela quadratura de Gauss não são acurados. Para resolver esse problema uma das soluções que foi adotada é aumentar o número de pontos de Gauss para realizar a integração numérica, obtendo com isso resultados mais acurados para o campo de deslocamentos.

Além disso, há outras soluções na literatura para lidar com esse problema (Khoei, 2015) como a subdivisão do domínio cortado pela fratura em subtriângulos, criando-se um novo mapeamento dos subelementos, sendo esse mapeamento utilizado apenas na integração, não sendo adicionado graus de liberdade ao sistema e nenhuma condição é imposta a respeito da forma dos subtriângulos. Na Figura 2.30 é possível observar a subdivisão realizada nos elementos.

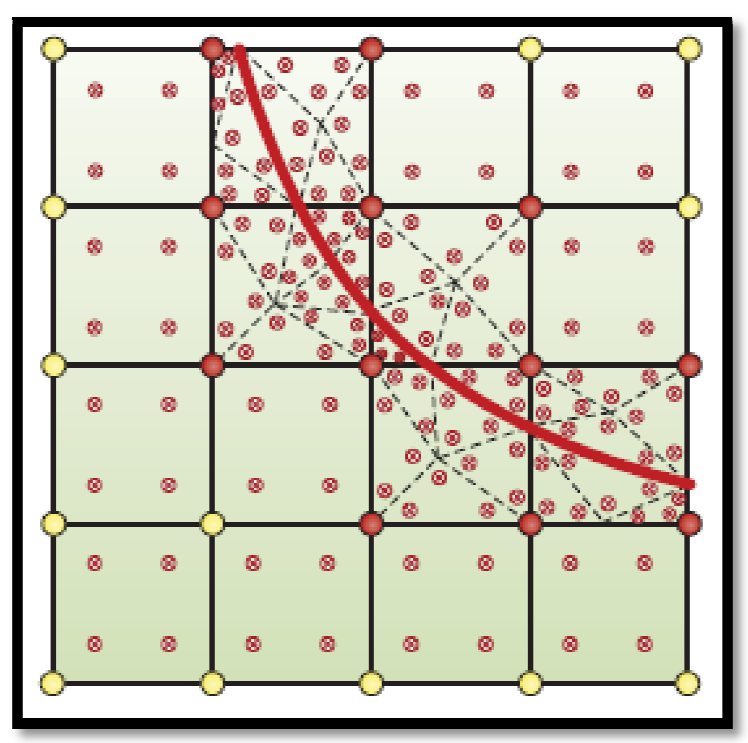

Figura 2.30 Subtriangularização do elemento cortado pela fratura (Khoei, 2015)

\subsubsection{ELEMENTOS DE TRANSIÇÃO}

O XFEM é um método que foi possibilitado devido à utilização da partição de unidade. As funções de enriquecimento são adicionadas onde há a necessidade de representar uma descontinuidade. Devido ao XFEM ser um método aplicado localmente, são gerados 
automaticamente os elementos mistos ou de transição ao redor dos elementos que contém as descontinuidades. Nos elementos de transição apenas alguns nós são enriquecidos o que pode gerar problemas de convergência da solução, sendo algumas vezes necessário adotar algumas modificações nos elementos mistos para melhorar a solução final do problema.

Três regiões são geradas ao se utilizar o XFEM na resolução de um problema: a região padrão onde nenhuma função de enriquecimento é aplicada, a região enriquecida, onde são aplicadas as funções de enriquecimento para representar uma descontinuidade e por fim uma região no domínio onde há mistura entre o domínio enriquecido e o domínio padrão, sendo os elementos dessa região chamados de elementos mistos (Figura 2.31). Essas regiões de mistas podem gerar erros na obtenção dos resultados. Nelas a partição de unidade não se aplica, ou seja, o somatório das funções é diferente de 1 e as funções de enriquecimento não são corretamente reproduzidas nesses elementos de transição.

Além disso, o erro gerado pela partição de unidade poderá afetar o resultado final e também a convergência do XFEM. Quando se utiliza a função Heaviside nos elementos mistos não se tem grande alteração nos resultados finais, os maiores problemas podem ocorrer quando são utilizadas as funções crack tip.

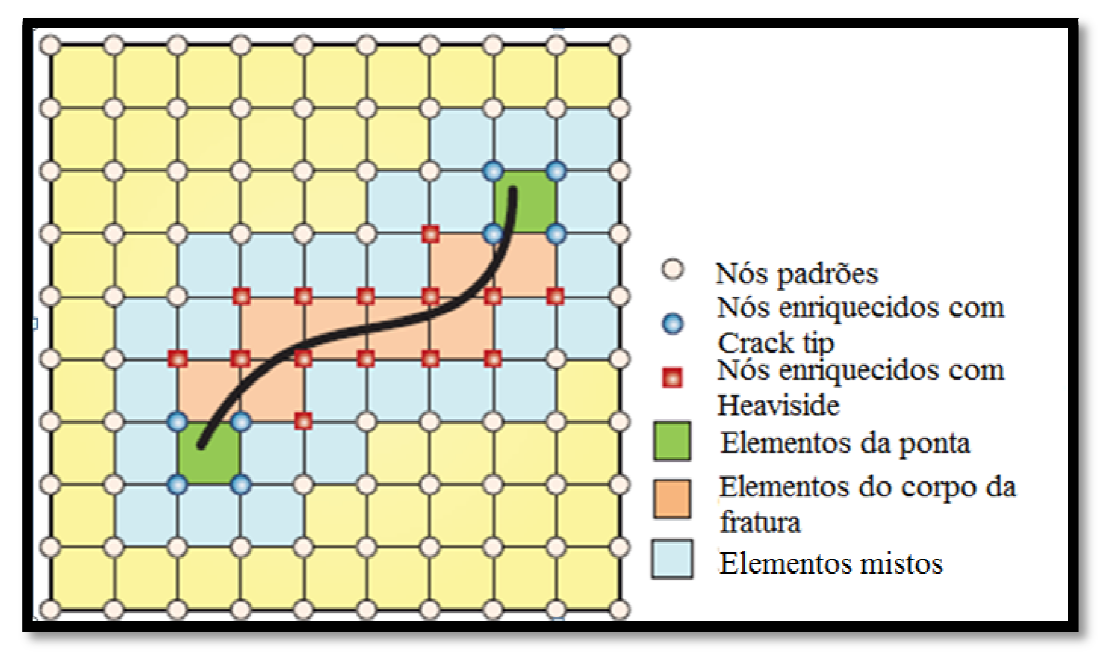

Figura 2.31 Domínio enriquecido, Domínio misto e Domínio padrão (modificada Khoei, (2015)) 


\section{MODELO PKN DE FRATURAMENTO HIDRÁULICO}

O modelo PKN de fraturamento hidráulico desenvolvido por Perkins e Kern(1961) e Nordgren (1972) já foi estudado por vários autores (Gordeyev, et al. 1990, Detornay et al., 1990), e diversas formulações foram desenvolvidas para a resolução desse problema que é caracterizado pela alteração do domínio que a equação é válida e uma forte não linearidade nas equações que o descrevem. No modelo PKN a fratura possui seção vertical com formato de elipse, e se propaga perpendicularmente ao plano da seção criada. Além disso, o modelo considera que o comprimento da fratura será muito maior que a sua altura e a sua abertura será muito menor que as duas outras dimensões. Será apresentado neste capítulo o estudo realizado do modelo PKN de fraturamento utilizando a formulação de Jing Xiang (2011) modificado por Morais (2013).

\subsection{FORMULAÇÃO DE JING XIANG MODIFICADO POR MORAIS (2013)}

Jing Xiang (2011) estudou o modelo PKN de fraturamento hidráulico. Ele se baseou nos trabalhos desenvolvidos por Detournay et al. (1990) que consideram a poroelasticidade, um coeficiente de vazamento constante e utiliza a mudança de coordenadas. Além disso, ele utilizou a modelagem numérica desenvolvida por Jung Ge (2009).

A poroelasticidade descreve o comportamento acoplado entre fluidos e sólidos em meios porosos. No estudo do fraturamento hidráulico com análise de tensões, deve ser considerado que, além do aumento da poropressão causado pela deformação da rocha, ocorre a dilatação da rocha ao redor da fratura, devido ao vazamento de parte do fluido de fraturamento injetado e sua penetração no meio poroso.

As relações básicas que irão relacionar as tensões totais causadas pela deformação da rocha e pela pressão do fluido e que serão estudadas são: a equação de conservação de massa, uma lei de fluxo e o comportamento mecânico da rocha. Para avaliar os efeitos da poroelasticidade, Detournay et al. (1990) utilizou a função $f\left(t^{*}\right)$ que será apresentada no decorrer do capítulo. Na Figura 3.1 é possível observar o problema estudado. 


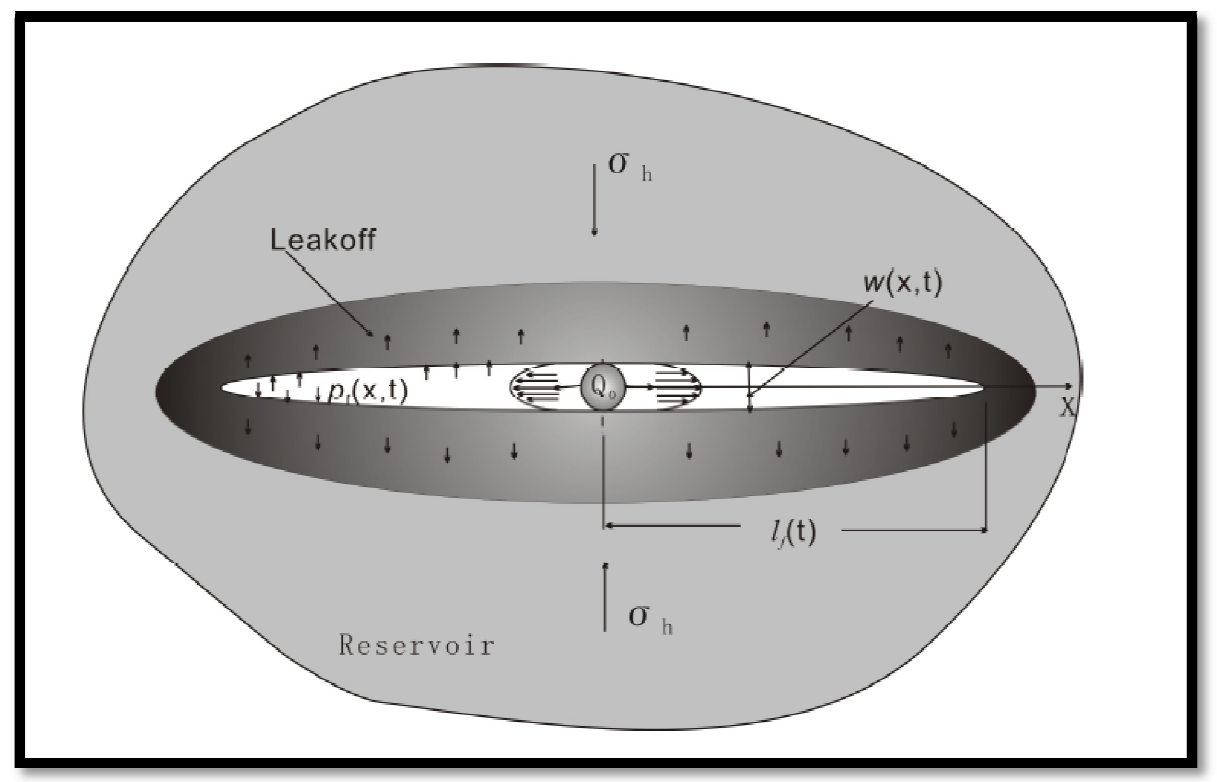

Figura 3.1- Mecânica da poroelasticidade (Xiang, 2011).

\subsubsection{DINÂMICA DOS FLUIDOS}

No fraturamento hidráulico um fluido é injetado sob alta pressão para criar e propagar uma fratura no meio. No modelo a pressão é uniforme em toda seção transversal da fratura, variando na direção de propagação da fratura e também com a taxa de injeção do fluido. A equação de fluxo para um fluido em regime laminar é dada por:

$\frac{\partial p f}{\partial x}=-\frac{2 K q|q|^{n-1}}{\psi^{n} w^{2 n+1}}$

onde $p f$ é a pressão do fluido na fratura , $q=Q /{ }_{H}$ é o fluxo por unidade de altura da fratura, $w=A / H$ é a abertura da fratura, $K$ e $n$ são constantes para fluidos viscosos e $\psi$ é o fator de forma dependente da geometria da seção vertical da fratura dado por:

$\psi=\frac{n}{2(2 n+1) H} \int_{-\frac{H}{2}}^{\frac{H}{2}}\left(\frac{w_{y}}{w}\right)^{\frac{2 n+1}{n}} d y$

onde $w_{y}$ é a função da área da seção transversal da fratura, $w$ é a abertura média e n é uma constante para fluidos viscosos. Para fraturas elípticas o valor de $\psi$ é igual a 0,1934. 


\subsubsection{BALANÇO DE MASSA}

O balanço de massa local do fluido de fraturamento estabelece que o volume de fluido, que é infiltrado, é igual a soma do volume da fratura criada e do fluido que é vazado para a formação rochosa. Considerando que $q$ é o volume de fluido injetado, $w$ é o volume da fratura e $u$ é o fluido perdido para a formação, o balanço de massa é dado por:

$\frac{\partial q}{\partial x}+\frac{\partial w}{\partial t}+u_{l}=0$

onde $u_{l}$ é a velocidade do vazamento do fluido, considerando as paredes dos dois lados da fratura. A teoria de Carter (1957) é utilizada para descrevê-lo e é escrita por:

$u_{l}=\frac{2 C_{l}}{\sqrt{t-\tau(x)}}$

onde $C_{l}$ é o coeficiente de vazamento, uma constante empírica relacionada a porosidade e permeabilidade da rocha, $t$ é o tempo desde o início do bombeamento e $\tau$ é o tempo de chegada da ponta da fratura em $\mathrm{x}$.

\subsubsection{RELAÇÃO PRESSÃO-ABERTURA}

A relação entre a abertura da fratura e a pressão do fluido é utilizada para fazer a conexão do balanço de massa com o fluxo. A abertura da fratura é composta por duas componentes:

$w=w^{e}+w^{p}$

onde $\mathrm{w}^{\mathrm{e}}$ é controla pela tensão líquida $\left(\mathrm{p}_{\mathrm{f}}-\sigma_{\mathrm{o}}\right)$ e $\mathrm{w}^{\mathrm{p}}$ é controlada pela pressão líquida $\left(\mathrm{p}_{\mathrm{f}}-\mathrm{p}_{0}\right)$. A tensão líquida é a diferença entre a pressão no fluido de fraturamento e a tensão normal ao plano de fratura. A pressão líquida é a diferença entre a pressão no fluido de fraturamento e a pressão do fluido existente nos poros. $\mathrm{O}$ efeito da tensão líquida segundo Detournay et al. (1990) é aproximada elasticamente por:

$w^{e}=M_{c}\left(p_{f}-\sigma_{o}\right)$ 
onde $M_{c}=\pi(1-v) H / 4 G$ é a rigidez da fratura, $v$ é o coeficiente de poisson, $G$ é o módulo de rigidez. O efeito da pressão líquida pode ser escrito por:

$w^{p}=-2 \eta \Delta p M_{c} f\left(t^{*}\right)$

onde $\eta$ é o coeficiente poroelástico que varia de $0 \leq \eta \leq 0,5$ e $f\left(t^{*}\right)$ é uma função que varia de 0 a 1 , utilizada para avaliar os efeitos da poroelasticidade. O símbolo $\left(t^{*}\right)$ é a dimensão de tempo de exposição da superfície da fratura e é definido por:

$t^{*}=\frac{4 c[t-\tau(x)]}{H^{2}}$

onde $c$ é o coeficiente de difusividade e $\tau(x)$ é o tempo de chegada da fratura no ponto variável $x$, o qual será apresentado no decorrer desse capítulo.

Para o modelo PKN de Xiang (2011) apud Boone and Detournay (1990) é adotada uma função $f\left(t^{*}\right)$ igual a:

$f\left(t^{*}\right)=\frac{4}{\pi} \int_{0}^{\infty} \operatorname{erfc}\left(\frac{y}{2 \sqrt{t^{*}}}\right) g(y) d y$

Onde

$g(y)=1-\sqrt{\frac{y}{2}} \sqrt{\sqrt{4+y^{2}}-y}$

Morais (2013) utilizou uma função aproximada, que reproduz a função utilizada originalmente, sem perder as características originais, igual a:

$f\left(t^{*}\right)=\frac{1}{\left(1+\left(60 t^{*}\right)^{-.04}\right)^{3}}$

Na Figura 3.2 pode ser observada a função $f\left(t^{*}\right)$ adotada por Morais (2013) e a função utilizada por Xiang (2011). 


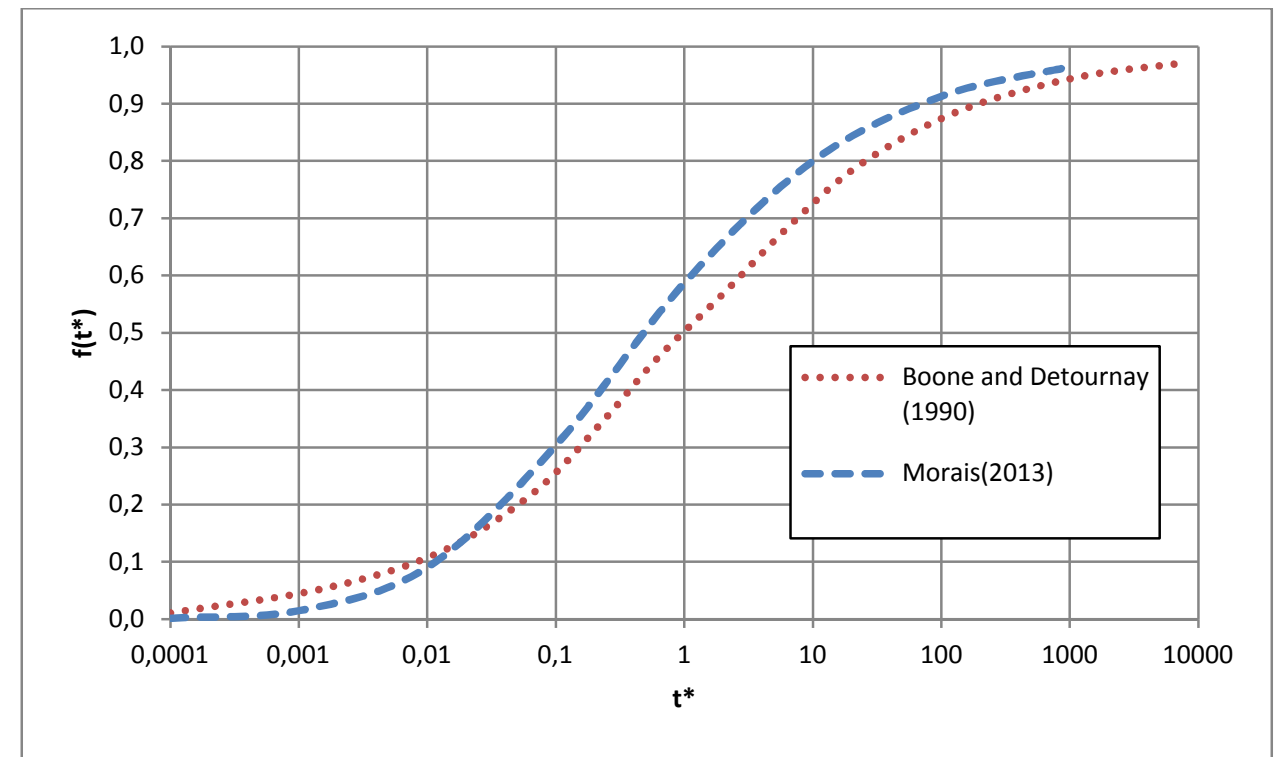

Figura 3.2 Comparação entre as Funções $f\left(t^{*}\right)$ proposta por Boone e Detournay (1990) e Morais (2013)

\subsubsection{MODIFICAÇÕES REALIZADAS POR MORAIS (2013)}

Devido a dificuldade na obtenção de alguns coeficientes e funções apresentadas no trabalho de Xiang (2011), Morais (2013) realizou algumas modificações na formulação apresentada em seu trabalho.

Para a equação de fluxo (Eq. 3.1) foi adotado uma lei de fluxo com $n=1$ diferente do trabalho original no qual foi adotado um $n=0,8$. Além disso, foi realizada uma simplificação da secção transversal da fratura. Ao invés da elipse, foi feita uma aproximação linear da elipse, ou seja, a elipse foi aproximada por um losango, conforme apresentado na Figura 3.3. Foi realizada a integração do fator de forma $\psi$ (Equação 4.2) para a área de um losango, considerando o valor do índice $\mathrm{n}$ igual a 1 . Sendo a abertura média $w_{m}$ igual a $w_{m}=\frac{W_{\max }}{2}$, a função da área do triângulo igual a $\mathrm{w}(y)=w_{\max }-\frac{w_{\max }}{H / 2} y$, o fator de forma $\psi$ pode ser escrito por:

$\psi=\frac{1}{6 H} \int_{-H / 2}^{H / 2}\left(\frac{W(y)}{W_{m}}\right)^{3} d y=\frac{1}{3}$ 


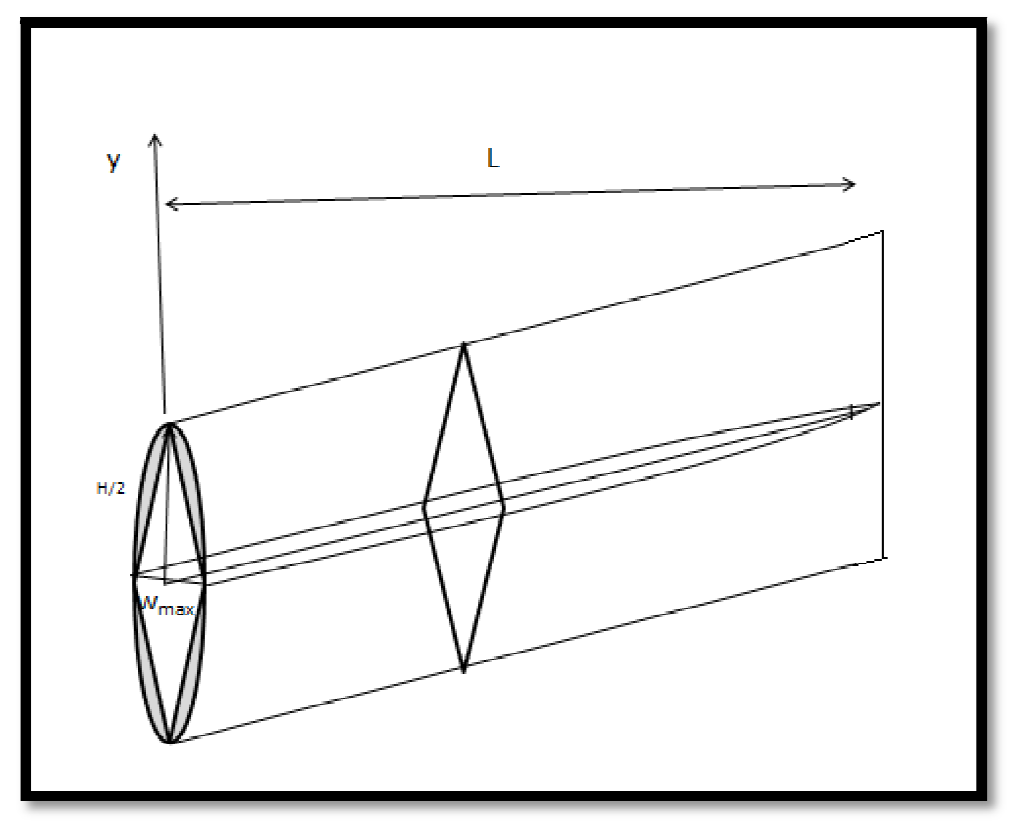

Figura 3.3 Modelo PKN modificado por Morais (2013)

Com as modificações realizadas, o gradiente da pressão do fluido se relaciona com a vazão por meio da equação:

$q=-\frac{w^{3}}{6 K} \frac{\partial p f}{\partial x}$

\subsubsection{CONDIÇÕES DE CONTORNO}

As condições de contorno utilizadas para a resolução das equações do problema de fraturamento hidráulico descrevem o estado do fluxo em 2 pontos: na entrada da fratura $(\mathrm{x}=0)$ e na ponta da fratura $(x=1)$. Na entrada da fratura a vazão do fluido é igual a vazão de injeção e na ponta da fratura a pressão líquida é zero, ou seja:

$q(0, t)=q_{o}(t) ; t>0$

$p(L, t)=0 ; t>0$

Além disso, é necessário ainda conhecer duas outras informações a respeito do comprimento da fratura no tempo inicial e da pressão da fratura também no tempo $t=0$, ou seja:

$\mathrm{L}(0)=0$

$\mathrm{p}(\mathrm{x}, 0)=0$ 


\subsubsection{MUDANÇA DE COORDENADAS}

As equações apresentadas são definidas num domínio $0<\mathrm{x}<\mathrm{L}(\mathrm{t})$, sendo que $\mathrm{L}(\mathrm{t})$ varia com o tempo. Devido a variação do comprimento da fratura a cada intervalo de tempo, seria necessário um reajuste das equações a cada incremento de tempo. Assim, foi utilizado o sistema de mudança de coordenada para resolver o problema, onde:

$\theta=\frac{x}{L(t)}$

sendo que $\theta$ varia de $[0,1]$. Além disso, é necessário transformar as derivadas no espaço e no tempo para o novo sistema de coordenadas, por meio das equações a seguir:

$\left.\frac{\partial}{\partial x}\right|_{t}=\left.\frac{1}{L} \frac{\partial}{\partial \theta}\right|_{t}$

e

$\left.\frac{\partial}{\partial t}\right|_{t}=\left.\frac{\partial}{\partial t}\right|_{\theta}-\left.\theta \frac{\dot{L}}{L} \frac{\partial}{\partial \theta}\right|_{t}$

onde $\dot{L}=\frac{d L}{d t}$.

Usando a transformação acima, temos que as Equações 3.3 e 3.13 podem ser reescritas, respectivamente, por:

$\frac{\partial w}{\partial t}-\frac{\theta}{L} \frac{\partial L}{\partial t} \frac{\partial w}{\partial \theta}+\frac{1 \partial q}{L \partial \theta}+u=0$

$q=-\frac{w^{3}}{6 K L} \frac{\partial p f}{\partial \theta}$

E as condições iniciais de contorno podem ser reescritas por:

$q(0, t)=q_{0}(t) ; p(1, t)=0 ; t>0$

$L=0 ; p=0: t=0$

O problema de fraturamento hidráulico estudado é constituído por três equações 
(balanço de massa, deformação da rocha e variação do comprimento da fratura) e uma lei constitutiva (lei de fluxo). As variáveis do problema são $p(\theta, t), q(\theta, t), w(\theta, t), \mathrm{L}(\mathrm{t}) \mathrm{e}$ $u(\theta, t)$. Deve ser calculado o $\tau(\theta, t)$, que é o tempo de chegada da fratura em um ponto variável $x=\theta L(t)$,o qual é calculado por meio da função inversa de $\mathrm{L}(\mathrm{t})$ :

$\tau(\theta, t)=L^{-1}(\theta L(t))$

\subsection{FERRAMENTA DE MODELAGEM}

Para a solução do problema deverá ser utilizada uma ferramenta numérica que permita a solução das equações descritas no item anterior. Neste trabalho foi escolhida a ferramenta FLEXPDE (PDE solutions inc, 2015). O programa é capaz de construir modelos numéricos e

resolver equações diferenciais parciais utilizando para isso elementos finitos. É necessário que o usuário apenas descreva o problema por meio das equações e condições de contorno. A partir desse ponto, a ferramenta tem algoritmos que automatizam o processo de solução. Além disso, é possível obter diferentes tipos de gráficos que facilitam o processo de análise do problema. Maiores detalhes sobre o programa podem ser obtidos no site http://www.pdesolutions.com/help/.

A ferramenta numérica escolhida - FLEXPED - é capaz de resolver equações diferenciais parciais (EDP) de primeira e segunda ordem, em uma, duas ou três dimensões. Além disso, é capaz de resolver equações simultâneas, lineares ou não lineares, sendo as EDPs resolvidas de forma acoplada.

Devem ser inseridos os dados do problema por meio de um Script, que contém algumas seções identificadas por um cabeçalho (Figura 3.4). Inicialmente as variáveis do problema são introduzidas (VARIABLE), em seguida devem-se apresentar algumas definições tais como: parâmetros, relações constitutivas, funções, dentre outros (DEFINITIONS). Além disso, na seção de equações (EQUATIONs) deve ser inserida uma equação diferencial associada a cada variável e em seguida as condições de contorno (BOUNDARIES). Por último devem ser colocados quais os gráficos que irão ser apresentados pelo programa para apresentação dos resultados (PLOTS). 
TITLE 'Simple diffusion equation'

\{ this problem lacks sources and boundary conditions \}

VARIABLES

\section{u}

DEFINITIONS

$\mathrm{k}=3 \quad\{$ conductivity $\}$

EQUATIONS

$\operatorname{div}\left(k^{*} \operatorname{grad}(u)\right)=0$

BOUNDARIES

REGION 1

$\operatorname{START}(0,0)$

PLOTS

LINE TO $(1,0)$ TO $(1,1)$ TO $(0,1)$ TO CLOSE

CONTOUR(U)

END

$\operatorname{VECTOR}\left(k^{*} \operatorname{grad}(u)\right)$

Figura 3.4-Exemplo de script do programa FLEX PDE

\subsection{SIMULAÇÃO DO MODELO PKN DE FRATURAMENTO HIDRÁULICO}

Na simulação do problema no software FLEXPDE primeiramente foi utilizado para o comprimento da fratura $L$ a seguinte equação:

$L=L_{0}+\frac{q t}{w}$

sendo $w$ a abertura da fratura ao longo do tempo e $\mathrm{L}_{0}$ o comprimento inicial da fratura.

Além disso, a função $\tau(\theta, t)$ pode ser definido por:

$\tau=\frac{\theta\left(L-L_{0}\right) w}{q_{00}}$

Os valores iniciais das variáveis do problema $p_{f}$ e $w$ na simulação realizada por Morais (2013), necessários para a solução do problema devido ao método de solução escolhido, foram definidos, respectivamente, por:

$p_{f}=\sqrt{p_{f 0}^{2}(1-x)}+p_{f 0}$

$w=w_{0} \sqrt{1-x^{3}}$ 
onde $p_{f_{0}}=1$ e $w_{0}=0,002$.

Essas funções foram definidas por um processo interativo. Inicialmente obteve-se uma solução para o problema a partir da consideração dos valores iniciais constantes. A partir disso, foram obtidas soluções iniciais onde era possível identificar a forma das funções para as duas variáveis. Sabendo-se que a solução das equações para as variáveis $p_{f}$ e $w$ eram semelhantes a hipérboles, optou-se por utilizar as Equações 3.28 e 3.29. É interessante notar que o valor inicial de $p_{f}$ tem pouca influência na resposta final, enquanto que o valor inicial de $w$ tem forte influência no cálculo do L. Além disso, a utilização das equações deu ao programa uma maior estabilidade numérica conferindo uma convergência mais rápida.

Devido a uma limitação da ferramenta, não foi possível utilizar diretamente na equação do L (Equação 3.26) o valor de $w_{m}$, ou seja, o valor médio da abertura no tempo t. Desta forma, foi utilizado um procedimento semelhante ao utilizado para definir as Equações 3.28 e 3.29 de modo a propor uma equação para $w_{m}$ com o tempo. :

$w_{-} m=0,00166\left(1+\left(\frac{t}{1000}\right)^{0,5}\right)$

Cabe destacar que o valor de $\mathrm{w}_{m}$ tem pouca influência na resposta final da pressão e da abertura, sendo mais importante para o cálculo do valor final do L.

\subsection{SOLUÇÃO DO MODELO PKN DE FRATURAMENTO HIDRÁULICO}

Considerando o caso da fratura em rochas impermeáveis por um fluido Newtoniano bombeado a uma taxa constante, utiliza-se a solução analítica de Nordgren (Nordgren 1972) para comparação com o modelo obtido por elementos finitos.

Na solução de Nordgren tem-se que:

$$
\begin{aligned}
& L_{D}\left(t_{D}\right)=1,56 t_{D}^{\frac{4}{5}} \\
& w_{D}\left(0, t_{D}\right)=1,09 t_{D}^{\frac{1}{5}} \\
& p_{D}\left(0, t_{D}\right)=0,855 t_{D}^{\frac{1}{5}}
\end{aligned}
$$


$\mathrm{e}$

$$
\begin{aligned}
& L_{D}=\frac{1}{4}\left(\frac{G}{(1-v) \mu Q_{0}}\right)^{\frac{1}{3}} L \\
& W_{D}=\frac{1}{4}\left(\frac{G}{(1-v) \mu Q_{0}}\right)^{\frac{1}{3}} W_{m} \\
& p_{D}=\frac{1}{16}\left(\frac{(1-v)^{2} H}{G^{2} \mu Q_{0}}\right)^{\frac{1}{3}} p \\
& t_{D}=\frac{1}{16}\left(\frac{G^{2} Q_{0}}{(1-v)^{2} \mu^{2} H^{3}}\right)^{\frac{1}{3}} t
\end{aligned}
$$

Os parâmetros utilizados na simulação numérica e na solução analítica são apresentados na Tabela 1 .

Tabela 1- Dados de entrada para verificação e simulação do problema (Xiang, 2011)

\begin{tabular}{|l|l|}
\hline$\mu$ (viscosidade do fluido) & $5,6 \times 10^{-7} \mathrm{MPa} . \mathrm{s}$ \\
\hline$Q_{0}$ (taxa de injeção do fluido) & $4 \times 10^{-3} \mathrm{~m}^{3} / \mathrm{s}$ \\
\hline$v$ (poisson) & 0,2 \\
\hline$G$ (Módulo cisalhante) & $10.000 \mathrm{MPa}$ \\
\hline $\mathrm{H}$ (altura da fratura) & $10 \mathrm{~m}$ \\
\hline $\mathrm{T}$ (tempo) & $1000 \mathrm{~s}$ \\
\hline $\mathrm{K}$ (constante para fluido viscoso) & $1.53 \times 10^{-8} \mathrm{MPa} . \mathrm{s}$ \\
\hline $\mathrm{N}$ (constante para fluido viscoso) & 1 \\
\hline$\eta$ (coeficiente poroelástico) & 0,25 \\
\hline c (coeficiente de difusividade) & $0,4 \mathrm{~m}^{2} / \mathrm{s}$ \\
\hline
\end{tabular}

\subsubsection{RESULTADOS OBTIDOS}

Foram resolvidos as equações do problema inicialmente sem considerar o vazamento do fluido para o meio (leak-off) e posteriormente considerando o leak-off. Os resultados foram comparados com uma solução analítica de Nordgreen onde não é considerado o vazamento de fluido para o meio. As Figuras 3.5, 3.6 e 3.7 mostram os gráficos da variação do comprimento da fratura, abertura da fratura e pressão do fluido na abertura da fratura com o tempo, respectivamente.

Observando os resultados do comprimento da fratura e da abertura da fratura, sem considerar o vazamento do fluido, conclui-se que eles foram satisfatórios, pois ao serem comparados com a solução analítica de Nordgreen resultaram em pequenas diferenças nos 
valores obtidos. Com relação a pressão do fluido sem considerar o vazamento podemos observar que as diferenças com relação a Nordgreen foi mais significativo. Deve-se considerar, entretanto, que foram realizadas modificações no cálculo desta variável, como a utilização de uma lei de fluxo simplificada, onde a seção da fratura calculada foi para um losango, ao invés da seção elíptica do modelo PKN original. Ainda, o valor da constante n adotado foi de 1 ao invés de 0,8 adotado por Xiang (2011).

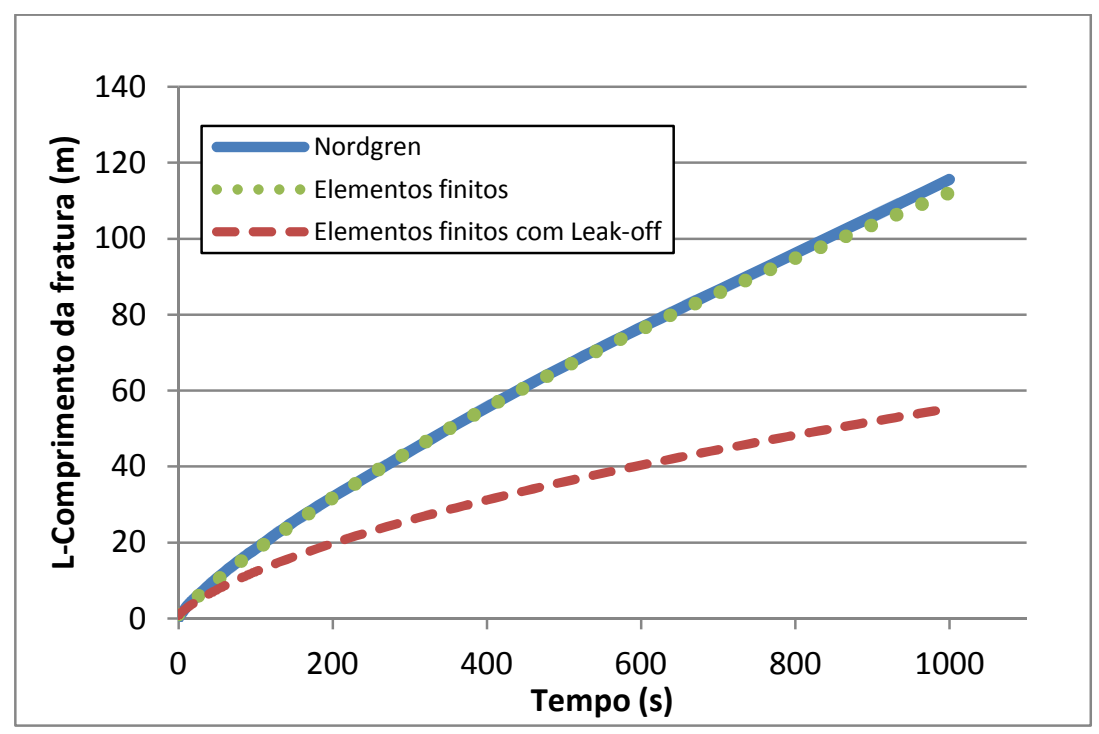

Figura 3.5 Variação do comprimento da fratura x tempo

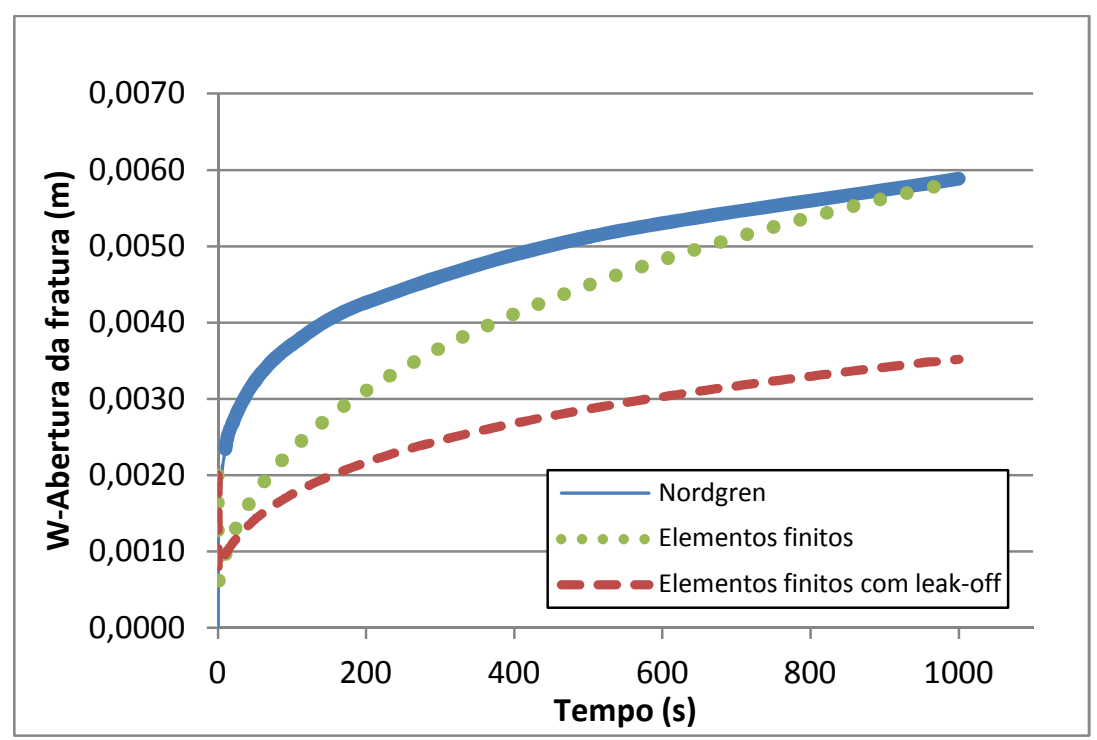

Figura 3.6 Variação da abertura da fratura x tempo 


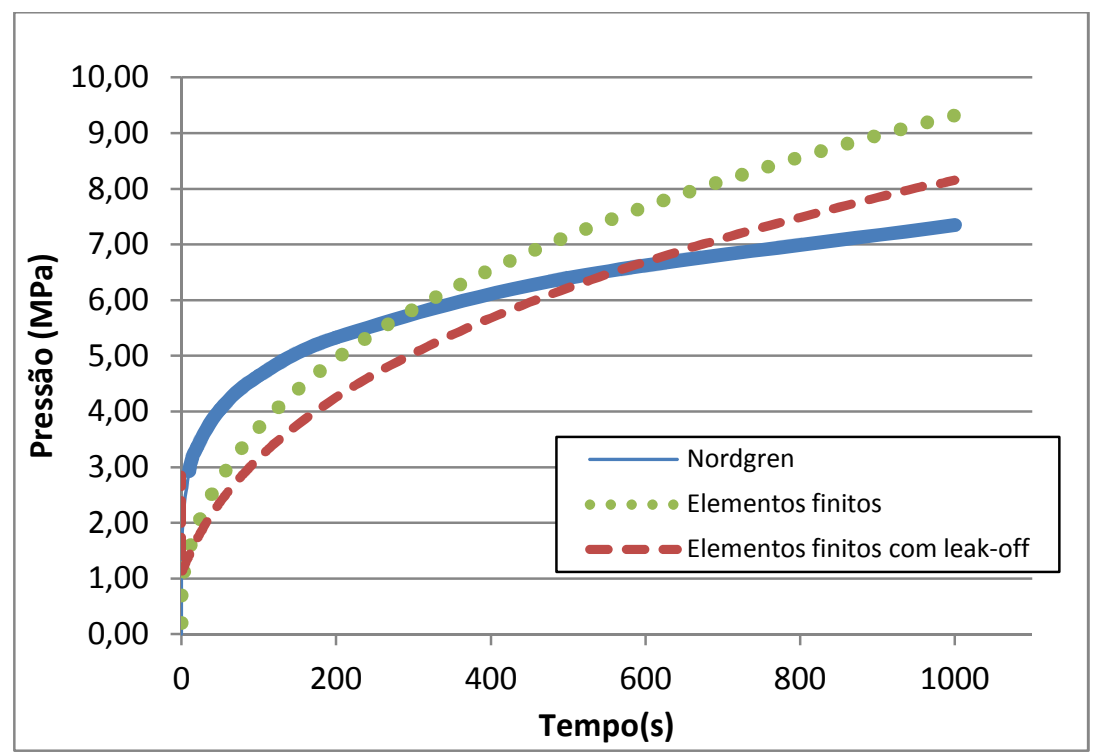

Figura 3.7 Variação da Pressão do fluido x tempo

Com relação aos resultados obtidos considerando o vazamento de fluido para a formação (leak-off), eles foram condizentes pois observa-se que o comprimento da fratura, a abertura da fratura e a pressão do fluido possuem valores menores que a solução onde não foi considerado o vazamento. Isso é explicado, pois devido à perda de fluido de fraturamento para o meio, em um mesmo tempo, ocorrerá uma dissipação da pressão do fluido para o meio, reduzindo o esforço de tração da rocha na zona de formação e propagação da fratura.

Comparando a solução numérica e a solução analítica foi observado que o programa possui vantagens, pois possibilita a simulação do vazamento de fluido (leak-off) para a formação. Além disso, na resolução do problema pela formulação de Xiang (2011) é considerado de forma simplificada o efeito da poroelasticidade.

Porém, mesmo utilizando uma ferramenta numérica para resolver o problema de fraturamento hidráulico por meio de modelos como o PKN não é possível observar o que acontece com o campo de tensão e deformação dentro de um reservatório. Para isso, seria necessária a utilização de ferramentas numéricas que permitam avaliar esses campos, como por exemplo, o método XFEM, que foi apresentado na Seção 2.7. 


\section{EQUAÇÕES BÁSICAS DO PROBLEMA DE EQUILIBRIO ACOPLADO}

Neste capítulo serão apresentadas as formulações para o desenvolvimento da ferramenta numérica para resolução de problemas hidromecânicos acoplados. Para isso será utilizado o método dos elementos finitos para resolver as equações de equilíbrio e de continuidade. Posteriormente será apresentado a discretização do Método dos Elementos Finitos Estendido (XFEM), método que foi escolhido neste trabalho para resolver problemas envolvendo fraturas.

\subsection{EQUAÇÕES BÁSICAS DO PROBLEMA}

Os problemas acoplados hidromecânicos saturados são resolvidos utilizando duas equações, uma para descrever o comportamento da fase sólida (equilíbrio estático) e a outra para descrever o comportamento da fase líquida (continuidade).

A equação de equilíbrio estático para um elemento de solo é dada por:

$\frac{\partial \sigma_{i j}}{\partial x_{j}}+b_{i}=0$

onde $\sigma_{i j}$ é o tensor de tensão total (segunda ordem para o nosso problema), $b_{i}$ são as forças de corpo e $x_{j}$ representa a direção do sistema de coordenadas cartesiano.

Essa equação é escrita em termos de tensão total, sendo que a tensão total é dada pela soma da tensão efetiva $\sigma_{i j}^{\prime}$ e da poropressão $u_{w}$. A tensão efetiva no meio poroso deformável se relaciona com as deformações por uma relação constitutiva. É assumido que o meio é elástico linear e o estado de tensão do problema é de deformação plana em que são realizadas as seguintes simplificações:

- São calculadas apenas as tensões em 2 planos $\left(\sigma_{x} e \sigma_{y}\right) \operatorname{com} \sigma_{z} \neq 0$.

- São calculadas as deformações $\varepsilon_{x}, \varepsilon_{y}$ e $\gamma_{x y}$ e a deformação em z é nula $\left(\varepsilon_{z}=0\right)$.

A matriz D do problema é uma matriz 3x3dada por:

$D=\frac{E}{(1+v)(1-2 v)}\left[\begin{array}{ccc}(1-v) & v & 0 \\ v & (1-v) & 0 \\ 0 & 0 & \frac{(1-2 v)}{2}\end{array}\right]$ 
O campo de deformações do problema é obtido a partir dos deslocamentos por meio da matriz B, a qual é dada por:

$B=\left[\begin{array}{cc}(N)_{, x} & 0 \\ 0 & (N)_{, y} \\ (N)_{, y} & (N)_{, x}\end{array}\right]$

A continuidade da fase líquida pode ser descrita pelas equações de conservação de massa. Pela Figura 4.1 pode-se observar o princípio de conservação de massa onde a diferença entre o que entra e o que sai é igual a variação da massa dentro do elemento.

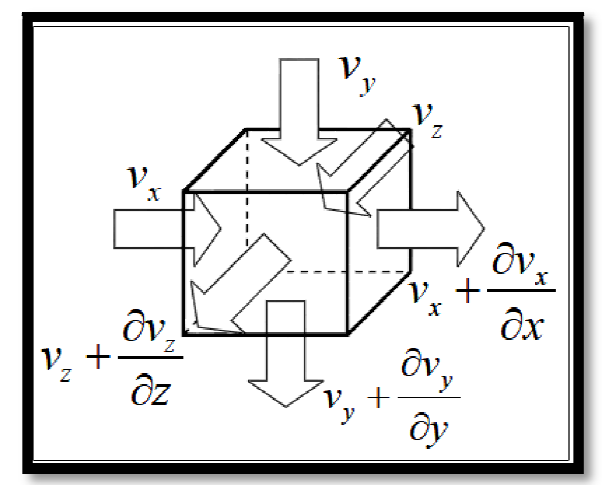

Figura 4.1 Conservação de massa (Cordão Neto, 1995)

Admitindo que a água é incompressível, tem-se então que a equação de continuidade da fase de água é dada por:

$\frac{\partial\left(v_{i}\right)}{\partial x_{i}}+\frac{\partial \theta_{w}}{\partial t}=0$

onde $\theta_{w}=n S$ é o volume de água no solo, $\mathrm{n}$ é a porosidade, $\mathrm{S}$ é o grau de saturação e $v_{i}$ é a velocidade da água. Pela lei de Darcy, a velocidade da água pode ser definida por:

$$
v_{i}=-k_{i j} \frac{d h}{d x_{j}}
$$

onde $k_{i j}$ é a matriz de permeabilidade e $\frac{d h}{d x_{j}}$ é o vetor de gradiente hidráulico. 
Para um meio saturado, homogêneo e isotrópico, a equação de continuidade da água pode ser simplificada, pois a variação do volume de água do meio poroso será igual a variação volumétrica do meio poroso e a equação pode ser escrita por:

$\frac{\partial\left(v_{i}\right)}{\partial x_{i}}+\frac{\partial \varepsilon_{v}}{\partial t}=0$

onde $\varepsilon_{v}$ é a deformação volumétrica de um elemento de solo.

\subsection{RESOLUÇÃO ACOPLADA DO SISTEMA DE EQUAÇÕES UTILIZANDO ELEMENTOS FINITOS}

As equações apresentadas no Item 4.1 requerem a utilização do Método dos Elementos Finitos para a sua resolução. A seguir será apresentada a resolução das equações do problema hidromecânico utilizando o Método dos Elementos Finitos semelhante à apresentada por Cordão Neto (2005).

Para a solução espacial da equação de equilíbrio será utilizado o princípio dos trabalhos virtuais. Nele inicialmente é definido o domínio do problema $(\Omega)$ e posteriormente as condições de contorno para as forças de superfície $\left(\Gamma_{1}\right)$ e para os deslocamentos $\left(\Gamma_{2}\right)$. Considerando um sistema em equilíbrio, o trabalho realizado pelas forças internas deverá se igualar ao trabalho realizado pelas forças externas (corpo e de superfície). Considerando o trabalho realizado por um deslocamento virtual $\left\{\delta u^{*}\right\}$, tem-se que:

$\int_{\Omega}\left\{\delta \varepsilon^{*}\right\}^{T}\{\dot{\sigma}\} d \Omega-\int_{\Omega}\left\{\delta u^{*}\right\}^{T}\{\dot{b}\} d \Omega-\int_{\Gamma_{1}}\left\{\delta u^{*}\right\}^{T}\{\dot{\tau}\} d \Gamma=0$

sendo $\left\{\delta \varepsilon^{*}\right\}$ deformações virtuais compatíveis com os deslocamentos virtuais, $\{b\}$ as forças de corpo que agem no domínio, $\{\tau\}$ as tensões que atuam na superfície e $\{\dot{x}\}$ é a derivada temporal de uma variável $\mathrm{x}$.

Considerando as condições de contorno apresentadas e utilizando a relação constitutiva do item 4.1, chega-se a solução do problema (no Apêndice A1 é possível observar os passos da resolução da Equação 4.7) dado por:

$[K]\{\dot{u}\}+[C]\{\dot{p}\}=\{F\}$ 
sendo

$[K]=\int_{\Omega}[B]^{T}[D][B] d \Omega$ a matriz de rigidez da parte sólida $(2 \mathrm{n}, 2 \mathrm{n})[F][L]^{-1}$

$[B]$ : a matriz deformação-deslocamento $(3 \mathrm{n}, 2 \mathrm{n})[L]^{-1}$

$[D]$ : matriz da relação constitutiva tensão-deformação $(3 \times 3)[F][L]^{-2}$

$\{\dot{u}\}:$ vetor da taxa de deslocamentos nodais $(2 \mathrm{n}, 1)[L][T]^{-1}$

$\{\dot{p}\}$ : vetor de taxa de poropressões nodais $(\mathrm{n}, 1)[F][L]^{-2}[T]^{-1}$

$[C]=\int_{\Omega}[B]^{T}\{H\}\left[N_{p}\right] d \Omega$ matriz de acoplamento entre a fase sólida e a água $(2 \mathrm{nxm})[L]^{-2}$

$\left[N_{p}\right]$ : matriz de interpolação de poropressões $(\mathrm{p})(1 \mathrm{xm})$ [ ] adimensional

$\{H\}$ : vetor da relação constitutiva tensão-sucção; (3x1) para formulação saturada[ ] adimensional

$\{m\}=\{1,1,0\}^{T}$

$\{F\}: \int_{\Omega}[N]^{T}\{\dot{b}\} d \Omega+\int_{\Gamma_{2}}[N]^{T}\{\dot{\tau}\} d \Omega$ vetor de taxa de forças externas (2n x1) $[F][T]^{-1}$

[N]: matriz de interpolação de deslocamento; (1xn) [ ] adimensional

A resolução espacial da equação de continuidade da água foi realizada utilizando o método de Galerkin. A Equação para um meio saturado pode então ser escrita por:

$\frac{\partial v_{x}}{\partial x}+\frac{\partial v_{y}}{\partial y}+\frac{\partial v_{z}}{\partial z}+\frac{\partial\left(\beta_{1} d \varepsilon_{v}\right)}{\partial t}=0$

Para a resolução dessa equação assume-se que a fronteira $\Gamma$ possui duas regiões $\Gamma_{1}$ e $\Gamma_{2}$. Sendo as condições naturais impostas exclusivamente em $\Gamma_{1}$ e as condições essenciais impostas exclusivamente em $\Gamma_{2}$.

Integrando a equação sobre o domínio, utilizando o método de Galerkin (no Apêndice A2 é possível observar os passos da resolução da Equação de continuidade) e aplicando as condições de contorno se obtém:

$[H]\{p\}+[L]\{\dot{u}\}=\{q\}$

onde

$[H]=\int_{\Omega}\left[B_{p}\right] \frac{1}{\gamma_{w}}[k]\left[B_{p}\right] d \Omega$ : matriz de fluxo (m x m); $[L]^{5}[F]^{-1}[T]^{-1}$ 
$\left[B_{p}\right]$ : matriz gradiente-poropressão(2xm) $[L]^{-1}$

$\gamma_{w}$ : massa específica da água; escalar $[F][L]^{-3}$

$[k]$ : matriz de condutividade $(2 \times 2)[L][T]^{-1}$

$\{p\}$ : vetor de poropressões nodais $(\mathrm{m} \times 1)[F][L]^{-2}$

$\{\dot{u}\}$ : vetor de taxa de deslocamentos nodais $(2 \mathrm{n} \times 1)[L][T]^{-1}$

$[L]=\int_{\Omega}\left[B_{p}\right]^{T} \beta_{1}[N] d \Omega$ : matriz de acoplamento da fase sólida e da água $(\mathrm{m} \times 2 \mathrm{n})[L]^{2}$

$\beta_{1}=\frac{\partial \theta_{\mathrm{w}}}{\partial \varepsilon_{v}}$, escalar, adimensional e para o caso saturado é igual a 1 .

[N]: matriz de interpolação de deslocamentos $(2 \times 2 \mathrm{n})$; [ ] (adimensional)

$\{q\}$ : vetor de vazões nodais impostas

O sistema resultante das equações do sistema discretizado pode ser resumido por:

$$
\begin{aligned}
& {[K]\{\dot{u}\}+[C]\{\dot{p}\}=\{\dot{F}\}} \\
& {[H]\{p\}+[L]\{\dot{u}\}=\{q\}}
\end{aligned}
$$

Sendo essas equações apresentadas na forma condensada por:

$[A]\{x\}+[B]\{\dot{x}\}=[Y]$

onde $[A]=\left[\begin{array}{cc}0 & 0 \\ 0 & {[H]}\end{array}\right],[B]=\left[\begin{array}{cc}{[K]} & {[C]} \\ {[L]} & 0\end{array}\right],\{X\}=\left\{\begin{array}{l}\{u\} \\ \{p\}\end{array}\right\}$ e $\{Y\}=\left\{\begin{array}{l}\{F\} \\ \{q\}\end{array}\right\}$

Para resolução do problema de consolidação é necessário realizar a integração no tempo, além da integração no espaço, para obter uma solução estacionária equivalente ao problema transiente. Assim dentro de um intervalo de tempo $\Delta t$, o vetor de incógnitas $\{x\}$ tem variação linear, sendo:

$\{x\}_{t+\alpha \Delta t}=(1-\alpha)\{x\}_{t}+\alpha\{x\}_{t+\Delta t}$

Onde $\alpha$ é o parâmetro que controla o esquema de integração, $\{x\}_{t}$ é o valor do vetor de incógnitas no instante inicial e $\{x\}_{t+\Delta t}$ é o valor do vetor de incógnitas no estágio de tempo a ser calculado. A derivada temporal do vetor de incógnitas é dada por: 


$$
\{\dot{x}\}_{t+\alpha \Delta t}=\frac{\{x\}_{t+\Delta t}-\{x\}_{t}}{\Delta t}
$$

A Equação 4.13 avaliada no instante de tempo $t+\alpha \Delta t$ é expressa por:

$$
[A]_{t+\alpha \Delta t}\{x\}_{t+\alpha \Delta t}+[B]_{t+\alpha \Delta t}\{\dot{x}\}_{t+\alpha \Delta t}=\{Y\}_{t+\alpha \Delta t}
$$

Para obter a solução em termos do incremento do vetor de incógnitas substituem-se as Equações 4.14 e 4.15 em 4.16:

$$
\left[\Delta t \alpha[A]_{t+\alpha \Delta t}+[B]_{t+\alpha \Delta t}\right]\{\Delta x\}=\Delta t\{Y\}_{t+\alpha \Delta t}-[A]_{t}\{x\}_{t}
$$

$$
\begin{aligned}
& \text { Onde }[A]_{t+\alpha \Delta t}=\left[A\left(\{x\}_{t+\alpha \Delta t}\right)\right]=\left[A\left((1-\alpha)\{x\}_{t}+\alpha\{x\}_{t+\Delta t}\right)\right] \\
& {[B]_{t+\alpha \Delta t}=\left[B\left(\{x\}_{t+\alpha \Delta t}\right)\right]=\left[B\left((1-\alpha)\{x\}_{t}+\alpha\{x\}_{t+\Delta t}\right)\right]} \\
& \{Y\}_{t+\alpha \Delta t}=\left[Y\left(\{x\}_{t+\alpha \Delta t}\right)\right]=\left[Y\left((1-\alpha)\{x\}_{t}+\alpha\{x\}_{t+\Delta t}\right)\right]
\end{aligned}
$$

\subsection{DISCRETIZAÇÃO DO XFEM}

No XFEM apenas o campo de deslocamentos é enriquecido (equilíbrio), sendo as funções de enriquecimento acrescentadas nas matrizes da função de forma e nas respectivas derivadas.

Aplicando o XFEM e utilizando as funções de interpolações apresentadas anteriormente podemos reescrever a equação por:

$\int_{\Omega}[\mathrm{B}]^{\mathrm{T}}\{\sigma\} d \Omega=\int_{\Gamma_{\mathrm{t}}}[N]^{T}\{t\} \mathrm{d} \Gamma+\int_{\Omega}[N]^{T}\{b\} d \Omega$

onde $[\mathrm{B}]=\left[\mathrm{B}^{\mathrm{u}}, \mathrm{B}^{\mathrm{a}},\right],[\mathrm{N}]=\left[\mathrm{N}^{\mathrm{u}}, \mathrm{N}^{\mathrm{a}}\right]$, sendo $u$ a forma padrão e a $a$ forma enriquecida, onde o tipo de enriquecimento das matrizes $\mathrm{B}^{\mathrm{a}}$ e $\mathrm{N}^{\mathrm{a}}$ podem ser do tipo Heaviside ou crack tip (funções vistas na Seção 2.7).

Resolvendo a Equação 4.17 da mesma forma que foi resolvida a Equação 4.7, acrescentando as modificações relativas ao XFEM, é obtido um sistema de equações linear discretas em equilíbrio: 
$\left[\begin{array}{ll}K^{u u} & K^{u a} \\ K^{a u} & K^{a a}\end{array}\right]\left\{\begin{array}{l}u \\ a\end{array}\right\}-\left\{\begin{array}{l}F_{u} \\ F_{a}\end{array}\right\}=0$

onde $\{u\}$ é o vetor de graus de liberdade para a forma padrão e $\{a\}$ e para a forma enriquecida e $\left\{F_{u}\right\}$ é o vetor de forças externas padrão e $\left\{F_{a}\right\}$ é o vetor de forças externas enriquecidas. A matriz $\mathrm{K}$ para cada elemento da malha será dado por:

$\left[\begin{array}{ll}K^{u u} & K^{u a} \\ K^{a u} & K^{a a}\end{array}\right]=\left[\begin{array}{ll}\int_{\Omega}\left[\mathrm{B}^{\mathrm{u}}\right]^{T}[D]\left[\mathrm{B}^{\mathrm{u}}\right] d \Omega & \int_{\Omega}\left[\mathrm{B}^{\mathrm{u}}\right]^{T}[D]\left[\mathrm{B}^{\mathrm{a}}\right] d \Omega \\ \int_{\Omega}\left[\mathrm{B}^{\mathrm{a}}\right]^{T}[D]\left[\mathrm{B}^{\mathrm{u}}\right] d \Omega & \int_{\Omega}\left[\mathrm{B}^{\mathrm{a}}\right]^{T}[D]\left[\mathrm{B}^{\mathrm{a}}\right] d \Omega\end{array}\right]$

Além disso, o vetor é $\{F\}$ é dado por:

$\{F\}=\left\{\begin{array}{l}\int_{\Gamma_{\mathrm{t}}}\left[N^{u}\right]^{T}\{t\} \mathrm{d} \Gamma+\int_{\Omega}\left[N^{u}\right]^{T}\{b\} d \Omega \\ \int_{\Gamma_{\mathrm{t}}}\left[N^{a}\right]^{T}\{t\} \mathrm{d} \Gamma+\int_{\Omega}\left[N^{a}\right]^{T}\{b\} d \Omega\end{array}\right\}$

A matriz B das funções de forma é dada por:

$B^{u}=\left[\begin{array}{cc}\left(N_{i}\right)_{, x} & 0 \\ 0 & \left(N_{i}\right)_{, y} \\ \left(N_{i}\right)_{, y} & \left(N_{i}\right)_{, x}\end{array}\right]$

$B^{a}=\left[\begin{array}{cc}\left(H N_{i}\right)_{, x} & 0 \\ 0 & \left(H N_{i}\right)_{, y} \\ \left(H N_{i}\right)_{, y} & \left(H N_{i}\right)_{, x}\end{array}\right]$

$B^{a}=\left[\begin{array}{cc}\left(F_{\alpha} N_{i}\right)_{, x} & 0 \\ 0 & \left(F_{\alpha} N_{i}\right)_{, y} \\ \left(F_{\alpha} N_{i}\right)_{, y} & \left(F_{\alpha} N_{i}\right)_{, x}\end{array}\right] \operatorname{com} \alpha=1,2,3$ e 4 
$N^{u}=\left[\begin{array}{l}N_{i} \\ N_{i}\end{array}\right]$

$N^{a}=\left[\begin{array}{lll}N_{i} & N_{i} & H \\ N_{i} & N_{i} & H\end{array}\right]$

$N^{a}=\left[\begin{array}{lll}N_{i} & N_{i} & F_{\alpha} \\ N_{i} & N_{i} & F_{\alpha}\end{array}\right] \operatorname{com} \alpha=1,2,3$ e 4

\subsubsection{TRANSFORMAÇÃO DAS COORDENADAS POLARES EM CARTESIANAS - FUNÇÃO CRACK TIP}

As derivadas das funções de forma crack tip com relação às coordenadas globais são dadas por:

$\frac{d F}{d X}=\frac{\partial F}{\partial r} \frac{\partial r}{\partial X}+\frac{\partial F}{\partial \theta} \frac{\partial \theta}{\partial X}$

$\frac{d F}{d Y}=\frac{\partial F}{\partial r} \frac{\partial r}{\partial Y}+\frac{\partial F}{\partial \theta} \frac{\partial \theta}{\partial Y}$

A função crack tip é definida em função de coordenadas polares. Desta forma, é necessário apresentar uma série de derivadas intermediárias que permitam realizar os cálculos das derivadas necessárias. As derivadas das funções de enriquecimento crack tip em relação ao sistema de coordenadas polares locais são dadas por:

$\frac{\partial F_{1}}{\partial r}=\frac{1}{2 \sqrt{r}} \cos \frac{\theta}{2}$

$\frac{\partial F_{2}}{\partial r}=\frac{1}{2 \sqrt{r}} \sin \frac{\theta}{2}$

$\frac{\partial F_{3}}{\partial r}=\frac{1}{2 \sqrt{r}} \sin \frac{\theta}{2} \sin \theta$ 


$$
\frac{\partial F_{4}}{\partial r}=\frac{1}{2 \sqrt{r}} \cos \frac{\theta}{2} \sin \theta
$$

$$
\frac{\partial F_{1}}{\partial \theta}=\frac{\sqrt{r}}{2} \sin \frac{\theta}{2}
$$

$$
\frac{\partial F_{2}}{\partial \theta}=\frac{\sqrt{r}}{2} \cos \frac{\theta}{2}
$$

$$
\begin{aligned}
& \frac{\partial F_{3}}{\partial \theta}=\frac{1}{2 \sqrt{r}}\left(\sin \frac{\theta}{2}+\sin \frac{3 \theta}{2} \cos \theta\right) \\
& \frac{\partial F_{4}}{\partial \theta}=\frac{1}{2 \sqrt{r}}\left(\cos \frac{\theta}{2}+\cos \frac{3 \theta}{2} \cos \theta\right)
\end{aligned}
$$




\section{IMPLEMENTAÇÃO E VALIDAÇÃO DO CÓDIGO}

O código implementado foi baseado no código apresentado por Farias (1993) e Cordão Neto (2005), acrescentando à formulação acoplada de equilíbrio e fluxo a formulação do Método dos Elementos Finitos Estendido (XFEM). Além disso, o código foi desenvolvido para testar alguns algoritmos como o algoritmo de crescimento de fratura e o algoritmo de integração da função J.

Para escrever o código foi utilizada a linguagem de programação FORTRAN por ela ser simples e permitir a implementação de malhas mais robustas do que outras ferramentas, como, por exemplo, o MATLAB. O código, entretanto, foi limitado a 20.000 elementos devido a limitações do compilador.

Na Figura 5.1 é possível observar a estrutura geral do código implementado. Cada retângulo corresponde a uma função responsável por uma tarefa específica. As funções em preto circundadas em vermelho correspondem às funções já existentes que foram modificadas quando se acrescentou o XFEM. As funções em vermelho correspondem as funções que foram criadas para implementar o XFEM. Além disso, é possível observar a estrutura de repetição dos estágios de carregamentos, sendo essas condições de contorno naturais ou essenciais para as equações de equilíbrio e de fluxo.

Para a montagem da malha do problema e visualização dos resultados foi utilizado o software GID 12.0. O GID (http://www.gidhome.com) é um pré e pós-processador desenvolvido para visualização de simulações numéricas. Com ele é possível modelar geometricamente o problema, definir os dados da análise, transferir dados para software e visualizar os resultados numéricos. Ele pode ser utilizado principalmente para problemas de dinâmica de fluidos, geomecânica, eletromagnetismo, transferência de calor, nos quais são utilizados elementos finitos, volumes finitos, elementos de contorno, diferenças finitas, elementos discretos, entre outros. Na Figura 5.2 pode-se visualizar a abertura de uma fratura pelo software GID.

\subsection{DESCRIÇÃO DAS FUNÇÕES}

As funções implementadas no código, presentes no fluxograma da Figura 5.1, serão descritas para compreensão da finalidade de cada uma delas.

- INPUTDATA- Leitura no arquivo das principais características do problema como o número de nós, número de elementos, número de materiais, tipo de elemento, ordem, tempo e análise. 


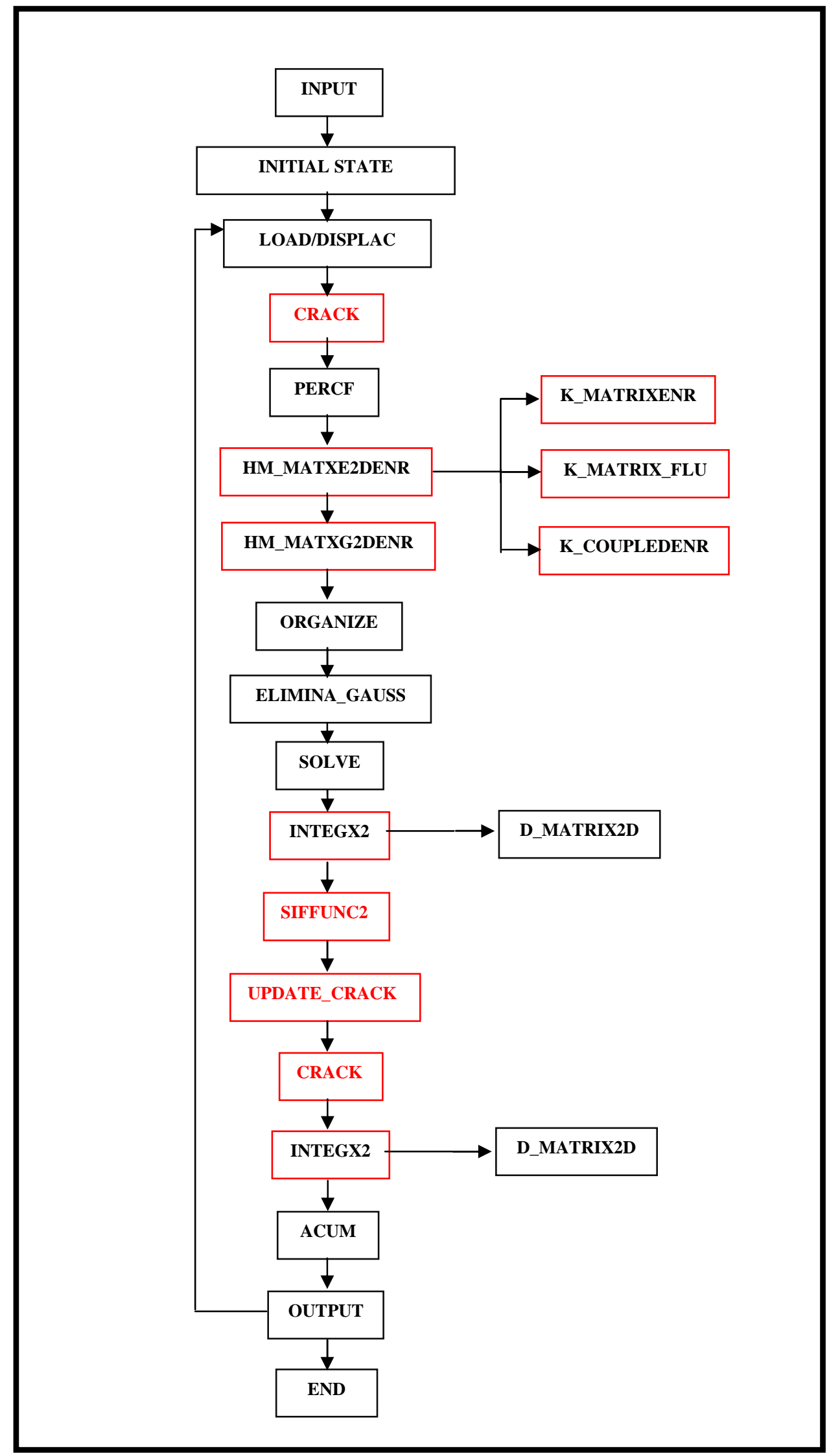

Figura 5.1 Fluxograma do código de XFEM 


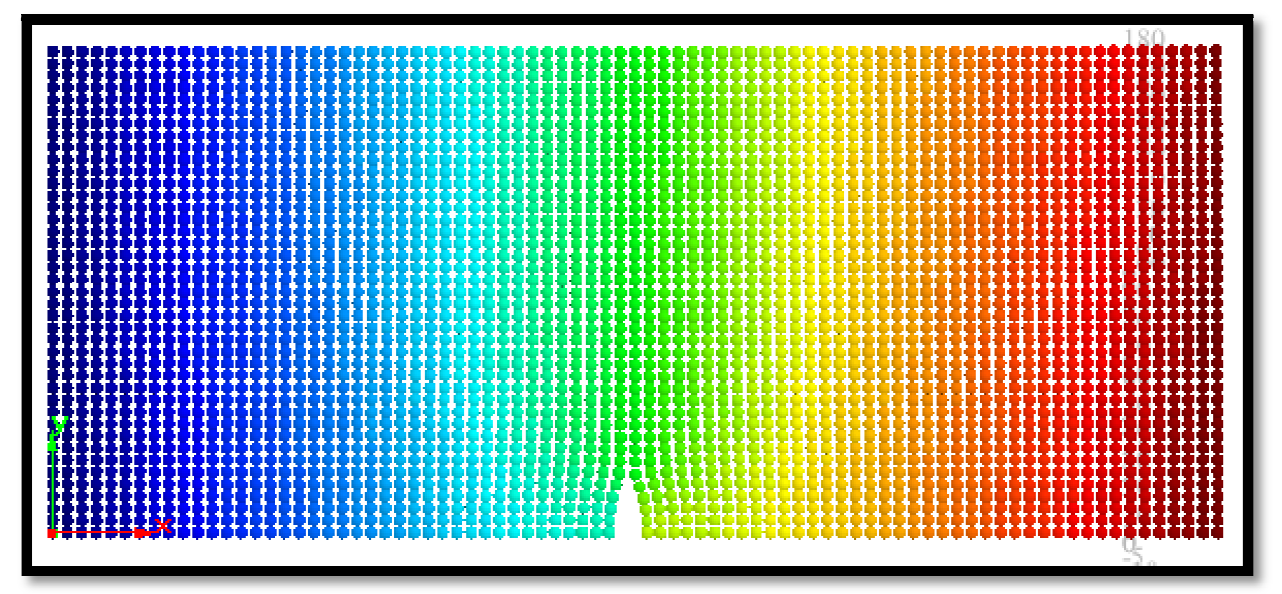

Figura 5.2 Exemplo software GID

- INITIAL_STATE- Responsável, quando necessário, pela leitura do estado de tensões inicial do solo e poropressão inicial.

- $\quad$ LOAD/DISPLAC- Leitura dos carregamentos do problema.

- $\quad$ CRACK- Leitura das coordenadas da fratura, e localização dos elementos que serão enriquecidos.

- $\quad$ PERCF- Cálculo das forças de percolação do problema.

- HM_MATXE2DENR- Montagem das matrizes de cada elemento, podendo ele ser enriquecido ou não, utilizando o XFEM na construção das matrizes.

- $\quad$ HM_MATXG2DENR- Montagem da matriz global padrão e enriquecida.

- $\quad$ ORGANIZE- Organização das equações do problema.

- $\quad$ ELIMINA_GAUSS- Eliminação de gauss para a resolução do problema.

- $\quad$ SOLVER- Resolução do sistema de equações do problema.

- INTEGX2- Cálculo das deformações, tensões e poropressões correspondentes aos deslocamentos do problema e as forças internas.

- $\quad$ SIFFUNC- Cálculo do SIF e a integral J do problema.

- ACUM- Armazenamento e acúmulo dos valores das tensões e deformações calculadas.

- D_MATRIX2D- Contém a matriz da relação constitutiva do problema. Foi implementada apenas a relação linear elástica.

- $\quad$ OUTPUT- Impressão dos resultados.

\subsection{VALIDAÇÃO DO CÓDIGO}

Foram realizadas dois grupos de validações para o código. Primeiramente foram feitos dois exemplos, os mesmo utilizados por Cordão Neto (2005), para verificar a correta a implementação da formulação de fluxo e de equilíbrio 2D: o adensamento unidimensional de Terzaghi (Figura 5.3) e um problema de deformação plana (Figura 5.4) cuja solução é apresentada por Biot. Em uma segunda etapa foram realizados alguns exemplos da literatura 
para verificar a correta implementação da formulação do XFEM em 2D.

\subsubsection{VALIDAÇÃO DA FORMULAÇÃO DE FLUXO E EQUILÍBRIO 2D}

As validações realizadas têm como objetivo comprovar a eficácia do código para resolver problemas bidimensionais de consolidação na condição saturada. Os resultados foram comparados com soluções analíticas dos problemas. Primeiramente foi realizada a validação da formulação Hidromecânica, pois apesar de já existir um código de elementos finitos acoplado na Universidade de Brasília, o código de Elementos Finitos foi reescrito sendo necessário fazer a validação da formulação. O primeiro problema analisado foi o adensamento unidimensional de Terzaghi (Figura 5.3).

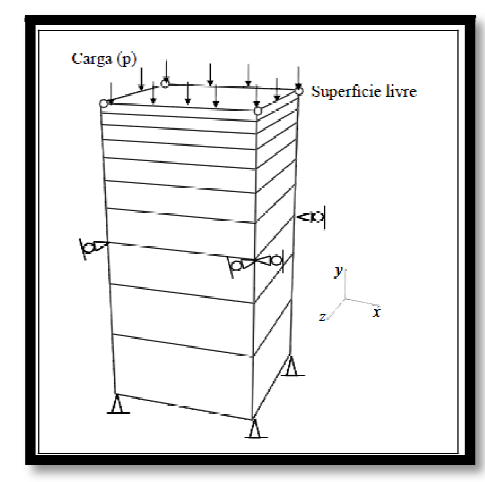

Figura 5.3 Problema Terzaghi (Cordão Neto, 2005)

Uma coluna de solo de $1 \mathrm{~m}$, confinado lateralmente é submetida a um carregamento distribuído p em sua superfície livre, no primeiro estágio de tempo. A superfície livre é a região superior da coluna de solo. As condições de contorno aplicadas tornaram o problema semelhante a condição 1D. A malha utilizada continha dez elementos quadriláteros de quatro nós.

Para a resolução do problema tem-se que: o tempo normalizado T é dado por $T=\frac{c_{v} t}{h_{d}^{2}}$, onde $c_{v}$ é o coeficiente de adensamento, $h_{d}$ é a altura de drenagem e t é o tempo real. O módulo adotado foi de $25.000 \mathrm{MPa}$ e o Poisson 0,3. Além disso, a permeabilidade do meio é de $1.10^{-6} \mathrm{~m} / \mathrm{s}$.

Na Figura 5.4 é possível observar que os resultados obtidos pela análise numérica são condizentes com a resolução analítica do problema. 


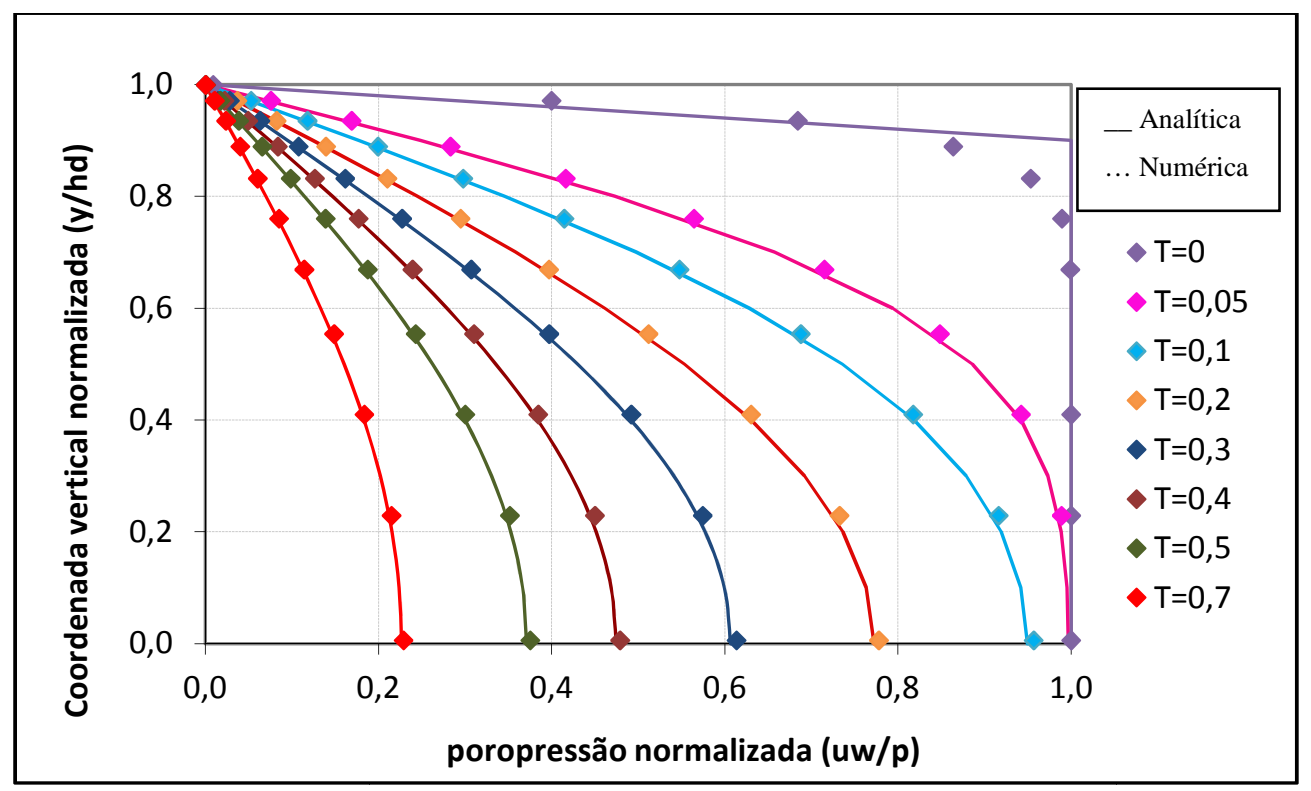

Figura 5.4 Resultado da validação realizada utilizando o problema de Terzaghi

A segunda validação realizada é um problema de deformação plana em que uma camada infinita de argila é submetida a um carregamento distribuído de uma sapata em sua superfície (Figura 5.5). A argila se encontra na condição saturada. A malha utilizada continha 200 elementos quadriláteros de quatro nós. A solução obtida foi compara a solução analítica obtida em Biot (1940).

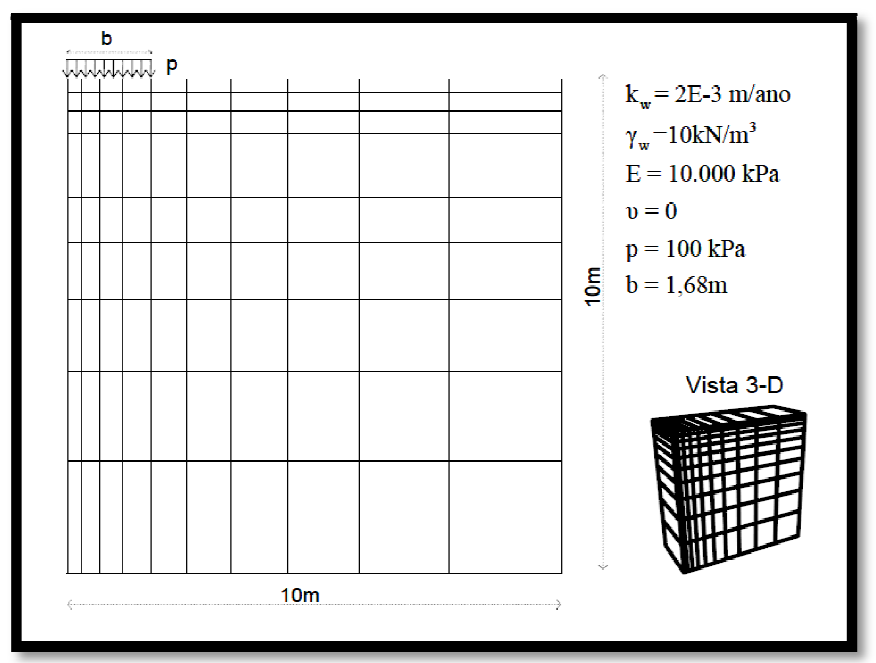

Figura 5.5 Malha e propriedades do problema de consolidação de deformação plana, vista no plano x-y. (Cordão Neto,2005)

No exemplo w é o deslocamento superficial devido a carga p, 1 é a largura total do carregamento aplicado, 1 é a largura total do carregamento aplicado sendo igual a $2 \mathrm{~b}, \mathrm{t}$ é o 
tempo e $\mathrm{w}_{\text {inf }}=\mathrm{apl} /(4 \sqrt{\pi}), \mathrm{c}_{\mathrm{v}}$ é o coeficiente de compressibilidade, a é dado por:

$$
a=\frac{(1+v)(1-2 v)}{E(1-v)}
$$

Onde $E$ é o Módulo de Young e $v$ é o coeficiente de Poisson.

O deslocamento normalizado é dado por:

$d=\frac{w}{w_{\text {inf }}}$

$\mathrm{O}$ fator T é dado por:

$T=\frac{\sqrt{c_{v} t}}{l}$

Na Figura 5.6 é observada a comparação entre o resultado analítico e o resultado numérico obtido. Os resultados obtidos foram satisfatórios em relação à solução analítica. Algumas diferenças observadas podem ocorrer devido a discretização do domínio. Além disso, no exemplo numérico o domínio é finito enquanto no exemplo analítico é de um espaço semi-finito.

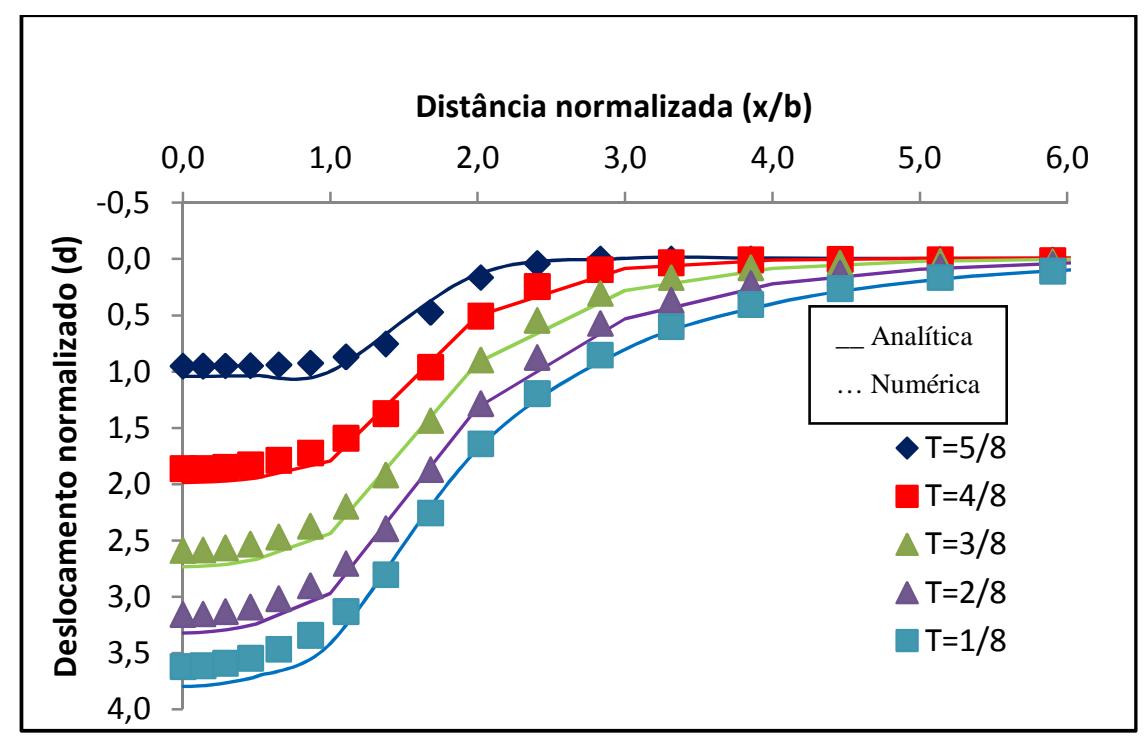

Figura 5.6 Resultados da validação utilizando o problema de deformação plana de Biot 


\subsubsection{VALIDAÇÃO DA IMPLEMENTAÇÃO DO MÉTODO DOS ELEMENTOS FINITOS ESTENDIDO (XFEM)}

Para a validação da implementação do X-FEM no código de elementos finitos foram realizados alguns exemplos que possuem solução na literatura.

O primeiro exemplo realizado é de uma viga bi-apoiada com carga pontual aplicada (Figura 5.7). Esse problema possui solução analítica na literatura (Bower, 2011) sendo o $\mathrm{K}_{\mathrm{I}}$ determinado a partir da geometria do problema e configuração da carga aplicada. É aplicada uma carga $\mathrm{P}$ central em uma viga de comprimento $\mathrm{S}$, largura $\mathrm{W}$, espessura $\mathrm{B}$ e o comprimento da fratura é $a$. As dimensões utilizadas para a resolução do problema para a vigas são $S=4 \mathrm{w}$ e $\mathrm{B}=1$. A solução analítica para o fator de intensidade de tensões $\mathrm{K}_{\mathrm{I}}$ é dado por:

$K_{I}=\frac{4 P}{B} \sqrt{\frac{\pi}{W}}\left[1,6\left(\frac{a}{W}\right)^{1 / 2}-2,6\left(\frac{a}{W}\right)^{3 / 2}+12,3\left(\frac{a}{W}\right)^{5 / 2}-21,2\left(\frac{a}{W}\right)^{7 / 2}+21,8\left(\frac{a}{W}\right)^{9 / 2}\right]$

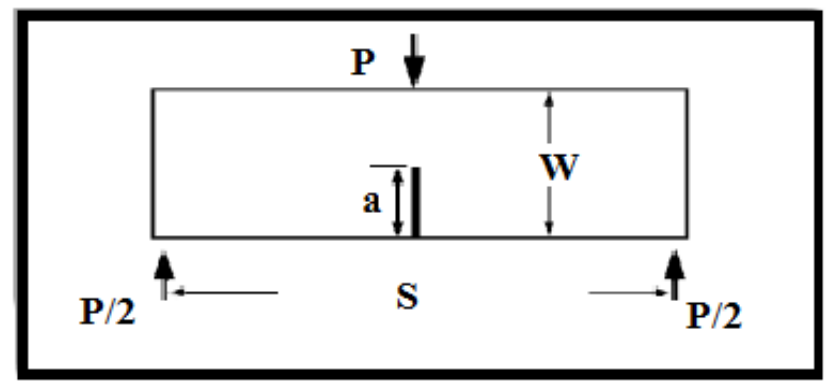

Figura 5.7 Viga Bi-apoiada

Utilizando uma malha com 1785 elementos, sendo os elementos quadriláteros com quatro nós (Figura 5.8) pode-se observar os resultados obtidos para o campo de tensão e deslocamento (Figuras 5.8 e 5.9) e os resultados obtidos para o valor de $\mathrm{K}_{\mathrm{I}}$, com um raio da Integral $\mathbf{J}$ de 0,4 , na Tabela 2. Foi utilizada a função Heaviside nos elementos cortados pela fratura e a função crack tip no elemento da ponta da fratura.

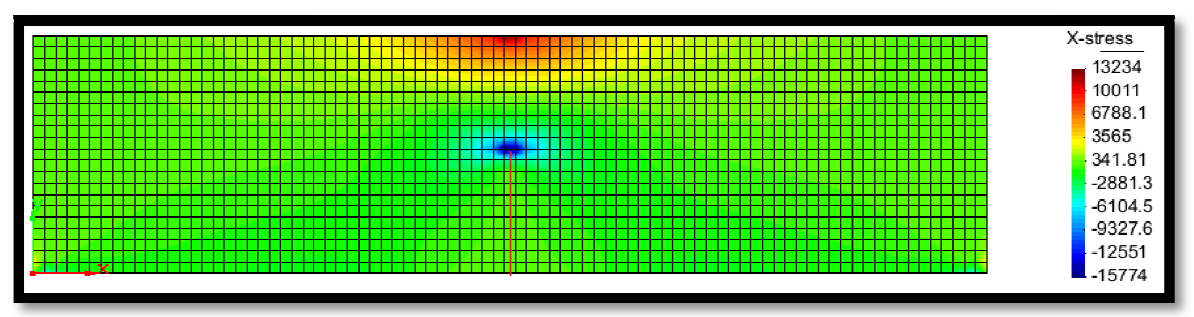

Figura 5.8 Malha do problema e campo de distribuição de tensões da validação realizada )

$$
\sigma(\mathrm{MPa})
$$




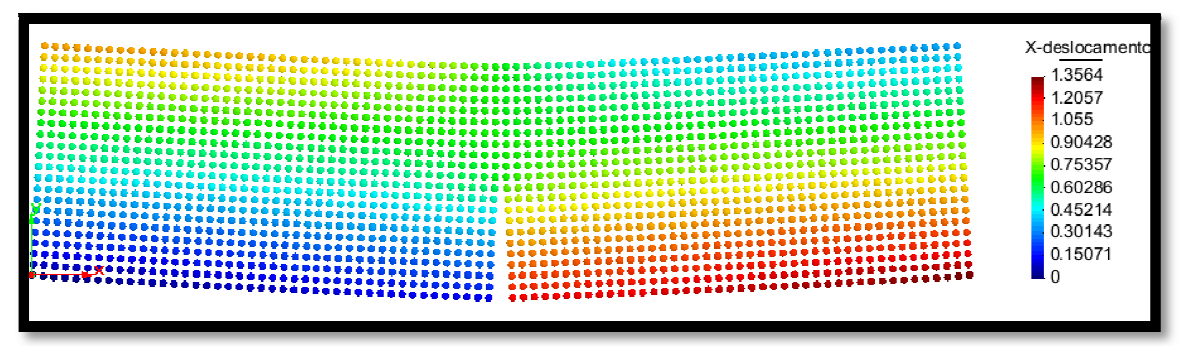

Figura 5.9 Campo de distribuição de deslocamentos da validação realizada $\delta(\mathrm{m})$

Tabela 2-Resultados obtidos Viga Bi-apoiada

\begin{tabular}{|l|l|}
\hline Tipo de análise & Valor de KI \\
\hline Solução analítica & 7400 \\
\hline XFEM (Morais, 2016) & 7380 \\
\hline
\end{tabular}

O segundo exemplo utilizado para a validação da implementação do XFEM foi de uma viga em estado de deformação plana fraturada (Figura 5.10) estudada por Khoei (2015). A viga é fixa em um lado e são aplicados deslocamentos prescritos na outra extremidade da viga de $\mathrm{u}=0,5 \mathrm{~mm}$. A fratura tem um comprimento de $30 \mathrm{~cm}$ e é localiza no meio da viga, sendo que ela está submetida apenas ao modo I de fraturamento. $\mathrm{E}=2.10^{6} \mathrm{Kg} / \mathrm{cm}^{2}$ e poisson é 0,3 .

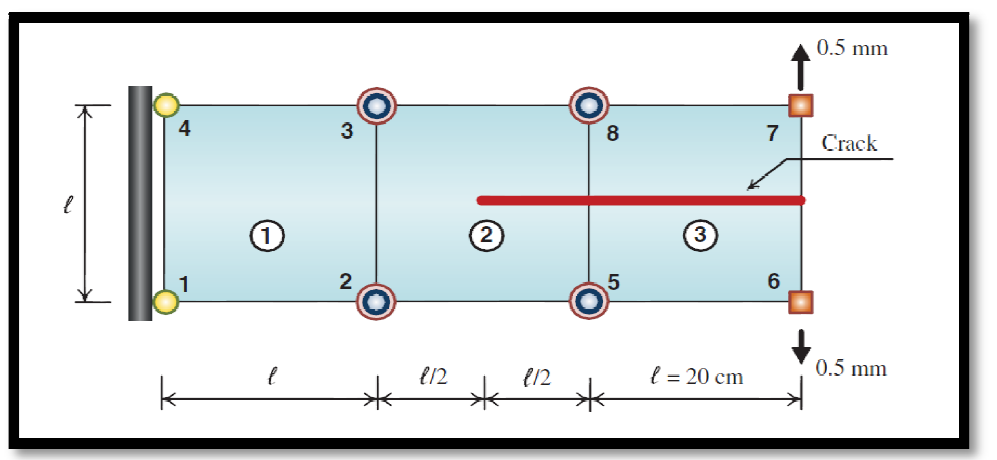

Figura 5.10 Viga em estado de deformação plana fraturada (Khoei,2015)

As malhas utilizadas para o problema são: de 45x15, de 75x25 e de 135x45 (Figura 5.11), com elementos quadriláteros de quatro nós. Foi aplicado ao longo dos elementos cortados pela fratura o enriquecimento com a função Heaviside e, onde está a ponta da fratura, o elemento foi enriquecido com a função crack tip. 


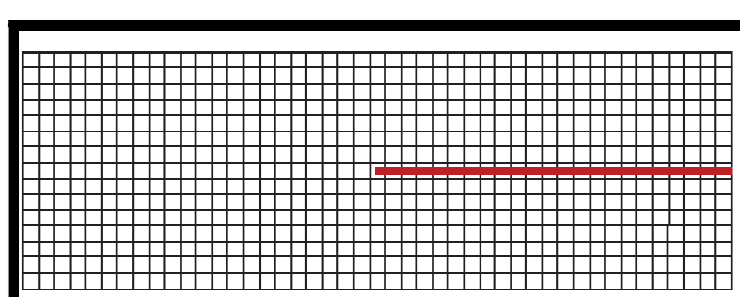

$\mathrm{X}$-FEM mesh $45 \times 15$

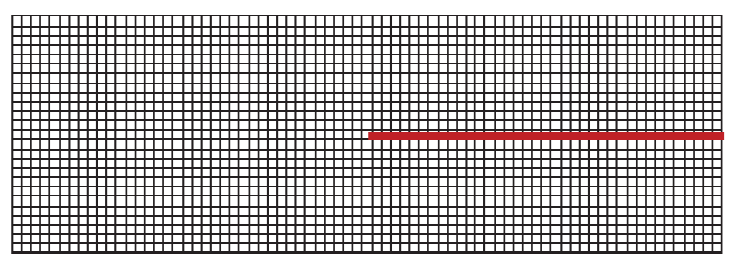

X-FEM mesh $75 \times 25$

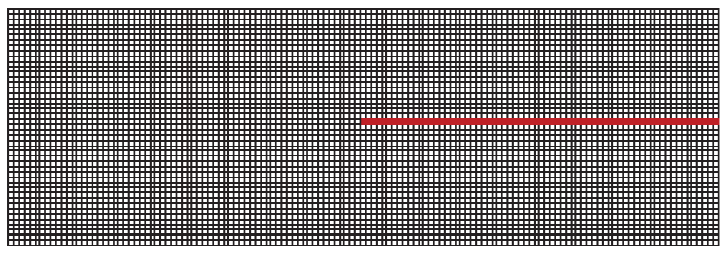

X-FEM mesh $135 \times 45$

Figura 5.11 Malhas utilizadas para simulação do problema (Khoei,2015)

É possível observar nas Figuras 5.13 que os resultados obtidos com o código implementado são similares aos resultados de Khoei (2015) tanto em termos de valores, como em termos de distribuição do campo de tensões. Os valores dos campos de tensão da Figura 5.13 (a) e da Figura 5.13(b) encontram-se com sinais diferentes pelo fato de o código implementado utilizar a notação geotécnica com tração tendo o sinal negativo e compressão positivo. Os resultados mostrados na Figura 5.13 possuem apenas valor ilustrativo.

Além disso, foi realizado um teste para observar a influência do raio de integração da Integral J no cálculo do SIF. Foram realizados algum teste variando-se o raio de integração da integral J e observado como a razão R/L, sendo L o tamanho do elemento, se relaciona com o valor do SIF obtido. A Figura 5.12 mostra esquematicamente o que foi feito.

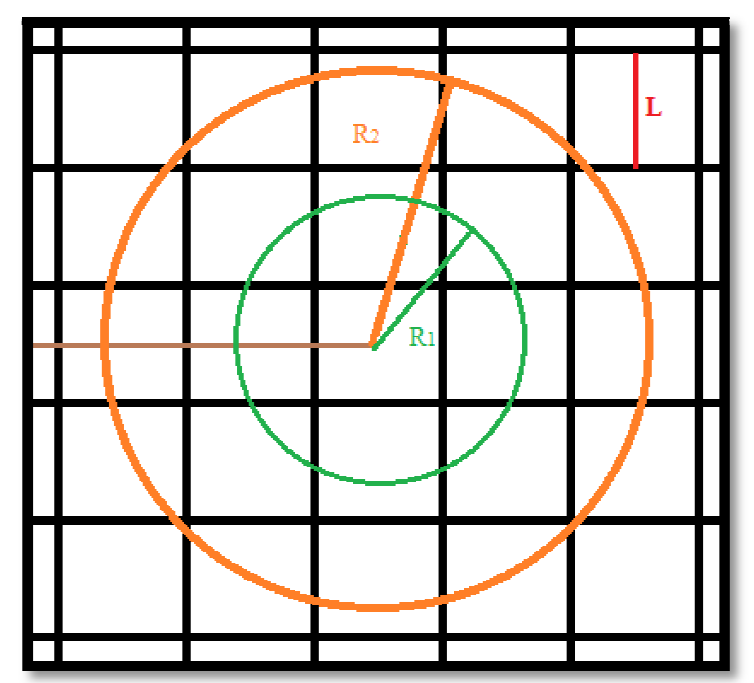

Figura 5.12 Esquema da variação do raio de integração da integral J no cálculo do SIF 
Foram utilizados para isso as três malhas apresentadas na Figura 5.11 e os resultados foram comparados com os obtidos por Khoei (2015). É possível observar nos resultados (Figuras 5.14, 5.15 e 5.16) que a partir de um raio de integração igual a três vezes o tamanho do elemento da malha (sendo L o comprimento do elemento da malha e R o comprimento do raio de integração) ocorre uma estabilização do valor da SIF e abaixo de três ocorre a influência do raio no cálculo do SIF, devendo, portanto, ser evitado. Além disso, quanto mais refinada a malha, os valores obtidos para a SIF ficaram mais próximos dos resultados de Khoei (2015).

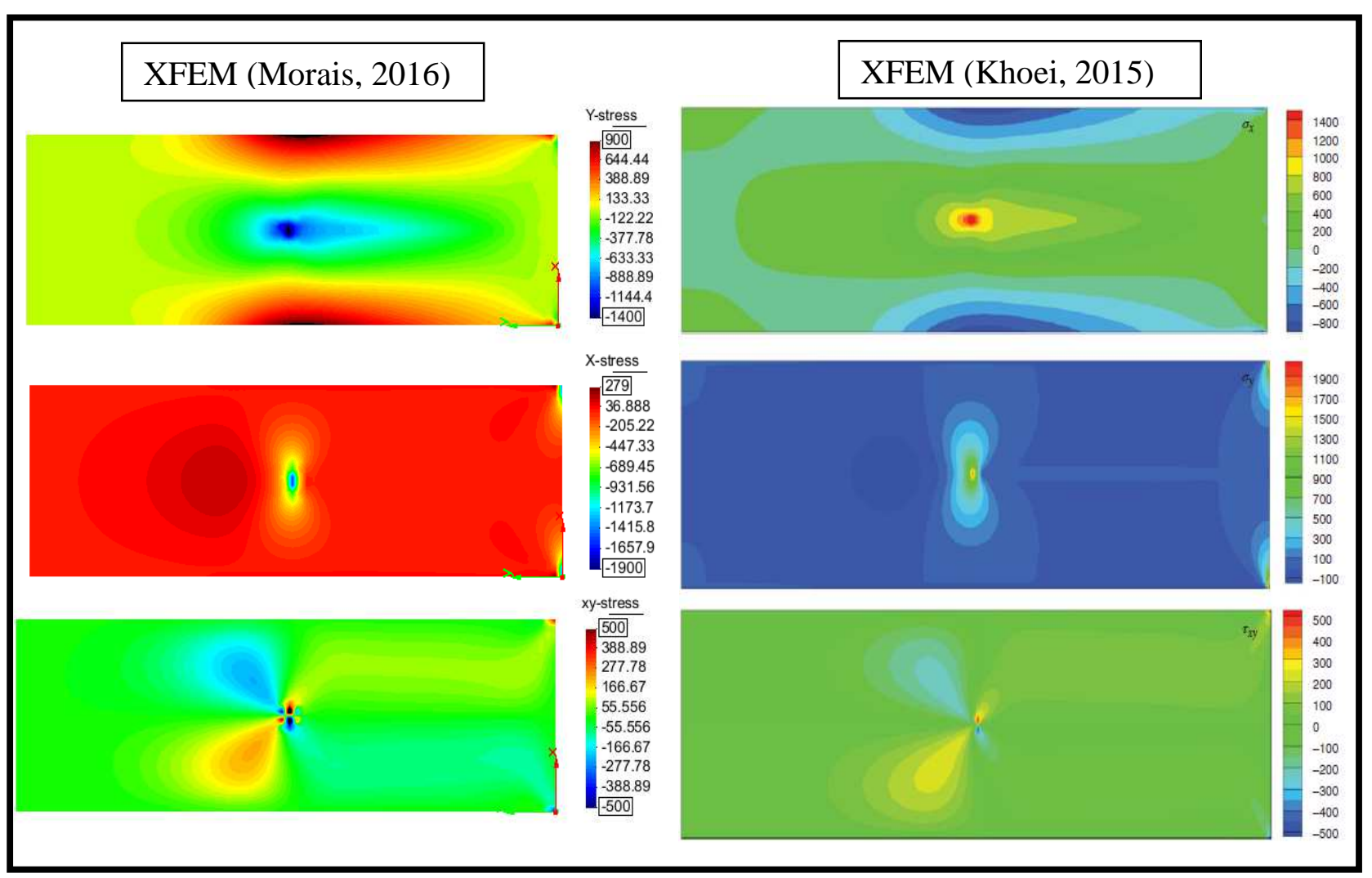

Figura 5.13 Comparação resultados dos campos de tensão obtidos (a)XFEM (Morais,2016) com (b) XFEM (Khoei, 2015) $\sigma\left(\mathrm{Kg} / \mathrm{cm}^{2}\right)$

Por último foi realizada a validação do código utilizando o problema estudado no trabalho de Tuan e Fei (2014). Uma placa retangular com uma fratura no centro é submetida a uma tensão (Figura 5.17). Foram comparados os valores obtidos para o SIF para diferentes tamanhos de fratura e diferentes cargas aplicadas com os resultados obtidos por Tuan e Fei (2014) utilizando EFG (Element Free Galerkin Method) e com a solução analítica do problema. O comprimento da fratura é de $2 \mathrm{a}=40 \mathrm{~cm}$, o comprimento da placa é de $\mathrm{H}=350 \mathrm{~cm}$, 
a largura da placa é de $b=175 \mathrm{~cm}$, o módulo é de $E=2 \cdot 10^{7} \mathrm{~N} / \mathrm{cm}^{2}$ e Poisson é 0,3 . Além disso, a rigidez da fratura é de $\mathrm{K}_{\mathrm{Ic}}=140 \mathrm{~N} / \mathrm{cm}^{3 / 2}$.

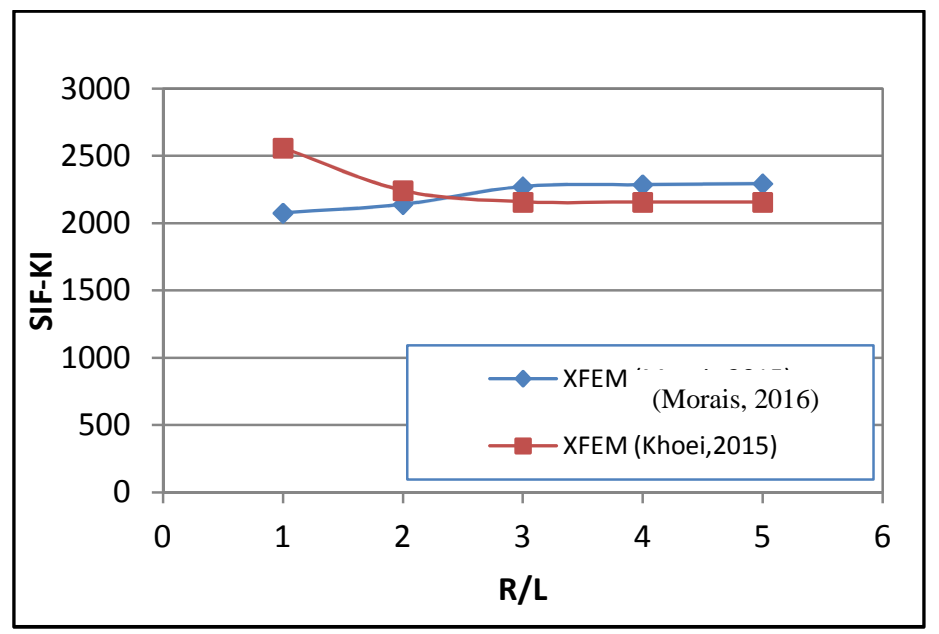

Figura 5.14 Avaliação da influência da razão R/L no calculo da SIF (Malha 15x45)

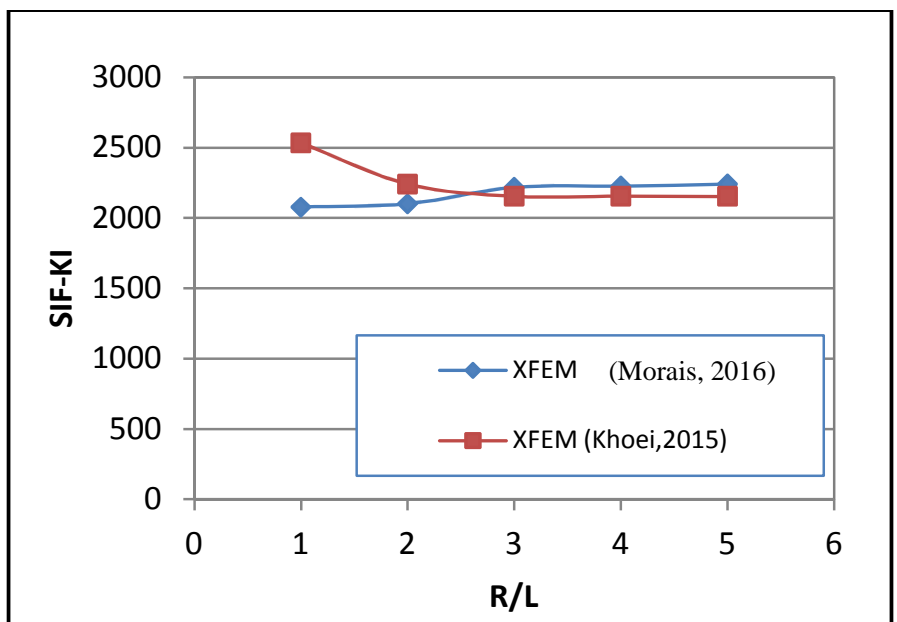

Figura 5.15 Avaliação da influência da razão R/L no calculo da SIF (Malha 25x45)

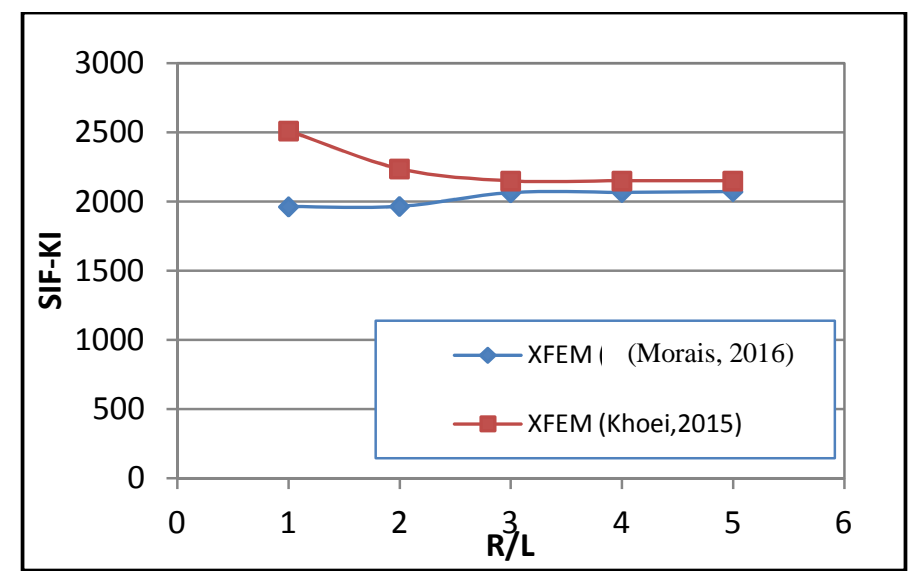

Figura 5.16 Avaliação da influência da razão R/L no calculo da SIF (Malha 45x135) 


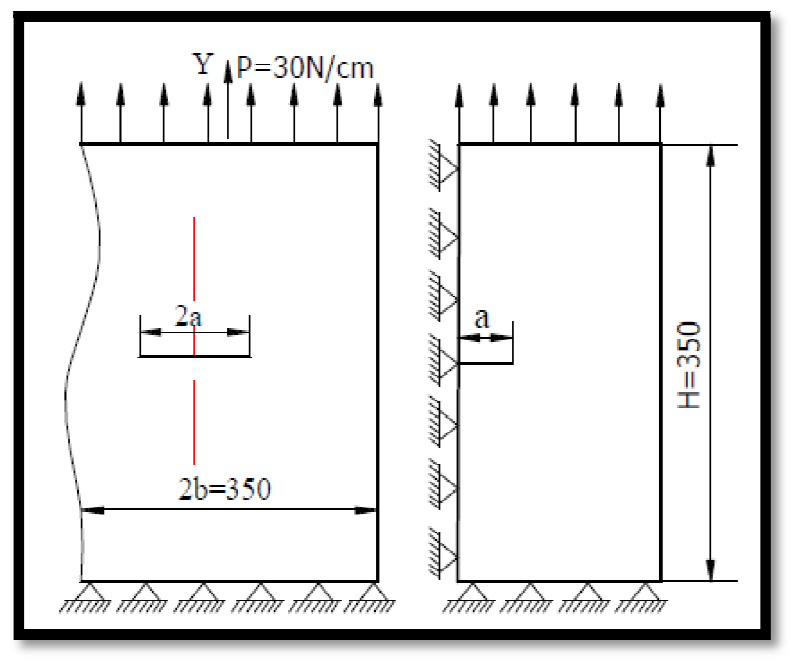

Figura 5.17 Placa retangular fraturada (Tuan et al., 2014)

O SIF teórico é obtido a partir da seguinte função:

$K_{\text {teórico }}=\sigma \sqrt{\pi a} F_{1}\left(\frac{a}{b}\right)$

A função F é dada por:

$$
F_{1}\left(\frac{a}{b}\right)=\left[1-0,025(a / b)^{2}+0,06(a / b)^{4}\right] \sqrt{\sec \frac{\pi a}{2 b}}
$$

O erro foi calculado com referência ao valor teórico da SIF, sendo:

$\operatorname{Error}(\%)=\frac{k_{c a l}-k_{t e o}}{k_{c a l}} \times 100 \%$

sendo os SIF calculados pelo código desenvolvido neste trabalho e por Tuan e Fei (2014).

São apresentados os gráficos obtidos variando o comprimento da fratura na Figura $5.18(a=5,10,20,30,40$ e 50) e variando a tensão aplicada na Figura 5.19 e Figura 5.20 ( $q=5,10,20,30,40$ e 50). É possível observar que os dois primeiros pontos do resultado obtido na Figura 5.18, quando se variou o comprimento da fratura, apresentam grandes erros. Isso pode ser explicado, pois devido a fratura possuir um pequeno comprimento, não há espaço para aplicar uma relação entre o raio de integração e o tamanho do elemento maior que três para obter o valor da SIF, o que geraria resultados mais acurados como foi visto na validação anterior. 
Realizando o teste da variação da carga para duas malhas (30x60 e 40x80) observa-se que quanto mais refinada a malha, mais próximos os resultados são da resposta teórica.

Observando os resultados obtidos conclui-se que estes foram satisfatórios, pois os resultados situaram-se com um erro menor de $2 \%$ se comparados com o teórico.

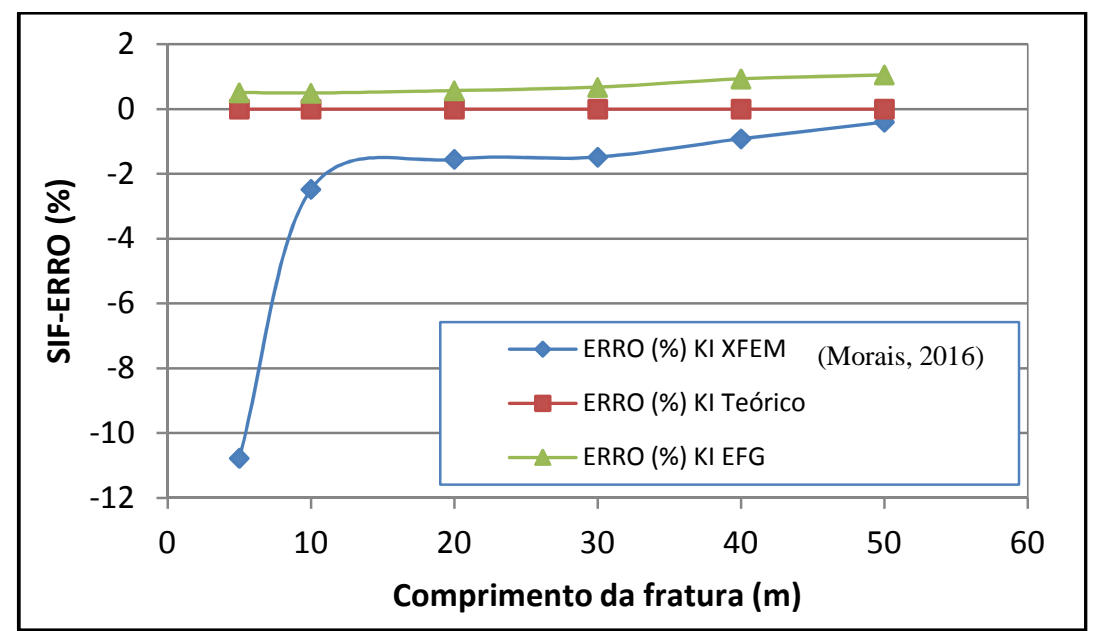

Figura 5.18 Avaliação da relação entre o comprimento da fratura e o erro da SIF (Malha 40x80)

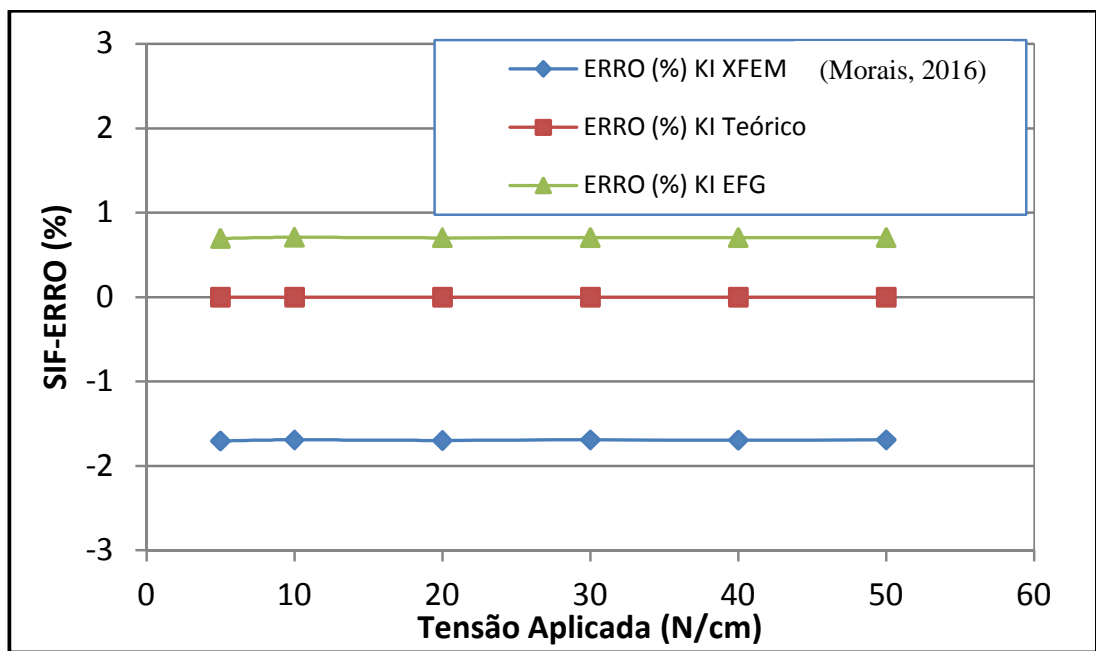

Figura 5.19 Avaliação da relação entre a tensão aplicada e o erro da SIF (Malha 30x60) 


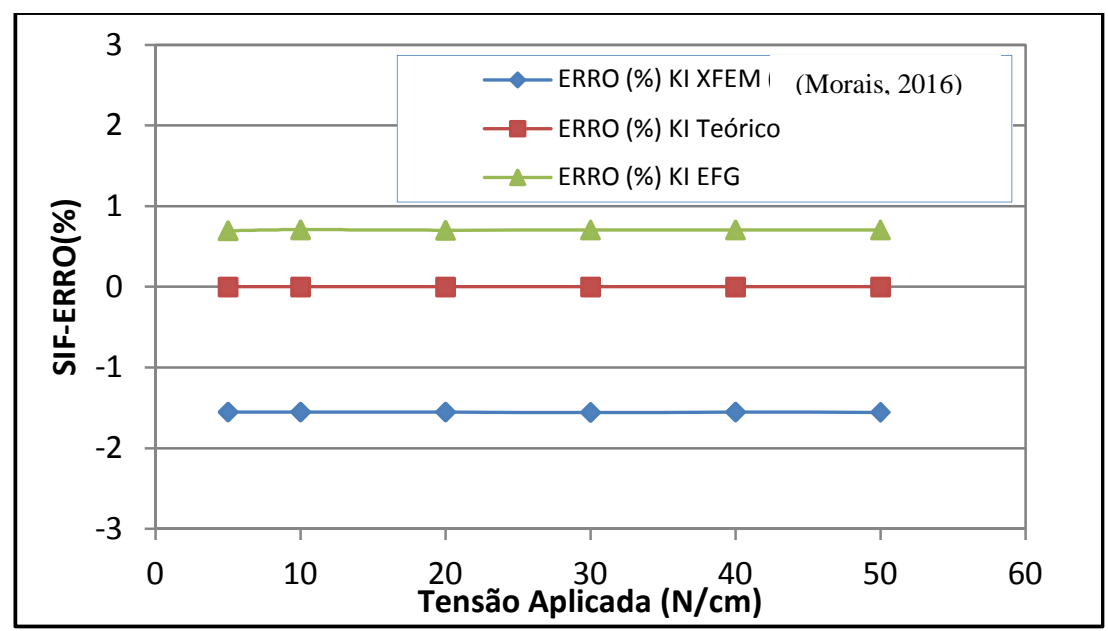

Figura 5.20 Avaliação da relação entre a tensão aplicada e o erro da SIF (Malha 40x80) 


\section{SIMULAÇÃO DE FRATURAMENTO HIDRÁULICO (INJEÇÃO DE FLUIDO PRESSURIZADO PARA FRATURAR O MEIO)}

Após validação do código foram realizadas algumas simulações simplificadas com o objetivo de observar a técnica do fraturamento hidráulico. Para simular o fraturamento hidráulico, injetou-se um fluido em um meio elástico, linear e homogêneo para gerar a propagação de uma fratura. O fluido foi injetado aplicando vazão nos nós da malha, sendo que o regime de fluxo dentro da fratura segue a lei de Darcy. Comparando com a formulação apresentada no PKN, observa-se que isso é uma simplificação, uma vez que no PKN o regime de fluxo dentro da fratura segue uma lei não Darcyniana.

A malha utilizada pode ser observada na Figura 6.1, sendo a malha de 30x60, com elementos quadriláteros de quatro nós. O objetivo da simulação é observar a propagação da fratura, sob diferentes condições. A vazão injetada foi de $2 \times 10^{-5} \mathrm{~m}^{3} / \mathrm{s}$, o Poisson é 0,3 , o módulo de Young é $2 \mathrm{MPa}$, o $\mathrm{K}_{\mathrm{Ic}}$ de $140 K P a \cdot m^{\frac{1}{2}}$.

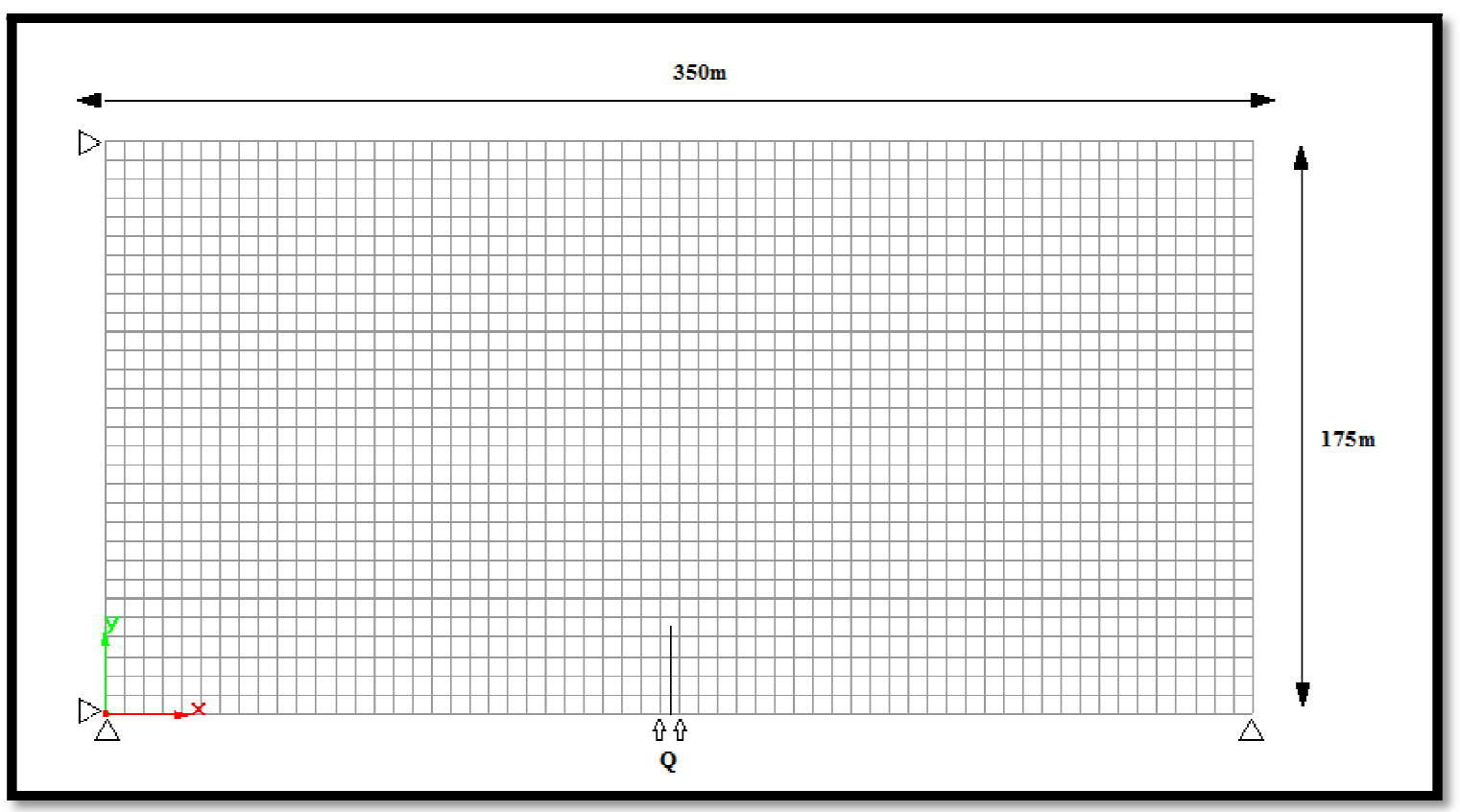

Figura 6.1 Malha utilizada para realização da simulação do Fraturamento Hidráulico

Na Figura 6.2 é observado o processo de fraturamento do meio. A fratura irá crescer a medida que o fluido é injetado. Alguns aspectos foram observados durante as simulações como: a influência da permeabilidade do meio e a permeabilidade da fratura no processo de fraturamento, a influência da permeabilidade do meio e da fratura na dissipação da 
poropressão no interior da fratura, a perda de fluido de fraturamento para a formação.

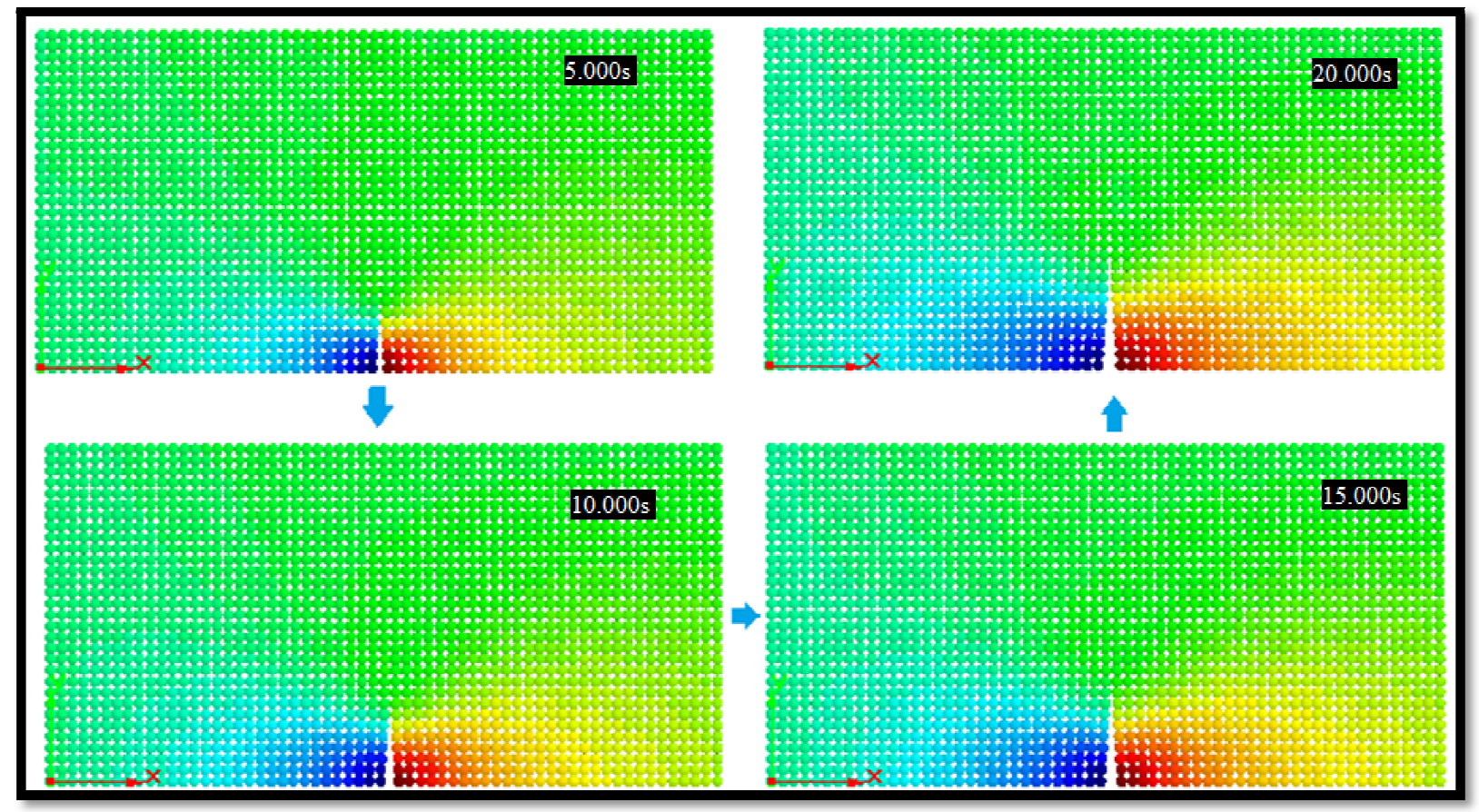

Figura 6.2 Abertura da fratura com o tempo, em meio com permeabilidade de $10^{-8} \mathrm{~m} / \mathrm{s}$, com a injeção de um fluido

Devido a impossibilidade de definir a permeabilidade dentro da fratura, foi adicionado um fator de multiplicação na permeabilidade do meio para os elementos cortados pela fratura, diferenciando a permeabilidade da fratura do meio em que ela se encontra. As primeiras simulações realizadas foram com a permeabilidade da fratura $100 \mathrm{x}$ maior que a permeabilidade do meio. Na Figura 6.3 observa-se o campo de poropressão no meio de permeabilidade de $10^{-5} \mathrm{~m} / \mathrm{s}, 10^{-6} \mathrm{~m} / \mathrm{s}, 10^{-7} \mathrm{~m} / \mathrm{s}$ e $10^{-8} \mathrm{~m} / \mathrm{s}$ após $20000 \mathrm{~s}$. No meio de permeabilidade de $10^{-5} \mathrm{~m} / \mathrm{s}$ ocorre a dissipação da poropressão, e devido as condições de contorno aplicadas e ao tempo decorrido ocorre a estabilização do campo de poropressões, ou seja, atinge-se o regime estacionário, conforme pode ser observado na Figura 6.5 onde o comprimento da fatura fica estável com o tempo. Para o mesmo intervalo de tempo e condições de contorno, isso não foi observado para os exemplos com permeabilidades maiores.

Diversos testes foram realizados, sendo que o primeiro visa testar a influência do tamanho do tempo na simulação. Esse teste se faz necessário devido ao fato de não ser utilizado nenhuma algoritmo especial para tratar a não linearidade existente no problema. 


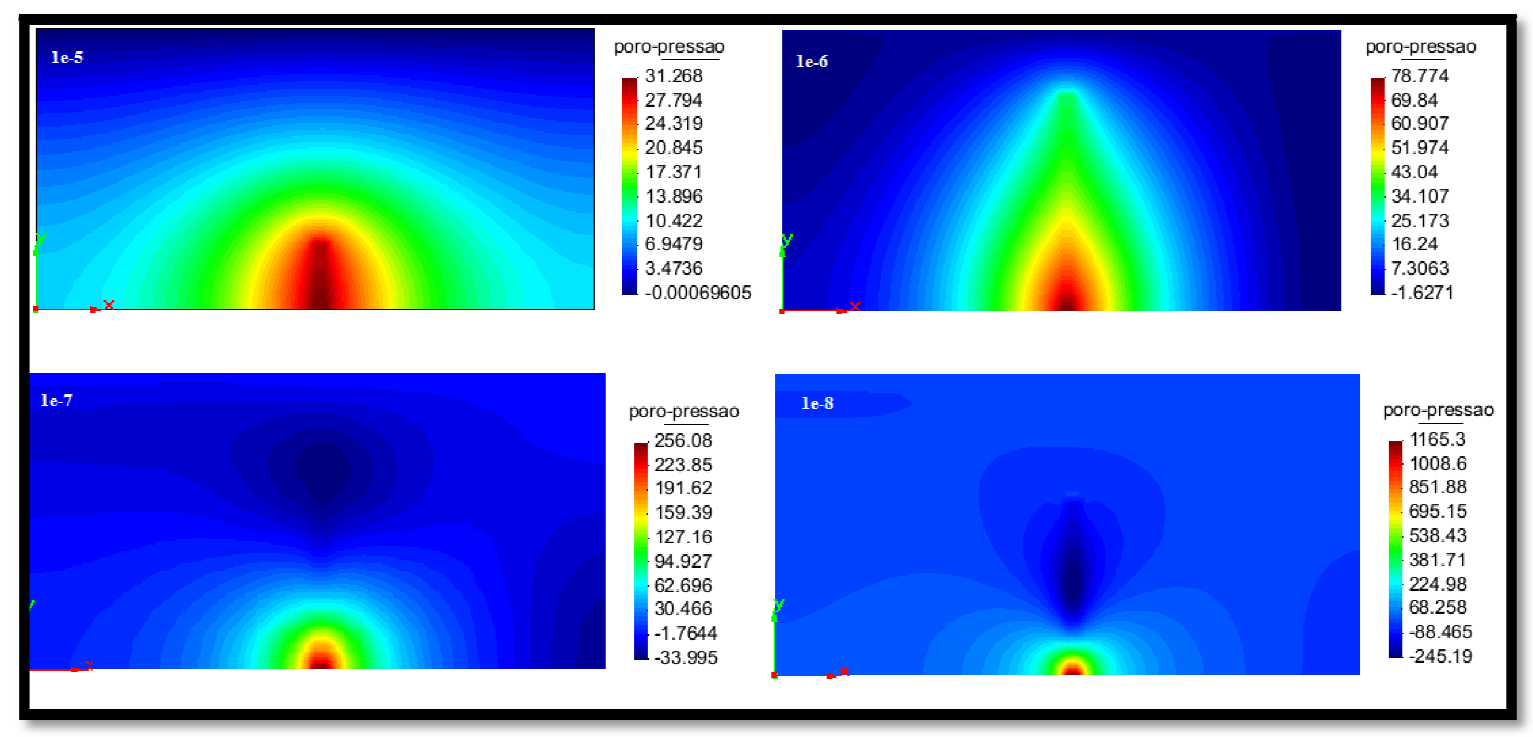

Figura 6.3 Poropressão no interior da fratura em meios com diferentes permeabilidades $\mathrm{u}_{\mathrm{w}}$ $(\mathrm{KPa})$

Na Figura 6.4 é apresentada uma simulação considerando o meio com permeabilidade igual a $10^{-5} \mathrm{~m} / \mathrm{s}$. Foram feitas quatro simulações com o mesmo tempo total (20000 s), alterando apenas o tamanho do passo de tempo utilizado (dez passos de tempo de $2000 \mathrm{~s}$, vinte passos de tempo de $1000 \mathrm{~s}$, quarenta passos de tempo de $500 \mathrm{~s}$ e oitenta passos de tempo de 250 s). Podemos observar na Figura 6.4 que a discretização do tempo irá influenciar no processo de fraturamento, gerando um erro se o tamanho do passo de tempo utilizado for muito grande. Observa-se que a partir do passo de quarenta os resultados obtidos são similares. Acredita-se que o controle do tamanho do passo de tempo pode ser considerado uma solução satisfatória para o problema de não linearidade. Porém, deve ser considerado que o problema possui não linearidade geométrica e que é necessário realizar a implementação de algum algoritmo que possibilite um melhor controle do erro.

Na Figura 6.5 é apresentado o resultado da mesma simulação, com o tamanho de passo de tempo de $500 \mathrm{~s}$ e como tempo total de $40.000 \mathrm{~s}$. É possível observar que ocorre a estabilização da fratura. Conforme discutido anteriormente, isso ocorre porque as condições de contorno aplicadas nesse tempo são suficientemente grandes para que seja atingida uma condição estacionária. Desta forma, pode-se concluir que a vazão injetada já não é suficiente para propagar a fratura, pois o fluido é perdido para formação numa velocidade maior do que a necessária para fraturar o meio. 


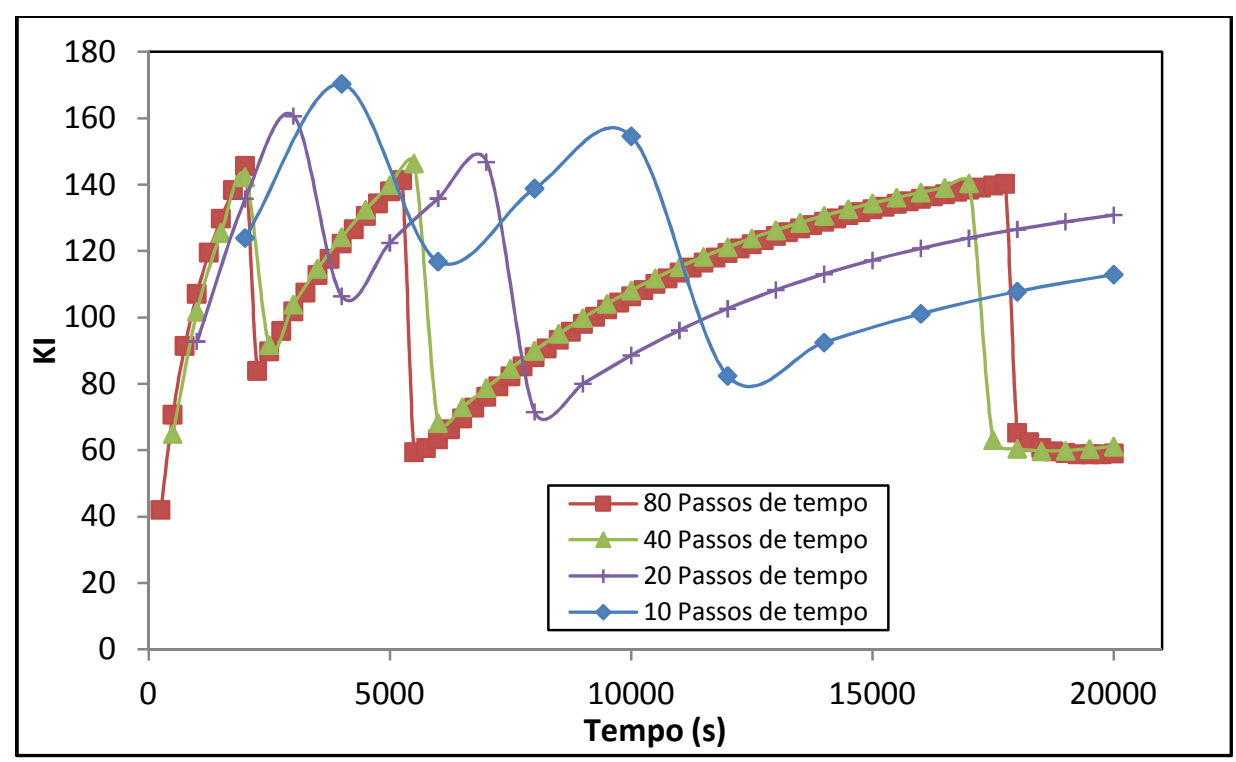

Figura 6.4 Avaliação do tamanho de passo de tempo ideal para meio com permeabilidade de $10^{-5} \mathrm{~m} / \mathrm{s}$

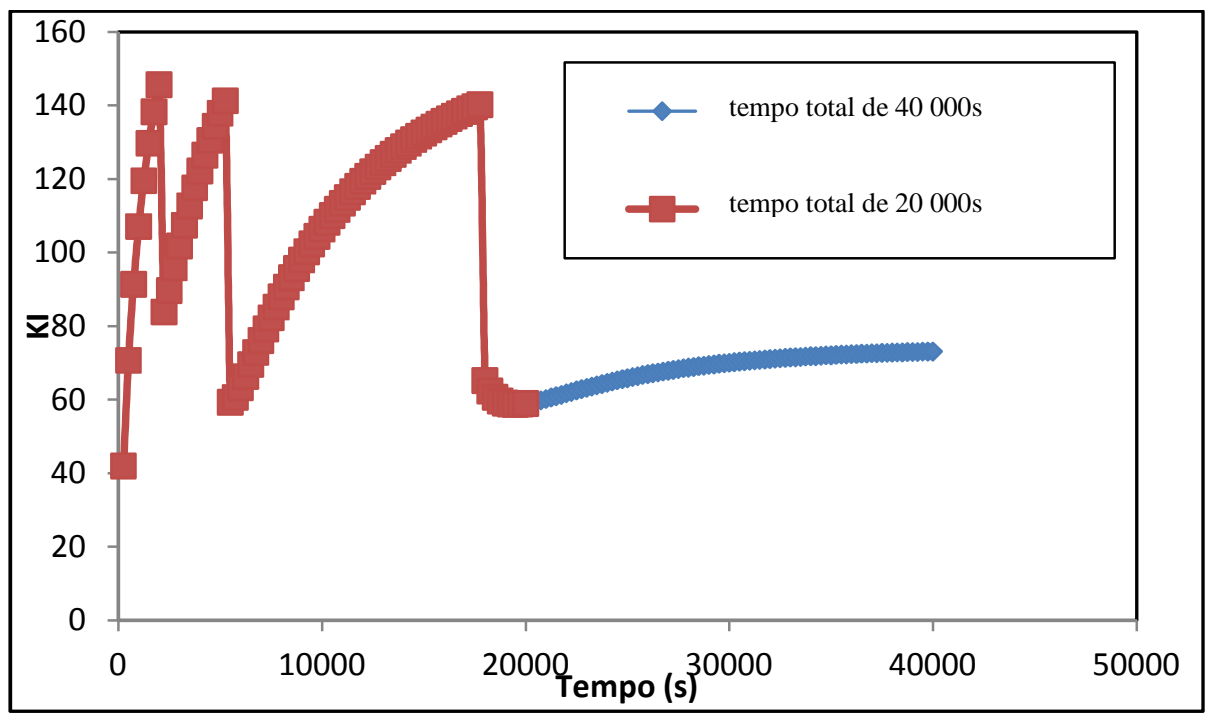

Figura 6.5 Verificação da estabilização da fratura após Fraturamento Hidráulico para meio com permeabilidade de $10^{-5} \mathrm{~m} / \mathrm{s}$

A partir dos resultados anteriores, foi observado que existe uma relação entre a vazão de injeção e a permeabilidade do meio. Caso seja utilizada uma mesma vazão de injeção do fluido, e a permeabilidade do meio seja muito alta, o fluido será perdido para a formação, não ocorrendo fraturamento. Realizou-se então cinco simulações com 80 passos de tempo de 250 s alterando apenas a permeabilidade do meio. Foram feitas as simulações com as permeabilidadede de: $10^{-3} \mathrm{~m} / \mathrm{s}, 10^{-4} \mathrm{~m} / \mathrm{s}, 10^{-6} \mathrm{~m} / \mathrm{s}, 10^{-7} \mathrm{~m} / \mathrm{s}$ e $10^{-8} \mathrm{~m} / \mathrm{s}$, mantendo-se a 
permeabilidade no interior da fratura constante.

Para valores de permeabilidade muito alta, a vazão utilizada como condição de contorno não foi suficiente para gerar o processo de propagação da fratura (Figura 6.6). Isso pode ser explicado devido ao processo de leak-off, ou seja, perda de fluido de fraturamento para a formação.

Na Figura 6.7 vê-se a simulação com permeabilidades menores onde ocorre o fraturamento do meio. Apesar da permeabilidade não ser a única variável que controla o fraturamento é possível observar nos dois gráficos que, mantendo a mesma vazão e rigidez do meio, o fraturamento será diferente variando a permeabilidade do meio e do interior da fratura.

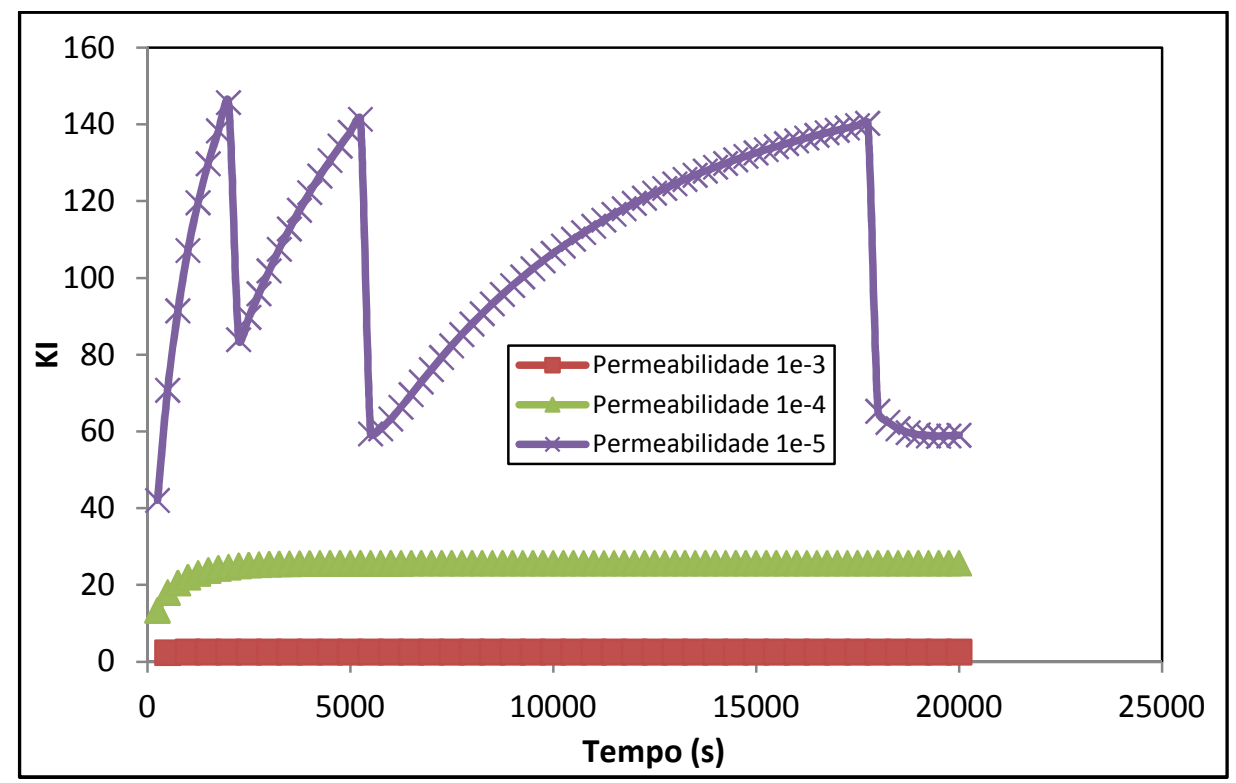

Figura 6.6 Simulação de Fraturamento Hidráulico em meios com permeabilidades maiores que $10^{-5} \mathrm{~m} / \mathrm{s}$

Além disso, foi observado nas simulações que ocorre uma relação diretamente proporcional entre o comprimento da fratura e a abertura da fratura quando a vazão injetada é a mesma. Isso pode ser observado nos gráficos das Figuras 6.8 e 6.9 onde observa-se a comparação do crescimento da fratura para diferentes permeabilidades do meio e o crescimento da abertura da fratura para diferentes permeabilidades do meio, em um mesmo tamanho de tempo, respectivamente. 


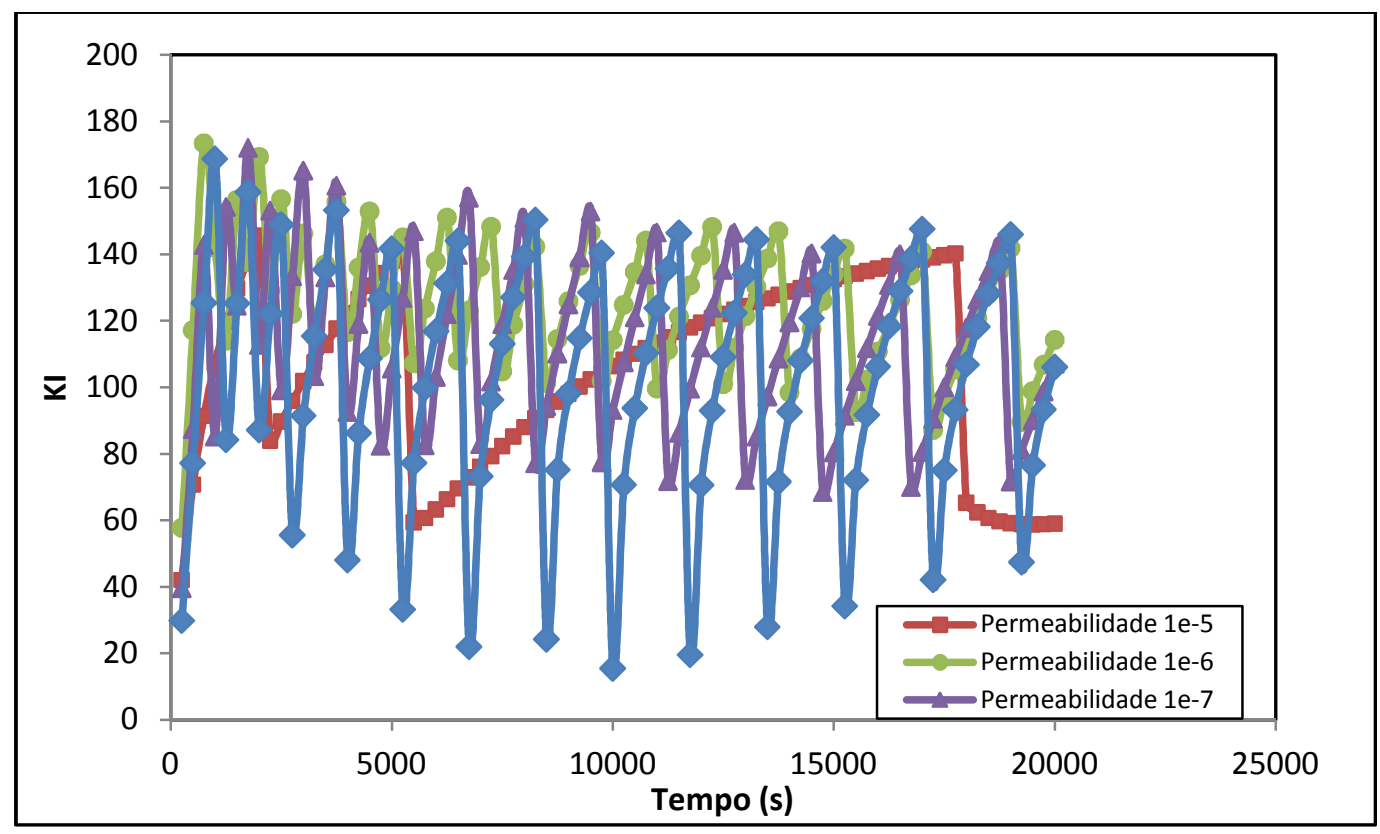

Figura 6.7 Simulação de Fraturamento Hidráulico em meios com permeabilidades menores que $10^{-5} \mathrm{~m} / \mathrm{s}$

No caso da permeabilidade de $10^{-5} \mathrm{~m} / \mathrm{s}$ a abertura da fratura é menor (Figura 6.9), devido a alta permeabilidade do meio. Isso porque, ocorre o vazamento do fluido para a formação, e a fratura irá crescer menos que nos outros meios com permeabilidades menores (Figura 6.8).

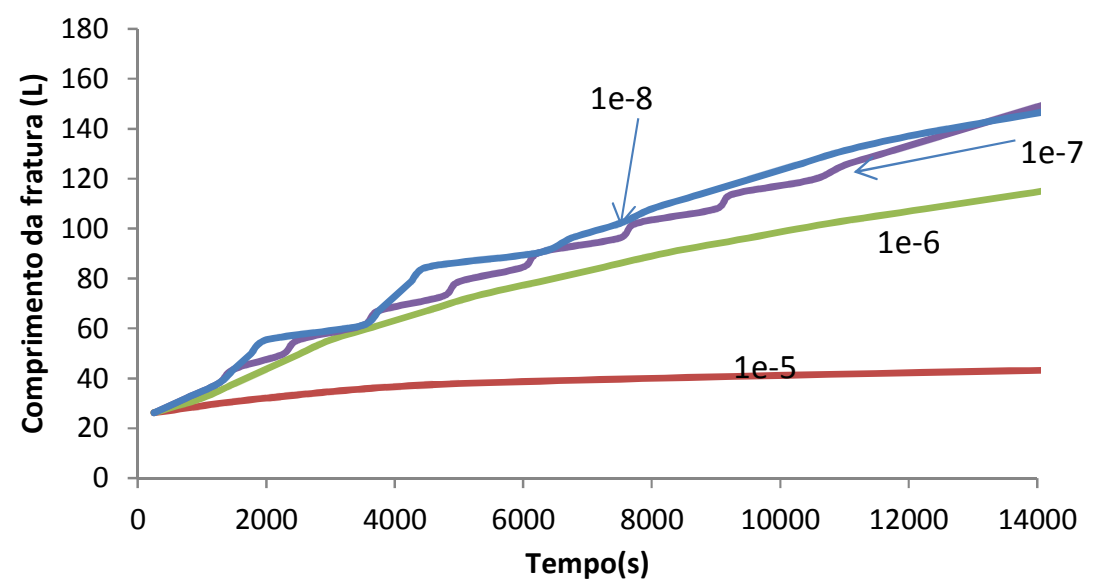

Figura 6.8 Crescimento da fratura por Fraturamento Hidráulico para meios permeabilidades menores que $10^{-5} \mathrm{~m} / \mathrm{s}$

Foi observado ainda que a permeabilidade no interior da fratura também tinha grande influência nos resultados pois, caso esta não fosse suficiente, não havia uma dissipação da 
poropressão no interior da fratura. No código foi realizada uma simplificação de modo a considerar a permeabilidade da fratura como uma função do meio. Apesar disso ser um simplificação grosseira, não foi encontrada na literatura outra alternativa para considerar as poropressões dentro da fratura. Posteriormente, pretende-se implementar uma lei de fluxo para a fratura, semelhante a utilizada no modelo PKN.

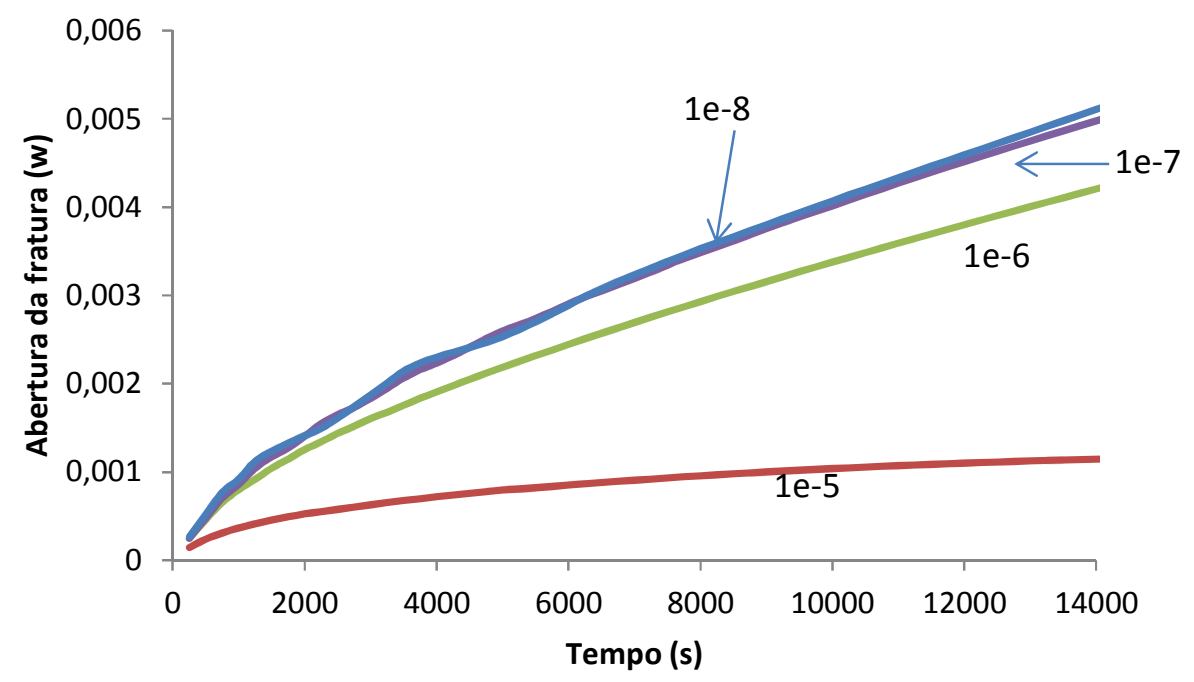

Figura 6.9 Abertura da fratura por Fraturamento Hidráulico pra meios com permeabilidades menores que $10^{-5} \mathrm{~m} / \mathrm{s}$

Neste trabalho, foi realizada uma análise de sensibilidade da permeabilidade no interior da fratura para observar a sua influência nos resultados. Foi adotada a permeabilidade do meio de $10^{-7} \mathrm{~m} / \mathrm{s}$, manteve-se as demais propriedades constantes, e três valores para a permeabilidade no interior da fratura foram utilizados: $10^{-4} \mathrm{~m} / \mathrm{s}$ (permeabilidade da fratura 1000x maior que a permeabilidade do meio), $10^{-5} \mathrm{~m} / \mathrm{s}$ (permeabilidade da fratura 100x maior que a permeabilidade do meio) e $10^{-6} \mathrm{~m} / \mathrm{s}$ (permeabilidade da fratura 10x maior que a permeabilidade do meio). Pode ser observado na Figuras 6.10 e na Figura 6.11 que quando a permeabilidade no interior da fratura é baixa, a poropressão não é dissipada e consequentemente o valor dela no interior da fratura é alto, e quase constante. Além disso, devido a baixa permeabilidade da fratura, a pressão é alta e a abertura da fratura é grande. Para o problema com permeabilidade na fatura 10x maior que a permeabilidade do meio, observa-se que há problemas de oscilação numérica, sendo que ocorrem valores negativos de poropressão dentro da fratura.

Na Figura 6.13 é possível observar a influência da permeabilidade da fratura no 
processo de fraturamento. Conforme dito anteriormente, a permeabilidade da fatura requer a definição de uma lei de fluxo específica e que permita reproduzir de modo mais acurado o fluxo dentro da fratura. Uma alternativa seria assumir algo similar ao apresentado no modelo PKN onde é levada em consideração a abertura da fratura (w) e o K, ou seja, um regime de fluxo diferente da Lei de Darcy. No PKN a lei de fluxo é:

$q=-\frac{w^{3}}{6 K} \frac{\partial p f}{\partial x}$

onde ocorre um decaimento parabólico no interior da fratura.

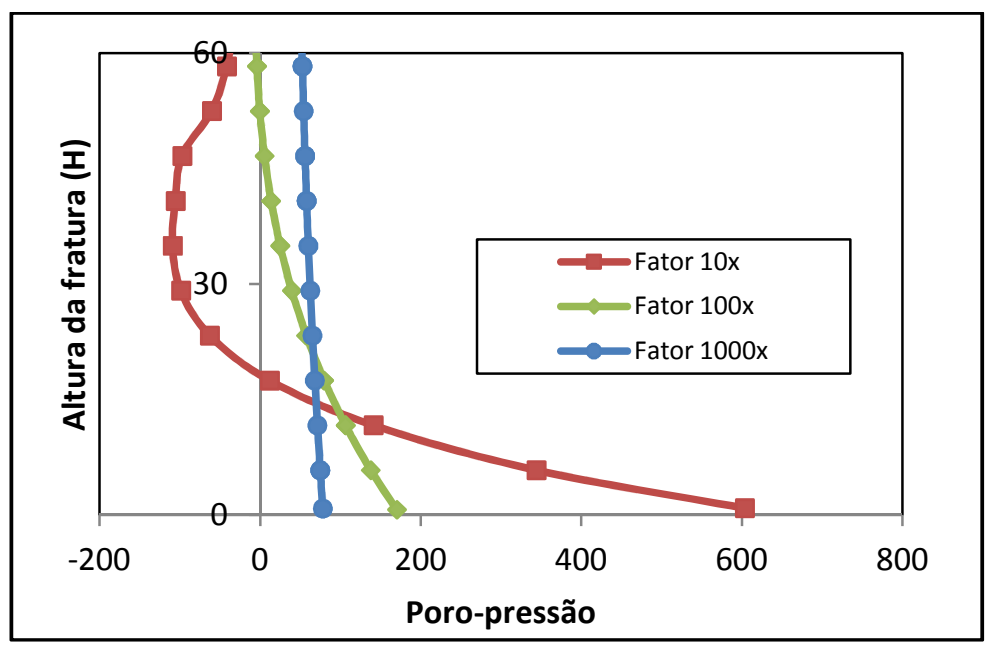

Figura 6.10 Variação da poropressão no interior da fratura por Fraturamento Hidráulico ao longo da altura

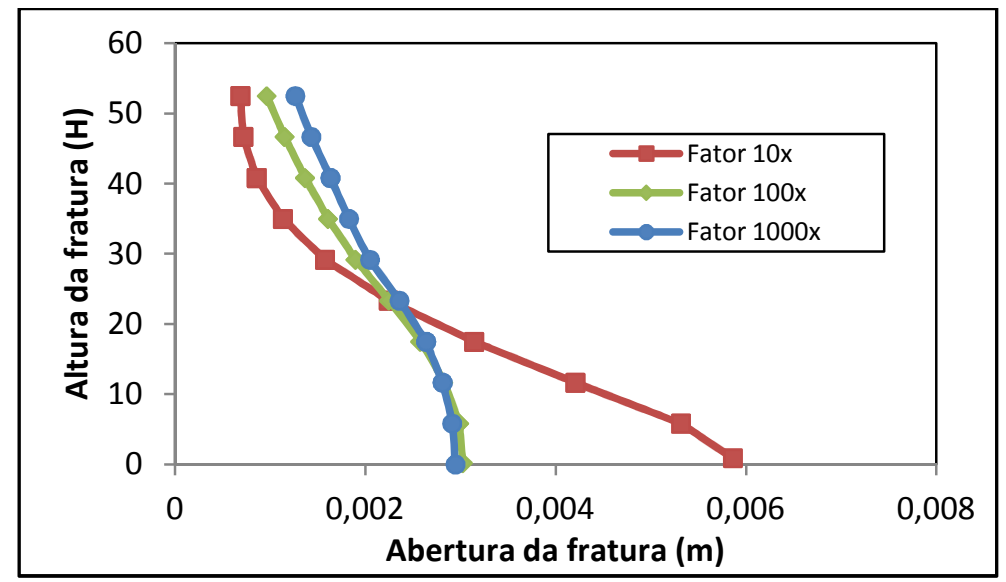

Figura 6.11 Variação da abertura da fratura por Fraturamento Hidráulico ao longo da altura da fratura 


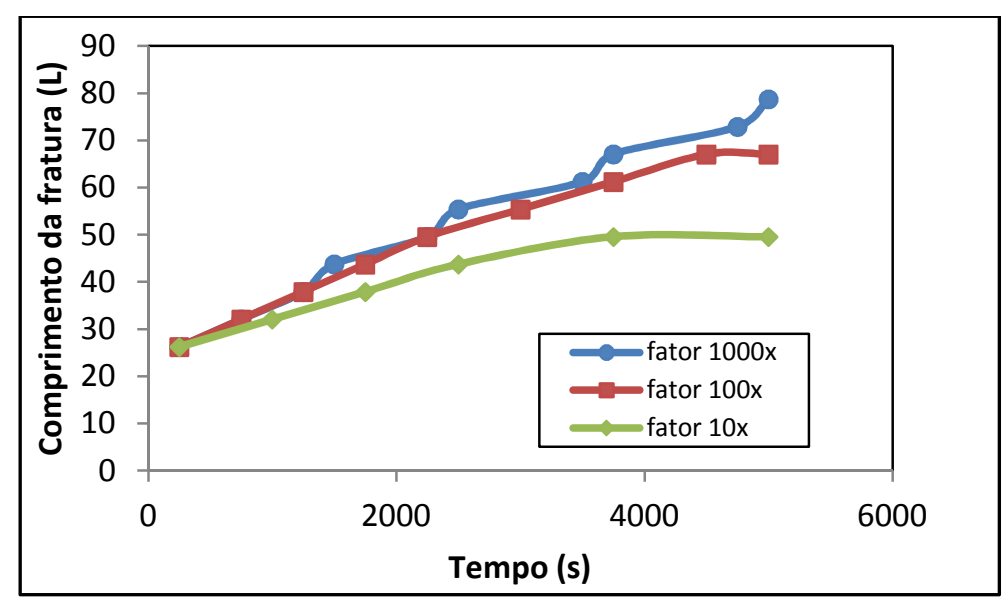

Figura 6.12 Variação do comprimento da fratura por Fraturamento Hidráulico para diferentes permeabilidades do interior da fratura

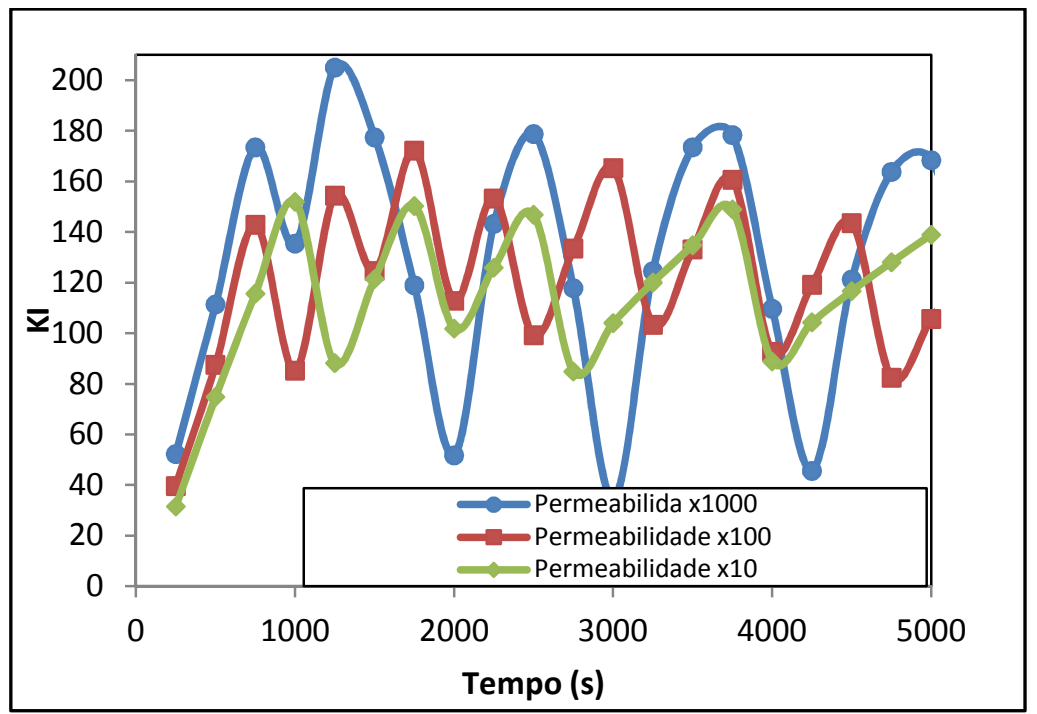

Figura 6.13 Fraturamento hidráulico de fraturas com mesma permeabilidade interna e diferentes permeabilidades do meio

Por último, realizou-se uma simulação onde se manteve a permeabilidade da fratura constante de $10^{-5} \mathrm{~m} / \mathrm{s}$ e variou-se a permeabilidade do meio em $10^{-6} \mathrm{~m} / \mathrm{s}, 10^{-7} \mathrm{~m} / \mathrm{s}$ e $10^{-8} \mathrm{~m} / \mathrm{s}$. Observando as Figuras 6.14, 6.15, 6.16 e 6.17 é observado uma maior similaridade do fenômeno visto que a permeabilidade da fratura é a mesma e a dissipação do fluido no interior dela é semelhante para as diferentes permeabilidades do meio. As diferenças geradas correspondem as diferentes permeabilidades dos meios que irão influenciar na taxa de vazamento de fluido para a formação. Quanto menor a permeabilidade do meio, menos fluido irá vazar maior será a pressão, maior a abertura da fratura e menor o comprimento da fratura. Foi observado ainda que nos meios com permeabilidade de $10^{-7} \mathrm{~m} / \mathrm{s}$ e $10^{-8} \mathrm{~m} / \mathrm{s}$, os resultados foram mais próximos, indicando que a partir da permeabilidade de $10^{-7} \mathrm{~m} / \mathrm{s}$ a taxa de 
vazamento irá influenciar menos nos resultados.

É verificado novamente que para alguns valores de permeabilidade ocorreram problemas de oscilação numérica e que valores de poropressão negativa surgem, sendo que esses valores não são esperados.

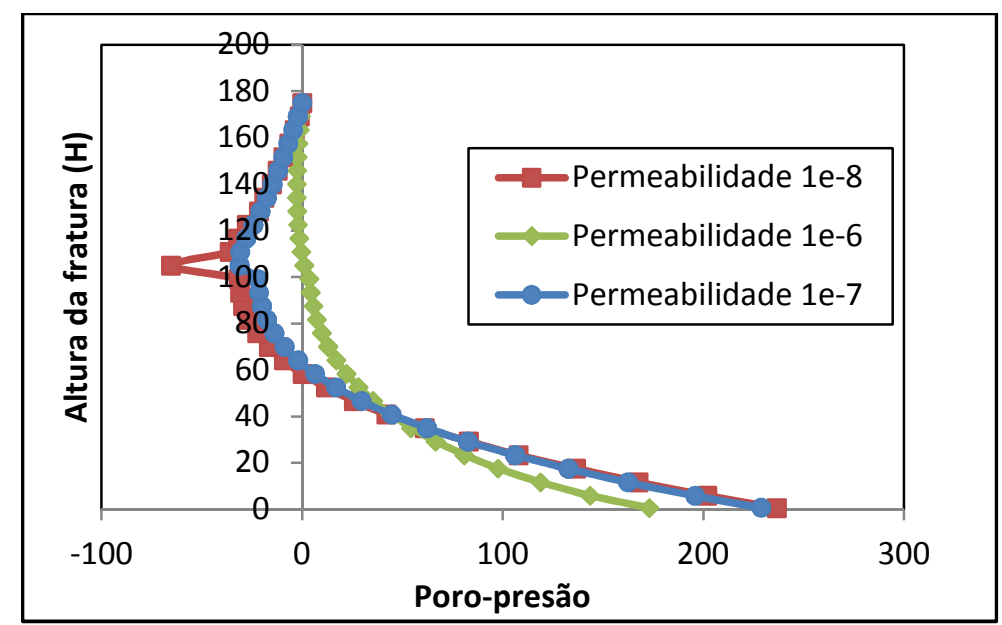

Figura 6.14 Variação da poropressão no interior da fratura por Fraturamento Hidráulico ao longo da altura

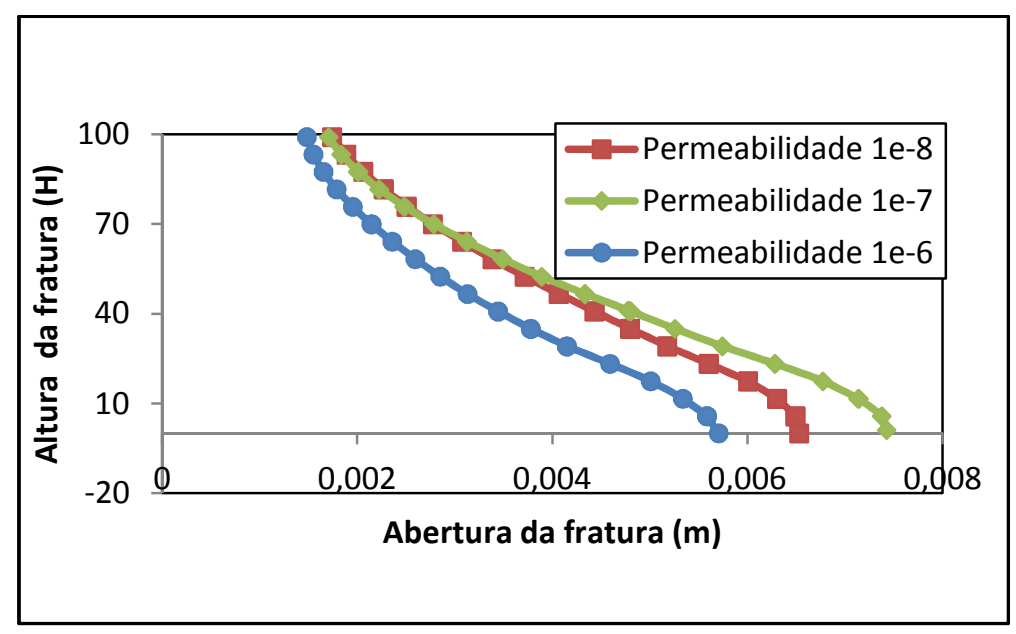

Figura 6.15 Variação da abertura da fratura por Fraturamento Hidráulico ao longo da altura da fratura 


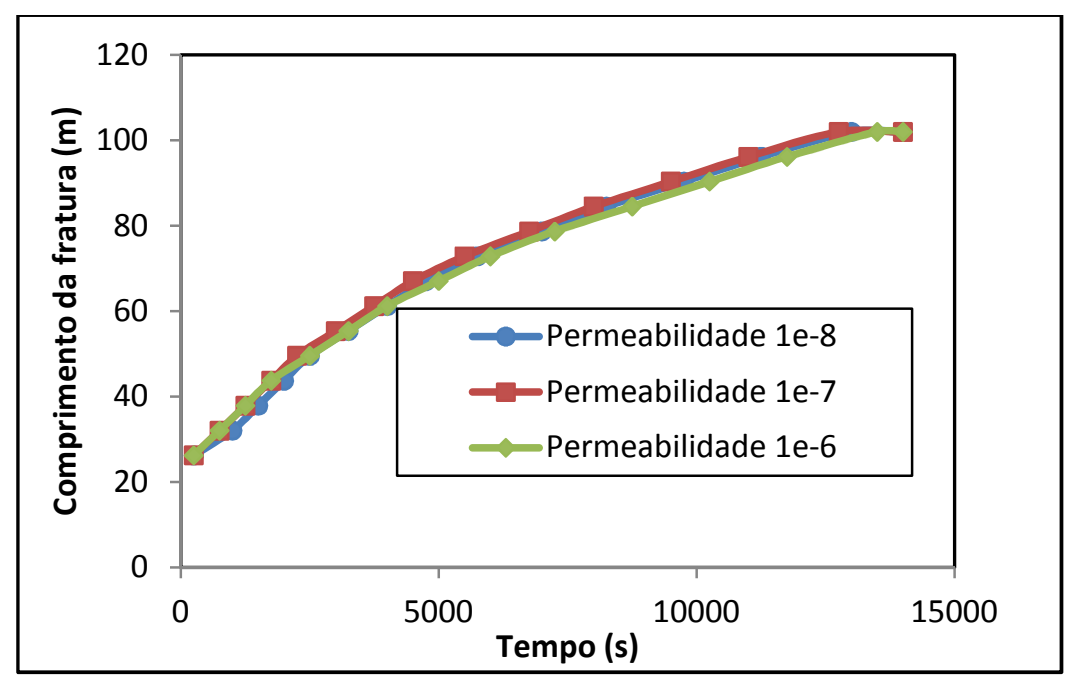

Figura 6.16 Variação do comprimento da fratura por Fraturamento Hidráulico para diferentes permeabilidades do meio

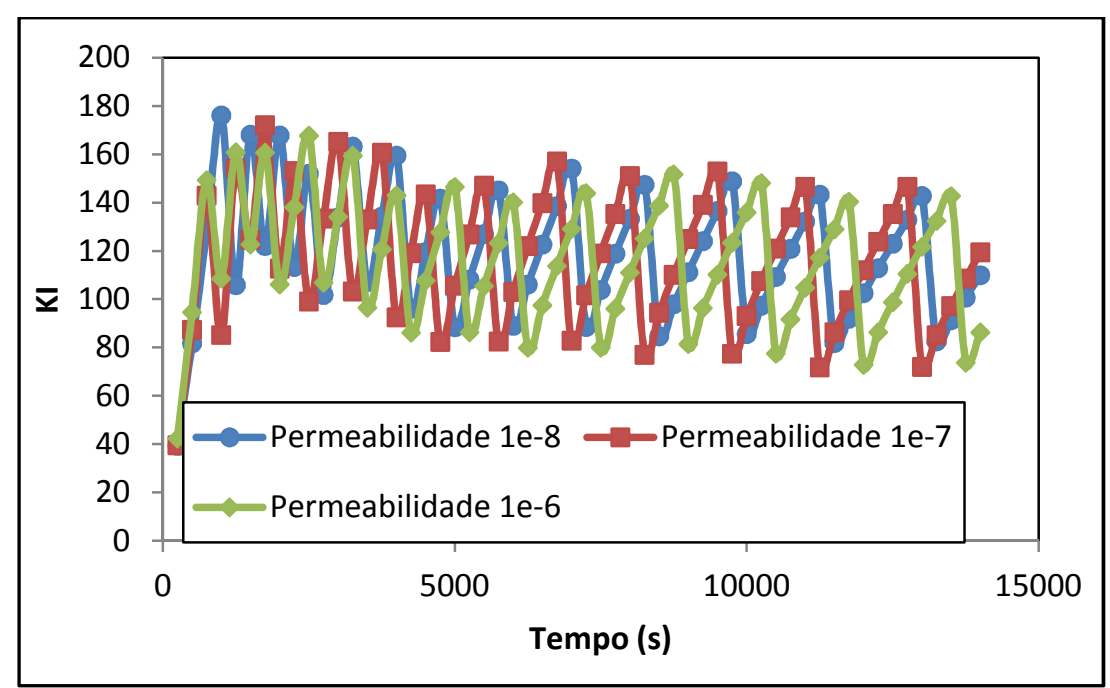

Figura 6.17 Fraturamento hidráulico de fraturas com mesma permeabilidade interna e diferentes permeabilidades do meio 


\section{CONCLUSÕES E PROPOSTAS PARA TRABALHOS FUTUROS}

Este capítulo visa apresentar um resumo das principais conclusões do trabalho bem como propostas para trabalhos futuros. Cabe ressaltar que apesar de ter havido um avanço significativo no projeto de implementar um código hidromecânico acoplado que permita análise do processo de fraturamento hidráulico, alguns pontos não foram cobertos e serão apresentados como temas de pesquisas futuras.

Apesar de haver tentativas de mudar a matriz energética mundial, hoje muito baseada no petróleo, este ainda tem papel fundamental no cenário global e pesquisas que visem uma maior eficiência nas diversas etapas existentes no processo de produção são necessárias. O processo de fraturamento hidráulico é um dos métodos de completação utilizados na estimulação de poço, e mais recentemente tem sido utilizado na estimulação de poço para extração de gás de folhelho, sendo que ele teve um papel fundamental na extração desse gás.

A principais conclusões do trabalho são:

- $\quad$ O processo de fraturamento hidráulico se apresenta com uma técnica controversa, e mal compreendida, e que por isso produz reações adversas na sociedade em geral. Parte dessa reações estão relacionadas à falta de informação da sociedade, que desconhece o método e o relaciona a exemplos mal executados e que produziram passivos ambientais. Desta forma, parte do problema está relacionado ao próprio processo de fraturamento que, se não for muito bem realizados, pode levar a grandes impactos. Porém, não há na literatura uma metodologia ou ferramentas que permitam a realização de análises acuradas do processo de fraturamento;

- O problema de fraturamento hidráulico se caracteriza por ser um problema hidromecânico acoplado que requer a solução de um conjunto de equações diferenciais que descrevem o problema. Tratar o problema de fraturamento hidráulico como um problema puramente mecânico pode levar a erros na interpretação dos resultados, uma vez que diversas variáveis do problema estão relacionadas ao problema de fluxo;

- Há na literatura diversos modelos analíticos que permitem a simulação do problema de fraturamento hidráulico de maneira simplificada. Porém, estes modelos não são capazes de prever por exemplo, mudanças no campo de pressão do reservatório, ou ainda quais são as consequências do processo de fraturamento hidráulico para as regiões adjacentes; 
- Apesar de existirem outros métodos, o XFEM se apresentou como uma boa alternativa para o tratamento de problemas de fraturamento hidráulico, um vez que sua implementação pode aproveitar parte dos códigos de elementos finitos já existentes e os resultados desse método se mostram satisfatórios quando comparados como outras soluções;

- $\quad$ A formulação implementada neste trabalho foi validada e os resultados se mostraram satisfatórios quando comparados com soluções analíticas. Isso permite afirmar que a ferramenta é capaz de simular o problema de fraturamento hidráulico. Porém, não foram realizadas comparações com soluções analíticas para o problema de fraturamento hidráulico, devido a diferenças nas condições de contorno e no regime de fluxo dentro da fatura;

- As simulações numéricas realizadas permitiram avaliar a influência da permeabilidade do meio e da permeabilidade da fratura, e os resultados demonstram que mesmo que as propriedades mecânicas do meio sejam mantidas constantes, as propriedades hidráulicas podem ter grande influência no processo de fraturamento hidráulico;

- $\quad$ A formulação de XFEM implementada apresenta não linearidade geométrica. Desta forma é necessário que algoritmos específicos para tratar este problema sejam implementados em um próxima fase da pesquisa. Porém, para os resultados apresentados nesta fase, o controle do tamanho do passo de tempo se mostrou suficiente para o controle do erros existente devido a natureza não linear do problema;

- $\quad$ o critério para determinar o momento em que a fratura avança no espaço, ou seja, o critério de crescimento da fratura foi a simples comparação entre o fator de intensidade $\mathrm{K}_{\mathrm{I}}$ do meio com o fator de intensidade crítico $\mathrm{K}_{\mathrm{Ic}}$. Esse ponto da pesquisa também requer especial atenção, principalmente porque para materiais geotécnicos, talvez seja necessário estabelecer outro critério. Além disso, esse critério não permite identificar o surgimento da fratura, só podendo ser aplicado se a fratura já existe.

A principais sugestões para pesquisas futuras são:

- Implementar um lei de fluxo mais adequada para o regime de fluxo dentro da fratura;

- Implementar algoritmos que permitam determinar a direção e a posição de novas fratura;

- Implementar algoritmos que permitam tratar de maneira mais rigorosa o problema de não linearidade geométrica;

- Implementar a formulação de modo a considerar a condição não saturada; 
- Implementar a formulação de modo a considerar a existência de mais de um fluido;

- Realizar validações considerando soluções analíticas do problema de fraturamento hidráulico, tais como PKN ou outras disponíveis.

- Realizar simualções de fraturamento hidráulico utilizando meios anisotrópicos. 


\section{REFERÊNCIAS BIBLIOGRÁFICAS}

BOWER, A.F. (2010) Applied Mechanics of Solids. CRC Press.

ADVANCED RESOURCES INTERNATIONAL, inc, Disponível em: http://www.advres.com/ Acesso em: 04 abril 2016

AGBALAKA C., ABHIJIT Y. D., SHIRISH L. P.l, KHATANIAR S., HEMSATH J.R. (2008). The Effect of Wettability on Oil Recovery: A Review. SPE 114496.

AHMED, T. (2001). Reservoir Engineering Handbook. Butterworth-Heinemann, Woburn, Massachusetts, USA, $1191 \mathrm{p}$.

ALJAZEERA, Disponível em : http://stream.aljazeera.com/story/americas-fracking-problem$\underline{0022005}$ Acesso em : 25 fev. 2013

ALMEIDA, A. S.(2004). Recuperação Secundária em Campos de Produção de Petróleo. Seminário Recursos Energéticos do Brasil: Petróleo, Gás, Urânio e Carvão, Clube de Engenharia.

AZEVEDO, C. T. (2011). Análise da curva de pressão do fraturamento de formações de alta permeabilidade para a estimativa dos parâmetros da fratura. Departamento de Engenharia Mecânica, Pontifícia Universidade Católica do Rio de Janeiro, Rio de Janeiro, RJ, 321p.

BERRYMAN, J. G., WANG, H. F. (2000). Elastic wave propagation and attenuation in a double-porosity dual-permeability medium. Internacional Journal of Rock Mechanics and Mining Sciences, vol. 37, p. 63-78

BARRETO, M. N. (2010). Caracterização de materiais para garantir a condutividade de fraturas hidraulicamente induzidas em poços de petróleo e gás. Tese de Doutorado, Departamento de Engenharia Mecânica, Pontifícia Universidade Católica do Rio de Janeiro, Rio de Janeiro, RJ, 255p.

BELYTSCHKO T., BLACK T. (1999). Elastic crack growth in finite elements with minimal remeshing. International Journal for Numerical Methods in Engineering, 45, p. 601-620.

BERUMEN, S., TIAB, D. and RODRIGUEZ F. (2000). Constant rate solutions for a fractured well with an asymmetric fracture. Journal of Petroleum Science and Engineering, 25, p. 49-58.

BOARD, M., RORKE, T., WILLIAMS, G., Gay N. (1992). Fluid injection for rock burst control in deep mining. Tillerson JR, Wawersik WR, Proceedings of the 33rd U.S. symposium on rock mechanics. Rotterdam, Balkema, p. 111-20.

BOONE, T.J., DETOURNAY, E. (1990) Response of a Vertical Hydraulic Fracture Intersecting a Poroelastic Formation Bounded by Semi-I nfinite Impermeable Elastic Layers. Int. J. Rock Mech. Mining Sci. \& Geomech, Abstr. 27, p. 189-197.

BORDAS, S.P.A., LEGAY A. (2005). X-FEM mini-course. EPFL, Lausanne. 
CARESTIATO, G. L. (2014). Estudo do Impacto Econômico da Produção de Shale Gas nos Estados Unidos, Projeto de Graduação, Curso de Engenharia de Petróleo, UFRJ/Escola Politécnica, Rio de Janeiro, RJ, 119p.

CASTRO, A. O. S. (2004). Seleção de Poços de Petróleo para Operação de Fraturamento Hidráulico: uma Abordagem Comparativa entre Sistemas Fuzzy-genético e Neuro-Fuzzy, Tese de Doutorado, Programa de Engenharia de Produção, Universidade Federal do Rio de Janeiro, COPPE, Rio de Janeiro, RJ, 172p.

CHEREPANOV , G.P. (1967). Crack propagation in continuous media. USSR Journal of Applied Mathematics and Mechanics, 31, p. 503-512.

CLARK, C., BURNHAM, A., HARTO, C., HORNER, R.(2013). Hydraulic Fracturing and Shale Gas Production: Technology, Impacts, and Regulations. Argonne National Laboratory. , Disponível em: http://www.afdc.energy.gov/uploads/publication/anl_hydraulic_fracturing.pdf , Acesso em: 20 jan. 2016.

CRAIG, F.F. Jr (1971). The Reservoir Engineering Aspects of Waterflooding. Monograph series, SPE, Richardson, TX.

CORDÃO NETO, M. P. (2005). Análise hidromecânica de barragens de terra construídas com materiais colapsíveis. Tese de Doutorado, Publicação G.TD - 028/05, Departamento de Engenharia Civil e Ambiental, Universidade de Brasília, Brasília, DF, 152 p.

CURBELO, F. D. S. (2006). Recuperação Avançada de petróleo utilizando tensoativos. Tese de Doutorado, UFRN, Programa de Pós-Graduação em Engenharia Química. Áreas de concentração: Processos de separação e Tecnologia de tensoativo,Natal, RN,169p.

Das, J. (2012). Extracting Natural Gas Through Desorption in Shale Reservoirs. Society of Petroleum Engineers. doi:10.2118/0112-011-TWA

DETOURNAY, E., CHENG, A. H. D., MCLENNAN, J.D. (1990). A Poroelastic PKN Hydraulic Fracture Model Based on an Explicit Moving Mesh Algorithm. J. Energy Res.Tech.Trans. ASME 112 (4): 7.

DOMINGUES, J. C. A. (2009). Perda do valor de recuperação em ativos de exploração e produção de petróleo e gás. Dissertação de Mestrado, Faculdade de Economia, Administração e Contabilidade de Ribeirão Preto, Universidade de São Paulo, Riberão Preto, SP, 149p.

Ente Vasco de la Energia, Disponível em: http://eve.es/web/Documentacion/Infografias/Extraccion-de-hidrocarburos/Extraccion-dehidrocarburos-A.aspx Acesso em : 20 jan. 2013

Environmental Protection Agency (2004). Evaluation of Impacts to Underground Sources of Drinking Water by Hydraulic Fracturing of Coalbed Methane Reservoirs, EPA 816R04003

Environmental Protection Agency d Disponível em : http://www.epa.gov/esd/cmb/GeophysicsWebsite/pages/reference/methods/Marine_Geophysi cal_Methods/Marine_Seismic_Methods.htm Acesso em : 20 jan. 2013 
EWEN C., BORCHARDT D., RICHTER S., HAMMERBACHER R. (2012). Study concerning the safety and environmental compatibility of hydrofracking for natural gas production from unconventional reservoirs (executive summary).

USP, Prospecção de Petróleo. Disponível em : http://www.ebah.com.br/content/ABAAAABt8AD/aula2-prospeccao. Acesso em: 18 nov. 2012

FTT , Equipamentos utilizados no Processo de Perfuração de poços para Extração de Petróleo. Disponível em : http://www.ebah.com.br/content/ABAAAAgMYAL/equipamentosutilizados-no-processo-perfuracao-pocos-extracao-pretroleo Acesso em: 18 nov. 2012

FAERSTEIN, Marcos (2010). Impactos da Molhabilidade da Rocha na Produção e Recuperação de Petróleo. Dissertação de Mestrado, Programa de Engenharia Civil, COPPE, Universidade Federal do Rio de Janeiro, Rio de Janeiro, RJ, 165p.

FARIAS, M. M. (1993). Numerical analysis of clay core dams. Ph. D Thesis, University of Wales, University College of Swansea.

GADELHA DE SOUSA, K. S. M., (2005). Estudo de Sistemas: Petróleo/Água/Tensoativo para aplicação na recuperação avançada do Petróleo. Monografia, Departamento de Engenharia Química, Programa de Recursos Humanos- PRH 14/ANP Universidade Federal do Rio grande do Norte, Natal, RN, 94p.

GARCIA, J. E. L. (1997). A Completação de Poços no Mar. Apostila,SEREC/CEN-NOR, Salvador, BA

GALP ENERGIA. Disponível em: http://www.galpenergia.com/PT/agalpenergia/os-nossosnegocios/Exploracao-Producao/fundamentos-engenharia-petroleo/Paginas/Perfuracao.aspx Acesso em: 15 fev. 2013

GIDLEY, J.L., HOLDITCH, S.A., NIERODE, D.E.(1989). Fracturing Fluids and Additives in Recent Advances in Hydraulic Fracturing, 131, Richardson, Texas: Monograph Series, SPE.

HAINEY, B.W., KECK, R.G., SMITH, M.B., LYNCH, K.W. , BARTH, J.W. (1999). Onsite fracturing disposal of oilfield-waste solids in Wilmington field. California, SPE PRODUCTION \& FACILITIES, Volume 14, pages: 88-93.

HAYASHI, K., SATO, A., ITO, T., (1997). In situ stress measurements by hydraulic fracturing for a rock mass with many planes of weakness. International Journal of Rock Mechanics \& Mining Sciences, 34, pages: 45-58.

HOLDITCH, S.A , MORSE, R.A., (1976). The Effects of Non-Darcy Flow on the Behavior of Hydraulically Fractured Gas Wells. J. Petrol. Technol., 28, 1169-1178. SPE Paper, 5586

HUNT, J.L., FRAZIER, K., PENDERGRAFT, B.P., SOLIMAN, M.Y., (1994). Evaluation and 13 completion procedures for produced brine and waste-water disposal wells. Journal of Petroleum Science and Engineering, 11, pages: 51-60. 
HEALY, D. (2012). Hydraulic Fracturing or 'Fracking': A Short Summary of Current Knowledge and Potential Environmental Impacts.

INSTITUTION OF CIVIL ENGINEERS, Shale gas. Disponível em: https://www.ice.org.uk/disciplines-and-resources/briefing-sheet/shale-gas Acesso em: 20 jan. 2016.

IRWIN, G. (1957). Analysis of stresses and strain near the end of a crack traversing a plate. Transactions ASME, J. Appl. Mech.

IRWIN, G. (1958). Fracture. Handbuch der Physik. Vol VI, Springer, Berlin.

JESUS, S.R.C.B.P. (2012). Coupled Hydro-mechanical Analysis Considering Fluid and Solids Compressibility. Dissertação de Mestrado, Publicação G.DM-207/12, Departamento de Engenharia Civil e Ambiental, Universidade de Brasília, Brasília, DF, 122 p.

JUN, G. (2009). Modeling and Analysis of Reservoir Response to Stimulation by Water Injection. Dissertação de Mestrado, Texas A\&M University, College Station, TX, USA

KHOEI, A. R. (2015). Extended Finite Element Method, Theory and Applications, John Wiley, (584 pages) 2015, ISBN: 978-1-118-45768-9

KUNERT, R., SILVA, A. L. F, RAMALHO, J. B. V. S, SOUZA FILHO, J. E. S, MELO, M.V., LEITE, M. M, BRASIL, N. I, PEREIRA Jr, O. A, P, OLIVEIRA, R.C. G, ALVES, R. P, COSTA, R, F. D, GOMES, W. (2007). Processamento primário de petróleo. Apostila do Programa de Formação.

LAGE, E., PROCESSI, L., DORES, P., GALOPPI, P. (2013). Gás não convencional: experiência americana e perspectivas para o mercado brasileiro. BNDES Setorial, $\mathrm{n}^{\mathbf{o}} 37$. BNDES: Rio de Janeiro, p. 33-88. Disponível em: <http://www.bndes.gov.br/SiteBNDES/export/sites/default/bndes_pt/Galerias/Arquivos/conhe cimento/bnset/set3702.pdf>. Acesso em: 08 jan. 2014.

LI, F.Z., SHIH, C.F., NEEDLEMAN, A. (1985) A comparison of methods for calculating energy release rates. Engineering Fracture Mechanics, 21, p. 405-421.

MARTÍNEZ, E.R. (2015). Modelagem Numérica de Fraturamento Hidráulico via Método dos Elementos Finitos Estendido. Dissertação de Mestrado, Publicação G.DM-253/2015, Departamento de Engenharia Civil e Ambiental, Universidade de Brasília, Brasília, DF, 109 p.

MOËS, N., DOLBOW, J., BELYTSCHKO, T. (1999). A finite element method for crack growth without remeshing. International Journal for Numerical Methods in Engineering, 46, p.131-150.

MOHAMMADI, S. (2008). Extended Finite Element Method for Fracture Analysis of Structures. Malden, MA:,Blackwell Publishing

MORAIS, L. P. (2013). Modelagem Numérica do Problema de Fraturamento Hidráulico 
aplicado a Reservatórios. Monografia de Projeto Final II, Publicação G.PF-001/13, Departamento de Engenharia Civil e Ambiental, Universidade de Brasília, Brasília, DF, 69p.

MURDOCH, L.C., SLACK, W.W. (2002). Forms of hydraulic fractures in shallow fine grained formations. Journal of Geotechnical and Geoenvironmental Engineering, 128, pages: 479-487.

MUSKHELISHVILI , N.I. (1953). Some basic problems of the mathematical theory of elasticity. Noordhoff International, Leyden

NORDGREN, R.P. (1972). Propagation of a Vertical Hydraulic Fracture. Society of Petroleum Engineering Journal 253, p. 306-314.

NORTON ROSE FULBRIGHT, (2013). Shale Gas Handbook: A Quick Reference Guide for Companies Involved in Unconventional Gas Resources. Disponível em: http://www.nortonrosefulbright.com/files/norton-rose-fulbright-shale-gas-handbook108992.pdf Acessado em: 20 jan. 2016

OLLER, S., (2001). Fractura Mecánica, Un enfoque global. CIMNE, Barcelona, Spain

OSBORN, S. G., Vengosh, A., Warner, N. R., Jackson, R. B.(2011) Methane Contamination of Drinking Water Accompanying Gas-Well Drilling and Hydraulic Fracturing. PNAS Early Edition. Disponível em: www.pnas.org/cgi.doi/10.1073/pnas.11100682108 Acesso em: 02 Set. de 2014

OWEN, D. R. J. , FAWKES, A. J. (1983). Engineering fracture mechanics: numerical methods and applications. Swansea: Peneridge Press, 305p.

PDE Solutions inc. Disponível em: http://www.pdesolutions.com Acesso em: 02 fev. 2015

PETROBRAS, Amortecimento de Poços. Disponível em: http://pt.scribd.com/doc/83055270/amortecimento-de-pocos Acesso em: 20 dez. 2012

PGT, PETROLEUM GEOSCIENCE TECHNOLOGY, Geologia de Petróleo. Disponível em: https://albertowj.files.wordpress.com/2010/03/geologia_do_petroleo.pdf Acesso em: 18 jan. 2016

R7 notícias. Disponível em: http://noticias.r7.com/rio-de-janeiro/noticias/vazamento-de-oleona-bacia-de-campos-destroi-toda-a-vida-marinha-dizem-ambientalistas-20111116.html

Acesso em: 12 jan. 2015

RAAEN, A. M., SKOMEDAL, E., KJORHOLT, H., MARKESTAD, P., OKLAND, D., (2001). Stress determination from hydraulic fracturing tests: The system stiffness approach. International Journal of Rock Mechanics and Mining Sciences, 38, pages: 529-541.

RICE, J.R.(1968). A path independent integral and the approximate analysis of strain concentrations by notches and cracks. Journal of Applied Mechanics, 35, p. 379-386.

SALAS CACHAY, L. R. (2004). Fluxo de partículas de sustentação em poços de petróleo estimulados por fraturamento hidráulico. Dissertação de Mestrado, Pontifícia Universidade 
Católica do Rio de Janeiro, Rio de Janeiro, RJ, 132p.

SANTOS, A. R. (2007). Análise do colapso de telas utilizadas em sistemas de contenção de areia em poços horizontais. Dissertação de Mestrado, Departamento de Engenharia Mecânica Pontifícia Universidade Católica do Rio de Janeiro, Rio de Janeiro, RJ, 123p.

SANTOS, P. E. S., ARAuJO, R. B., LIMA, A. M. C., SANTANA, A. P. S. C. (2010). Métodos de Recuperação Secundária Convencionais. Cadernos de Graduação,Ciências Exatas e Tecnológicas (ISSN 1980- 1777)- v. 12 - n.12

SASAKI, S., (1998). Characteristics of microseismic events induced during hydraulic fracturing experiments at the Hijiori hot dry rock geothermal energy site. Yamagata, Japan, Tectonophysics, 289: 171-188.

SETHIAN, J.A.(1996). A marching level set method for monotonically advancing fronts. Proceeding of the National Academy of Sciences, 93: 1591-1595.

SMITH, M.B., SHLYAPOBERSKY, J.W. (2000). Basics of Hydraulic Fracturing, chapter 5 in Reservoir Stimulation, Economides, M. J. and Nolte, K. G. (Eds.), Reservoir Stimulation, third edition Wiley \& Sons, Ltd.,pp. 5-1 - 5-28.

SOCIETY Of PETROLEUM ENGINEERS, Petróleo e gás natural, (2007). Disponível em: http://energy4me.org/wp-content/uploads/Brazil-Portuguese_oil_gas_WEB.pdf Acessado em: 18 jan. 2016

TALEGHANI, A.D. (2009). Analysis of hydraulic fracture propagation in fractured reservoirs: an improved model for the interaction between induced and natural fractures. Tese de Doutorado, The University of Texas at Austin, TX, Estados Unidos

THIERCELIN, M. C., ROEGIERS, J.C. (2000). Formation Characterization: Rock Mechanics. Economides, M. J., Nolte, K. G. (Eds.), Reservoir Stimulation, third edition Wiley \& Sons, Ltd., pp. 3-1 - 3-35.

THE NETWORK FOR PUBLIC HEALTH LAW. Disponível em : http://www.networkforphl.org/_asset/w74j2w/Fracking_Environmental_Impacts.pdf Acesso em: 25 jan. 2013

THOMAS, J.E. (2001). Fundamentos de Engenharia de Petróleo. Petrobrás. Rio de Janeiro: Interciência.

TLR, THREE LEGS RESOURCES, An introduction to shale gás, (2011). Disponível em : www.3legsresources.com Acesso em: 20 de Agosto de 2014

TUAN, B. M., FEI, C. Y. (2014), Analysis and prediction of crack propagation in plates by enriched free Galerkin method. International Journal of Mechanical Engineering and Applications, p.78-86

UFPR, Curso técnico de Petróleo. Disponível em: http://www.tecnicodepetroleo.ufpr.br/apoio_didatico.htm Acesso em: 08 jan. 2013 
VALE, M. L. C. (2009). Análise de Sinais Geofísicos na Prospecção de Petróleo. Certificação de Especialista em Engenharia de Instrumentação, Centro de Tecnologia e Geociências da Universidade Federal de Pernambuco, Recife, PE, 47p.

VOLTATONI, T. (2012). Emprego de ciclodextrinas para a recuperação avançada de petróleo. Dissertação de Mestrado, Programa de Pós-Graduação em Energia, Universidade Federal do ABC, Santo André, SP, 73p.

XIANG, J. B.S. (2011). A PKN Hydraulic Fracture Model Study and Formation Permeability. MSc Thesis, Texas A\&M University, College Station, TX, USA

ZHANG, X., Jeffrey, R.G., THIERCELIN M., (2009). Mechanics of fluid-driven fracture growth in naturally fractured reservoirs with simple network geometries. J. Geophys. Res., $114,16 \mathrm{p}$.

Mohammadi, S. (2008). Extended finite element method for fracture analysis of structures.

Blackwell Pub, 2008.

US EIA, Energy Information Administration. 2014a. Annual energy outlook 2014, with projections to 2040. EIA. Rep. US Energy Information Administration, Washington, DC. Disponível em: http://www.eia.gov/forecasts/aeo Acesso em: 20 Jan. 2016.

US EIA, Energy Information Administration, 2015. World Shale Resource Assessments.EIA. Rep. US Energy Information Administration, Washington, DC. Disponível em: http://www.eia.gov/analysis/studies/worldshalegas/ Acesso em: 20 Jan. 2016. 


\section{APÊNDICE}

\section{A1-RESOLUÇÃO DA EQUAÇÃO DE EQUILÍBRIO PELO PRINCÍPIO DOS TRABALHOS VIRTUAIS}

Sabendo que o trabalho realizado pelas forças internas é igual ao trabalho realizado pelas forças externas temos que:

$\int_{\Omega}\left\{\delta \varepsilon^{*}\right\}^{T}\{\sigma\} d \Omega-\int_{\Omega}\left\{\delta u^{*}\right\}^{T}\{b\} d \Omega-\int_{\Gamma_{2}}\left\{\delta u^{*}\right\}^{T}\{\tau\} d \Gamma=0$

Os deslocamentos virtuais e as deformações virtuais são obtidos pelas expressões:

$$
\begin{gathered}
\left\{u^{*}\right\}=\left\{\bar{u}^{*}\right\}^{T}[N] \\
\left\{\varepsilon^{*}\right\}=[B]\left\{\bar{u}^{*}\right\}
\end{gathered}
$$

Considerando o problema transiente e substituindo as relações acima citadas temos que a equação pode ser expressa por:

$$
\int_{\Omega}[B]^{T}\left\{\bar{u}^{*}\right\}\left\{\frac{\partial \sigma}{\partial t}\right\} d \Omega-\int_{\Omega}\left\{\bar{u}^{*}\right\}[N]^{T}\left\{\frac{\partial b}{\partial t}\right\} d \Omega-\int_{\Gamma_{2}}\left\{\bar{u}^{*}\right\}[N]^{T}\left\{\frac{\partial \tau}{\partial t}\right\} d \Gamma=0
$$

Os deslocamentos virtuais aparecem em todos os termos das equações e podem ser cortados. A relação tensão deformação pode ser substituída por:

$$
\{d \sigma\}=[D]\{d \varepsilon\}+\{h\} d p=[D][B]\{\bar{u}\}+\{h\}\left[B^{p}\right]\{\bar{p}\}
$$

Por fim chegamos a seguinte expressão:

$$
\int_{\Omega}[B]^{T}[D][B] d \Omega\{\bar{u}\}+\int_{\Omega}[B]^{T}\{h\}\left[N^{p}\right] d \Omega\{\overline{\mathrm{p}}\}-\int_{\Omega}[N]^{T}\left\{\frac{\partial b}{\partial t}\right\} d \Omega-\int_{\Gamma_{2}}[N]^{T}\left\{\frac{\partial \tau}{\partial t}\right\} d \Gamma=0
$$

\section{A2- DISCRETIZAÇÃO DA EQUAÇÃO DE CONTINUIDADE}

A solução da equação de continuidade obtida pelo método de galerkin é expressa por:

$$
\int_{\Omega}\left\{N^{p}\right\}^{T}\left(\frac{\partial \theta}{\partial t}+\nabla \cdot\{v\}\right) d \Omega=0
$$

Aplicando a identidade matemática seguinte:

$$
f \nabla g=\nabla(f g)-\nabla(f) g
$$

Temos que a equação pode ser reescrita por:

$$
\int_{\Omega}\left\{N^{p}\right\}^{T} \frac{\partial \theta}{\partial t} d \Omega+\int_{\Omega} \nabla\left(\left\{\mathrm{N}^{\mathrm{p}}\right\}^{\mathrm{T}}\{\mathrm{v}\}\right) d \Omega-\int_{\Omega}\left[\mathrm{B}^{\mathrm{p}}\right]^{\mathrm{T}}\{v\} d \Omega=0
$$

E pelo teorema do divergente tem-se:

$$
\int_{\Omega}\{N\}^{T} \frac{\partial \theta}{\partial t} d \Omega-\int_{\Omega}\left[\mathrm{B}^{\mathrm{p}}\right]^{\mathrm{T}}\{\mathrm{v}\} d \Omega+\int_{\Gamma}\{\mathrm{N}\}^{\mathrm{T}}\{v\} \cdot n d \Gamma=0
$$

O terceiro termo da equação pode ser reescrito por:

$$
\int_{\Gamma}\{\mathrm{N}\}^{\mathrm{T}}\{v\} \cdot\{n\} d \Gamma=\int_{\Gamma 1}\{\mathrm{~N}\}^{\mathrm{T}}\{v\} \cdot\{n\} d \Gamma+\int_{\Gamma 2}\{\mathrm{~N}\}^{\mathrm{T}}\{v\} \cdot\{n\} d \Gamma
$$

Como o fluxo na fronteira $\Gamma 1$ é zero e consequentemente a velocidade, é zero e $\{v\} \cdot\{n\}=\hat{q}$, então podemos reescrever a equação acima por: 
E usando a relação constitutiva:

$$
\int_{\Gamma}\{\mathrm{N}\}^{\mathrm{T}}\{v\} \cdot\{n\} d \Gamma=\int_{\Gamma 2}\{\mathrm{~N}\}^{\mathrm{T}} \hat{q} d \Gamma
$$

$$
d \theta_{w}=\beta_{1} \varepsilon_{v}+\beta_{2} d p
$$

E a lei de Darcy

Obtem-se a expressão final:

$$
\{v\}=[k] \nabla\left(\frac{u_{w}}{\gamma_{w}}+y\right)
$$

$$
\begin{gathered}
\int_{\Omega} \beta_{1}\{N\}^{T}\{m\}^{T}\left[B_{p}\right] d \Omega\left\{\frac{\partial \overline{\mathrm{u}}}{\partial \mathrm{t}}\right\}-\int_{\Omega} \beta_{2}\{\mathrm{~N}\}^{\mathrm{T}}\{\mathrm{N}\} d \Omega\left\{\frac{\partial \overline{\mathrm{p}}}{\partial \mathrm{t}}\right\}+\int_{\Omega}\left[\mathrm{B}^{\mathrm{p}}\right]^{\mathrm{T}}\left(\frac{1}{\gamma_{\mathrm{w}}}[\mathrm{k}]\left[\mathrm{B}^{\mathrm{p}}\right]\right) d \Omega\{\overline{\mathrm{p}}\} \\
+\int_{\Omega}\left[\mathrm{B}^{\mathrm{p}}\right]^{\mathrm{T}}\{[k] \nabla y\} d \Omega+\int_{\Gamma 2}\{\mathrm{~N}\}^{\mathrm{T}} \hat{\mathrm{q}} d \Gamma=0
\end{gathered}
$$

